Federal Reserve Bank of Minneapolis Research Department

\title{
The Over-the-Counter Theory of the Fed Funds Market: A Primer*
}

\author{
Gara Afonso and Ricardo Lagos \\ Working Paper 711
}

April 2014

\begin{abstract}
We present a dynamic over-the-counter model of the fed funds market and use it to study the determination of the fed funds rate, the volume of loans traded, and the intraday evolution of the distribution of reserve balances across banks. We also investigate the implications of changes in the market structure, as well as the effects of central bank policy instruments such as open market operations, the discount window lending rate, and the interest rate on bank reserves.
\end{abstract}

Keywords: Fed funds market; Search; Bargaining; Over-the-counter market JEL classification: G1, C78, D83, E44

\footnotetext{
*Afonso: Federal Reserve Bank of New York. Lagos: New York University and Federal Reserve Bank of Minneapolis. Lagos is grateful for the support from the C.V. Starr Center for Applied Economics at NYU and the Cowles Foundation for Research in Economics at Yale University. Part of this research was conducted while Lagos was a visitor at the Federal Reserve Bank of Minneapolis. The views expressed herein are those of the authors and not necessarily those of the Federal Reserve Bank of New York, the Federal Reserve Bank of Minneapolis, or the Federal Reserve System.
} 


\section{Introduction}

Financial institutions in the United States keep reserve balances at the Federal Reserve Banks to meet requirements, earn interest, or clear financial transactions. The market for federal funds is an interbank over-the-counter market for unsecured, mostly overnight loans of dollar reserves held at Federal Reserve Banks. This market allows institutions with excess reserve balances to lend reserves to institutions with reserve deficiencies. A particular average measure of the market interest rate on these loans is commonly referred to as the fed funds rate.

The fed funds market is primarily a mechanism that reallocates reserves among banks. As such, it is a crucial market from the standpoint of the economics of payments and the branch of banking theory that studies the role of interbank markets in helping banks manage reserves and offset liquidity or payment shocks. The fed funds market is the setting where the interest rate on the shortest maturity, most liquid instrument in the term structure is determined. This makes it an important market from the standpoint of finance. The fed funds rate affects commercial bank decisions concerning loans to businesses and individuals, and has important implications for the loan and investment policies of financial institutions more generally. This makes the fed funds market critical to macroeconomists. The fed funds market is the epicenter of monetary policy implementation: The Federal Open Market Committee (FOMC) communicates monetary policy by choosing the fed funds rate it wishes to prevail in this market and implements monetary policy by instructing the trading desk at the Federal Reserve Bank of New York to "create conditions in reserve markets" that will encourage fed funds to trade at the target level. As such, the fed funds market is of first-order importance for economists interested in monetary theory and policy. For these reasons, we believe it is crucial to pry into the micro mechanics of trade in the market for federal funds in order to understand the mechanism by which this market reallocates liquidity among banks and the determination of the market price for this liquidity provision - the fed funds rate. To this end, we develop a dynamic equilibrium model of trade in the fed funds market that explicitly accounts for the two distinctive features of the over-the-counter structure of the actual fed funds market: search for counterparties and bilateral negotiations. In the theory, banks randomly contact other banks over time, and once they meet, they bargain over the loan size and interest rate.

Section 2 offers a brief institutional description of the market for federal funds. Section 3 presents the theoretical model and relates the main ingredients to the main institutional features 
of the fed funds market. Section 4 defines and characterizes equilibrium. In Section 5 we use the theory to identify the determinants of empirical measures of trade volume, trading delays, and the fed funds rate. We show that the equilibrium exhibits endogenous intermediation: although all banks have the same trading technology, some borrow reserves from counterparties who are willing to lend at relatively low rates and later lend those reserves to counterparties who are willing to borrow at higher rates. We also propose theory-based measures of the importance of bank-provided intermediation in the process of reallocation of reserves. In Section 6 we calibrate and simulate a large-scale version of the model to assess the ability of the theory to capture the salient empirical features of the market for federal funds in the United States, such as the intraday evolution of the distribution of reserve balances and the dispersion in loan sizes and fed funds rates. Finally, we use the large-scale calibrated model as a laboratory to study a key issue in modern central banking, namely, the effectiveness of policies that use the interest rate on banks' reserves as a tool to manage the fed funds rate. Appendix A contains all proofs. Appendix B studies the problem of a social planner who can reallocate reserves subject to the same bilateral trading technology available to private agents and shows that the equilibrium implements the efficient reallocation of reserves. Appendix $\mathrm{C}$ describes the data and estimation procedures used in the quantitative implementation of the theory. Appendix D contains supplementary policy experiments.

Previous research on the fed funds market includes the theoretical work of Poole (1968), Ho and Saunders (1985), and Coleman, Gilles, and Labadie (1996), and the empirical work of Hamilton (1996) and Hamilton and Jordà (2002). The over-the-counter nature of the fed funds market was highlighted by Ashcraft and Duffie (2007) in their empirical investigation and used by Bech and Klee (2011), Ennis and Weinberg (2009), and Furfine (2003) to try to explain certain aspects of interbank markets such as apparent limits to arbitrage, stigma, and banks' decisions to borrow from standing facilities. Relative to the existing literature on the fed funds market, our contribution is to model the intraday allocation of reserves and pricing of overnight loans using a dynamic equilibrium search-theoretic framework that captures the salient features of the decentralized interbank market in which these loans are traded. Our work is related to an emerging literature that studies search and bargaining frictions in financial markets. To date, this literature consists of two subfields: one that deals with macro issues and another that focuses on micro considerations in the market microstructure tradition.

On the macro side, for instance, Lagos (2010a, 2010b, 2011) uses versions of the Lagos and 
Wright (2005) search-based model of exchange to study the effect of liquidity and monetary policy on asset prices. On the micro side, Duffie, Gârleanu, and Pedersen (2005) and Lagos and Rocheteau (2009) employ search-theoretic techniques to model the trading frictions characteristic of real-world over-the-counter markets. ${ }^{1}$ Relative to this particular micro branch of the literature, our contribution is twofold. First, our model of the fed funds market provides a theoretical framework to interpret and rationalize the findings of existing empirical investigations of this market, such as Furfine (1999), Ashcraft and Duffie (2007), Bech and Atalay (2008), and Afonso, Kovner, and Schoar (2011). Our second contribution is methodological: we offer the first analytically tractable formulation of a search-based model of an over-the-counter market in which all trade is bilateral and agents can hold essentially unrestricted asset positions. ${ }^{2}$

\section{Institutional features of the market for federal funds}

The market for federal funds is a market for unsecured loans of reserve balances at the Federal Reserve Banks that allows participants with excess reserve balances to lend (or sell funds) to those with reserve balance shortages. These unsecured loans, commonly referred to as federal funds (or fed funds) are delivered on the same day, and their duration is typically overnight. ${ }^{3}$ The interest rate on these loans is known as the fed funds rate. Most fed funds transactions are settled through Fedwire Funds Services (Fedwire), a large-value real-time gross settlement system operated by the Federal Reserve Banks. Fedwire operates 21.5 hours each business day, from 9:00 pm eastern standard time (EST) on the preceding calendar day to 6:30 pm EST. Participants include commercial banks, thrift institutions, agencies and branches of foreign banks in the United States, government securities dealers, government agencies such as federal or state governments, and GSEs (e.g., Freddie Mac, Fannie Mae, and Federal Home Loan

\footnotetext{
${ }^{1}$ There is by now a growing search-theoretic literature on financial markets that includes Afonso (2011), Duffie, Gârleanu, and Pedersen (2007), Gârleanu (2009), Lagos and Rocheteau (2007), Lagos, Rocheteau, and Weill (2011), Miao (2006), Rust and Hall (2003), Spulber (1996), Vayanos and Wang (2007), Vayanos and Weill (2008), and Weill $(2007,2008)$, to name a few. See Ashcraft and Duffie (2007) for more on the over-the-counter nature of the fed funds market.

${ }^{2}$ In contrast, the tractability of the model of Lagos and Rocheteau (2009) (the only other tractable formulation of a search-based over-the-counter market with unrestricted asset holdings) relies on the assumption that all trade among investors is intermediated by dealers who have continuous access to a competitive interdealer market. While there are several examples of such pure dealer markets, the market for federal funds is not one of them.

${ }^{3}$ There is a term fed funds market where maturities range from a few days to more than a year. This market has been estimated to be much smaller than the overnight market (Meulendyke, 1998, Kuo et al., 2010).
} 
Banks). ${ }^{4}$ The market for fed funds is an over-the-counter market: in order to trade, a financial institution must first find a willing counterparty and then bilaterally negotiate the size and rate of the loan.

\section{The model}

There is a large population of agents that we refer to as banks, each represented by a point in the interval $[0,1]$. Banks hold integer amounts of an asset that we interpret as reserve balances and can negotiate these balances during a trading session set in continuous time that starts at time 0 and ends at time $T$. Let $\tau$ denote the time remaining until the end of the trading session, so $\tau=T-t$ if the current time is $t \in[0, T]$. The reserve balance that a bank holds (e.g., at its Federal Reserve account) at time $T-\tau$ is denoted by $k(\tau) \in \mathbb{K}$, with $\mathbb{K}=\{0,1, \ldots, K\}$, where $K \in \mathbb{Z}$ and $1 \leq K$. The measure of banks with balance $k$ at time $T-\tau$ is denoted $n_{k}(\tau)$. A bank starts the trading session with some balance $k(T) \in \mathbb{K}$. The initial distribution of balances, $\left\{n_{k}(T)\right\}_{k \in \mathbb{K}}$, is given. Let $u_{k} \in \mathbb{R}$ denote the flow payoff to a bank from holding $k$ balances during the trading session, and let $U_{k} \in \mathbb{R}$ be the payoff from holding $k$ balances at the end of the trading session. All banks discount payoffs at rate $r$.

Banks can trade balances with each other in an over-the-counter market where trading opportunities are bilateral and random and represented by a Poisson process with arrival rate $\alpha$. We model these bilateral transactions as loans of reserve balances. Once two banks have made contact, they bargain over the size of the loan and the quantity of reserve balances to be repaid by the borrower. After the terms of the transaction have been agreed upon, the banks part ways. We assume that (signed) loan sizes are elements of the set $\overline{\mathbb{K}}=\mathbb{K} \cup\{-K, \ldots,-1\}$ and that every loan gets repaid at time $T+\Delta$ in the following trading day, where $\Delta \in \mathbb{R}_{+}$. Let $x \in \mathbb{R}$ denote the net credit position (of reserves due at $T+\Delta$ ) that has resulted from some history of trades. We assume that the payoff to a bank with a net credit position $x$ that makes a new loan at time $T-\tau$ with repayment $R$ at time $T+\Delta$ is equal to the post-transaction discounted net credit position, $e^{-r(\tau+\Delta)}(x+R)$.

\footnotetext{
${ }^{4}$ More than 7,000 Fedwire participants can potentially lend and borrow in the fed funds market. In 2008, the average daily number of borrowers and lenders were estimated to be 164 and 255, respectively (see Afonso, Kovner, and Schoar, 2011).
} 
Discussion. We use a search-based model to capture the over-the-counter nature of the fed funds market. In practice there are two ways of trading federal funds. Two participants can contact each other directly and negotiate the terms of a loan, or they can be matched by a fed funds broker. Since nonbrokered transactions represent the bulk of the volume, we abstract from brokers in our baseline model. ${ }^{5}$ Notice that search entails two layers of uncertainty in this environment. First, the time it takes a bank to contact a counterparty is an exponentially distributed random variable with mean $1 / \alpha$. Second, conditional on having contacted a counterparty at time $T-\tau$, the reserve balance $k$ of the counterparty is a random variable with probability distribution $\left\{n_{k}(\tau)\right\}_{k \in \mathbb{K}}$. So even if a bank were able to contact counterparties fairly quickly, the fact that search is random with respect to the counterparties' reserve holdings implies that the bank will typically have to engage in several trades with different counterparties in order to achieve a desired holding of reserve balances.

Fed funds activity is concentrated in the last two hours of the operating day. ${ }^{6}$ Until late afternoon, transfers of reserves across banks are mostly due to their primary business activities. For example, a profit center at Bank A may draw down reserve balances in order to pay for an asset purchase from Bank B, or a client at Bank C may issue a payment to a client at Bank D, resulting in a transfer of reserves from Bank C to Bank D. By around 4:00 pm, the fed funds trading desk at each bank has a good estimate of the send and receive transactions pending until the end of the day and begins actively trading fed funds to push the bank's reserve balance in the desired direction. From this point on, the dynamics of the reserve balance is mostly controlled by the fed funds traders, who expect other profit centers at the bank to avoid large unscheduled transactions near the end of the day. ${ }^{7}$ Thus, in the theory, we think of $t=0$ as standing in for 4:00 pm and use the initial condition $\left\{n_{k}(T)\right\}_{k \in \mathbb{K}}$ to represent the distribution

\footnotetext{
${ }^{5}$ Ashcraft and Duffie (2007), for example, estimate that nonbrokered transactions represented 73 percent of the volume of federal funds traded in 2005. Federal fund brokers do not take positions themselves; they act only as matchmakers, bringing buyers and sellers together.

${ }^{6}$ In 2008, for example, Furfine estimates suggest that more than 75 percent of the value of fed funds traded among banks was traded after 4:00 pm. In line with this observation, Bartolini et al. (2005) and Bech and Atalay (2008) report very high fed funds loan activity during the latter part of the trading session. (See the illustrations of intraday loan networks for each half hour in a trading day in their Figure 6.)

${ }^{7}$ Ashcraft and Duffie (2007) and Duffie (2012) document this kind of institutional knowledge obtained from fed funds traders. In line with these observations, Bartolini et al. (2005) attribute the late afternoon rise in fed funds trading activity to the clustering of institutional deadlines, e.g., the settlement of securities transactions ends at 3:00 pm, causing some institutions to defer much of their money market trading until after that time, once their security-related balance sheet position becomes certain. Uncertainty about client transactions and other payment flows diminishes in the hour or two before Fedwire closes, which also contributes to the concentration of fed funds trading activity late in the day.
} 
of actual reserve balances given to the banks' fed funds trading desks at this time.

The motives for trading fed funds may vary across participants and their specific circumstances on any given day, but there are two main reasons in general. First, some institutions such as commercial banks use the fed funds market to offset the effects on their reserve balances of transactions (initiated either by their clients or by profit centers within the banks themselves) that would otherwise leave them with a reserve position that does not meet Federal Reserve regulations. Also, some participants regard fed funds as an investment vehicle - an interest-yielding asset that can be used to "deposit" balances overnight. In our model, all payoff-relevant policy and regulatory considerations are captured by the intraday and end-ofday payoffs, $\left\{u_{k}, U_{k}\right\}_{k \in \mathbb{K}} \cdot{ }^{8}$

\section{Equilibrium}

Let the function $V_{k}(\tau): \mathbb{K} \times[0, T] \rightarrow \mathbb{R}$ denote the maximum attainable payoff that a bank can obtain from $k \in \mathbb{K}$ units of reserve balances when the time until the end of the trading session is $\tau \in[0, T]$. Whenever two banks meet during the trading session, they bargain over the size of the loan and the size of the repayment. Consider a bank with $k$ balances that contacts a bank with $k^{\prime}$ balances. For any pair of pre-trade reserve balances of the two banks, $k, k^{\prime} \in \mathbb{K}$, the set $\Pi\left(k, k^{\prime}\right)=\left\{\left(q, q^{\prime}\right) \in \mathbb{K} \times \mathbb{K}: q+q^{\prime}=k+k^{\prime}\right\}$ contains all feasible pairs of post-trade balances that could result from the bilateral negotiation. This set embeds the restriction that an increase in one bank's balance must correspond to an equal decrease in the other bank's balance and that no bank can transfer more balances than it currently holds. For every pair of banks that hold pre-trade balances $\left(k, k^{\prime}\right) \in \mathbb{K} \times \mathbb{K}$, the set $\Pi\left(k, k^{\prime}\right)$ induces the set of all feasible (signed) loan sizes, $\Gamma\left(k, k^{\prime}\right)=\left\{b \in \overline{\mathbb{K}}:\left(k-b, k^{\prime}+b\right) \in \Pi\left(k, k^{\prime}\right)\right\}$. Notice that $\Pi\left(k, k^{\prime}\right)=\Pi\left(k^{\prime}, k\right)$ and $\Gamma\left(k, k^{\prime}\right)=-\Gamma\left(k^{\prime}, k\right)$ for all $k, k^{\prime} \in \mathbb{K}$. The pair $\left(b_{k k^{\prime}}(\tau), R_{k^{\prime} k}(\tau)\right)$ denotes the bilateral terms of trade between a bank with balance $k$ and a bank with balance $k^{\prime}$ when the remaining time until the end of the trading session is $\tau$. That is, $b_{k k^{\prime}}(\tau)$ is the amount of reserves that the bank with balance $k$ lends to the bank with balance $k^{\prime}$, and $R_{k^{\prime} k}(\tau)$ is the amount of balances that the latter commits to repay the former at time $T+\Delta$. We take these terms of trade to be the outcome corresponding to the symmetric Nash solution to the bilateral bargaining problem.

\footnotetext{
${ }^{8}$ For example, if the Federal Reserve pays no interest on intraday holdings of reserves and interest rate $i_{f}$ on all reserves held at the end of the trading session, then $u_{k}=0$ and $U_{k}=\left(1+i_{f}\right) k$ for all $k \in \mathbb{K}$. As another example, see (15) in Section 6.3. In Section 6.1 we will adopt a general specification that captures the essential institutional arrangements currently in place in the United States.
} 
Then for any $k, k^{\prime} \in \mathbb{K}$ and any $\tau \in[0, T],\left(b_{k k^{\prime}}(\tau), R_{k^{\prime} k}(\tau)\right)$ is the solution to

$$
\max _{b \in \Gamma\left(k, k^{\prime}\right), R \in \mathbb{R}}\left[V_{k-b}(\tau)+e^{-r(\tau+\Delta)} R-V_{k}(\tau)\right]\left[V_{k^{\prime}+b}(\tau)-e^{-r(\tau+\Delta)} R-V_{k^{\prime}}(\tau)\right] .
$$

Thus for any $k \in \mathbb{K}$ and any $\tau \in[0, T]$,

$$
\begin{aligned}
V_{k}(\tau) & =\mathbb{E}\left\{\int_{0}^{\min \left(\tau_{\alpha}, \tau\right)} e^{-r z} u_{k} d z+\mathbb{I}_{\left\{\tau_{\alpha}>\tau\right\}} e^{-r \tau} U_{k}\right. \\
& \left.+\mathbb{I}_{\left\{\tau_{\alpha} \leq \tau\right\}} e^{-r \tau_{\alpha}} \sum_{k^{\prime} \in \mathbb{K}} n_{k^{\prime}}\left(\tau-\tau_{\alpha}\right)\left[V_{k-b_{k k^{\prime}}\left(\tau-\tau_{\alpha}\right)}\left(\tau-\tau_{\alpha}\right)+e^{-r\left(\tau+\Delta-\tau_{\alpha}\right)} R_{k^{\prime} k}\left(\tau-\tau_{\alpha}\right)\right]\right\}
\end{aligned}
$$

where

$$
\begin{aligned}
b_{k k^{\prime}}(\tau) & \in \arg \max _{b \in \Gamma\left(k, k^{\prime}\right)}\left[V_{k^{\prime}+b}(\tau)+V_{k-b}(\tau)-V_{k^{\prime}}(\tau)-V_{k}(\tau)\right] \\
e^{-r(\tau+\Delta)} R_{k^{\prime} k}(\tau) & =\frac{1}{2}\left[V_{k^{\prime}+b_{k k^{\prime}}(\tau)}(\tau)-V_{k^{\prime}}(\tau)\right]+\frac{1}{2}\left[V_{k}(\tau)-V_{k-b_{k k^{\prime}}(\tau)}(\tau)\right] .
\end{aligned}
$$

The expectation operator, $\mathbb{E}$, in (1) is with respect to the exponentially distributed random time until the next trading opportunity, $\tau_{\alpha}$, and $\mathbb{I}_{\left\{\tau_{\alpha} \leq \tau\right\}}$ is an indicator function that equals 1 if $\tau_{\alpha} \leq \tau$ and 0 otherwise. The first term contains the flow payoff to the bank from holding balance $k$ until the next trade opportunity or the end of the session, whichever arrives first. The second term says that in the event that the bank gets no trade opportunity before time $T$, it ends the day with $k$ balances and gets the end-of-day payoff $U_{k}$. The third term contains the expected discounted payoff in the event that the bank gets a trade opportunity with another bank before time $T$, i.e., at time $T-\left(\tau-\tau_{\alpha}\right)$. In this event the counterparty is a random draw from the distribution of balances at time $T-\left(\tau-\tau_{\alpha}\right)$, namely, $\left\{n_{k^{\prime}}\left(\tau-\tau_{\alpha}\right)\right\}_{k^{\prime} \in \mathbb{K}}$, and the expression inside the square bracket is the post-trade continuation payoff of the bank we are considering. ${ }^{9}$ Hereafter, we use $\boldsymbol{V} \equiv[\boldsymbol{V}(\tau)]_{\tau \in[0, T]}$, with $\boldsymbol{V}(\tau) \equiv\left\{V_{k}(\tau)\right\}_{k \in \mathbb{K}}$, to denote the value function. According to the bargaining solution (2) and (3), the loan size maximizes the joint gain from

\footnotetext{
${ }^{9}$ Notice that aside from the $k$ units of reserves it is holding at time $T-\tau$, a bank may also have a net credit position $x \in \mathbb{R}$ resulting from trades that occurred earlier in the trading session (to be settled after the end of the trading session, at time $T+\Delta$ ). Thus the total payoff of a bank will typically depend on its total asset position, $\boldsymbol{s}=(k, x) \in \mathbb{K} \times \mathbb{R}$. In Appendix A (Section A.1) we present the bargaining problem and the Bellman equation that must be satisfied by $J_{k}(x, \tau): \mathbb{K} \times \mathbb{R} \times[0, T] \rightarrow \mathbb{R}$, i.e., the value function of a bank that at time $T-\tau$ holds $k \in \mathbb{K}$ units of reserve balances and whose net credit position is $x \in \mathbb{R}$, and the bilateral terms of trade $\left(b_{s s^{\prime}}(\tau), R_{\boldsymbol{s}^{\prime} \boldsymbol{s}}(\tau)\right)$ that result in a meeting at time $T-\tau$ between a bank with total asset position $\boldsymbol{s}=(k, x) \in \mathbb{K} \times \mathbb{R}$ and a bank with total asset position $\boldsymbol{s}^{\prime}=\left(k^{\prime}, x^{\prime}\right) \in \mathbb{K} \times \mathbb{R}$. We also show (Lemma 2) that $J_{k}(x, \tau)=V_{k}(\tau)+e^{-r(\tau+\Delta)} x$, which means that the Nash bargaining outcome is independent of the net credit positions of the banks, $x$ and $x^{\prime}$. This allows us to simplify the exposition by working with $V_{k}(\tau)$.
} 
trade, and the repayment implements a division of this gain between the borrower and the lender that gives each a fraction equal to their bargaining power (i.e., one half). For example, if a bank with $i \in \mathbb{K}$ balances and a bank with $j \in \mathbb{K}$ balances meet at time $T-\tau$, they will negotiate a loan of size $b_{i j}(\tau)=i-k=s-j$, where $(k, s) \in \arg \max _{\left(k^{\prime}, s^{\prime}\right) \in \Pi(i, j)} S_{i j}^{k^{\prime} s^{\prime}}(\tau)$ with $S_{i j}^{k^{\prime} s^{\prime}}(\tau) \equiv V_{k^{\prime}}(\tau)+V_{s^{\prime}}(\tau)-V_{i}(\tau)-V_{j}(\tau)$. The implied joint gain from trade corresponding to this transaction is $S_{i j}^{k s}(\tau)$, and the individual gain from trade, e.g., of the bank with pre-trade balance equal to $i$, is $V_{k}(\tau)+e^{-r(\tau+\Delta)} R_{j i}(\tau)-V_{i}(\tau)=\frac{1}{2} S_{i j}^{k s}(\tau)$.

Consider a bank with $i$ balances that contacts a bank with $j$ balances when the time until the end of the trading session is $\tau$. Let $\phi_{i j}^{k s}(\tau)$ be the probability that the former and the latter hold $k$ and $s$ balances after the meeting, respectively, i.e., $\phi_{i j}^{k s}(\tau) \in[0,1]$, with $\sum_{k \in \mathbb{K}} \sum_{s \in \mathbb{K}} \phi_{i j}^{k s}(\tau)=1$. Feasibility requires that $\phi_{i j}^{k s}(\tau)=0$ if $(k, s) \notin \Pi(i, j)$. Given any feasible path for the distribution of trading probabilities, $\phi(\tau)=\left\{\phi_{i j}^{k s}(\tau)\right\}_{i, j, k, s \in \mathbb{K}}$, the distribution of balances at time $T-\tau$, i.e., $\boldsymbol{n}(\tau)=\left\{n_{k}(\tau)\right\}_{k \in \mathbb{K}}$, evolves according to

$$
\dot{n}_{k}(\tau)=f[\boldsymbol{n}(\tau), \boldsymbol{\phi}(\tau)] \quad \text { for all } k \in \mathbb{K},
$$

where

$$
\begin{aligned}
f[\boldsymbol{n}(\tau), \boldsymbol{\phi}(\tau)] & \equiv \alpha n_{k}(\tau) \sum_{i \in \mathbb{K}} \sum_{j \in \mathbb{K}} \sum_{s \in \mathbb{K}} n_{i}(\tau) \phi_{k i}^{s j}(\tau) \\
& -\alpha \sum_{i \in \mathbb{K}} \sum_{j \in \mathbb{K}} \sum_{s \in \mathbb{K}} n_{i}(\tau) n_{j}(\tau) \phi_{i j}^{k s}(\tau) .
\end{aligned}
$$

The first term on the right side of (5) contains the total flow of banks that leave state $k$ between time $t=T-\tau$ and time $t^{\prime}=T-(\tau-\varepsilon)$ for a small $\varepsilon>0$. The second term contains the total flow of banks into state $k$ over the same interval of time.

The following proposition provides a sharper representation of the value function and the distribution of trading probabilities characterized in (1), (2), and (3).

Proposition 1 The value function $\boldsymbol{V}$ satisfies (1), with (2) and (3), if and only if it satisfies

$$
r V_{i}(\tau)+\dot{V}_{i}(\tau)=u_{i}+\frac{\alpha}{2} \sum_{j \in \mathbb{K}} \sum_{k \in \mathbb{K}} \sum_{s \in \mathbb{K}} n_{j}(\tau) \phi_{i j}^{k s}(\tau)\left[V_{k}(\tau)+V_{s}(\tau)-V_{i}(\tau)-V_{j}(\tau)\right]
$$

for all $(i, \tau) \in \mathbb{K} \times[0, T]$, with

$$
V_{i}(0)=U_{i} \quad \text { for all } i \in \mathbb{K},
$$


and

$$
\phi_{i j}^{k s}(\tau) \begin{cases}\geq 0 & \text { if }(k, s) \in \Omega_{i j}[\boldsymbol{V}(\tau)] \\ =0 & \text { if }(k, s) \notin \Omega_{i j}[\boldsymbol{V}(\tau)],\end{cases}
$$

for all $i, j, k, s \in \mathbb{K}$ and all $\tau \in[0, T]$, with $\sum_{k \in \mathbb{K}} \sum_{s \in \mathbb{K}} \phi_{i j}^{k s}(\tau)=1$, where

$$
\Omega_{i j}[\boldsymbol{V}(\tau)] \equiv \arg \max _{\left(k^{\prime}, s^{\prime}\right) \in \Pi(i, j)}\left[V_{k^{\prime}}(\tau)+V_{s^{\prime}}(\tau)-V_{i}(\tau)-V_{j}(\tau)\right]
$$

The set $\Omega_{i j}[\boldsymbol{V}(\tau)]$ defined in (9) contains all the feasible pairs of post-trade balances that maximize the joint gain from trade between a bank with $i$ balances and a bank with $j$ balances that is implied by the value function $\boldsymbol{V}(\tau)$ at time $T-\tau$. For any pair of banks with balances $i$ and $j, \phi_{i j}^{k s}(\tau)$ defined in (8) is a probability distribution over the feasible pairs of post-trade balances that maximize the bilateral gain from trade. Thus together, (8) and (9) describe the pairs of post-trade balances (or equivalently, loan sizes) that may result from the bilateral bargaining. The Bellman equation described by (6) and (7) has a natural interpretation. The flow value of a bank that holds balance $i$ at time $T-\tau$, i.e., $r V_{i}(\tau)$, consists of the flow return from holding balance $i$, i.e., $u_{i}$, minus the flow capital loss associated with the reduction in the remaining time until the end of the trading session, i.e., $\dot{V}_{i}(\tau)$, plus the rate at which the bank meets counterparties, $\alpha$, times the expected gain from trade to the bank, i.e., $\sum_{j \in \mathbb{K}} \sum_{k \in \mathbb{K}} \sum_{s \in \mathbb{K}} n_{j}(\tau) \phi_{i j}^{k s}(\tau) \frac{1}{2} S_{i j}^{k s}(\tau)$.

Definition 1 An equilibrium is a path for the distribution of reserve balances, $\boldsymbol{n}(\tau)$, a value function, $\boldsymbol{V}$, and a path for the distribution of trading probabilities, $\phi(\tau)$, such that: (a) given the value function and the distribution of trading probabilities, the distribution of balances evolves according to (4); and (b) given the path for the distribution of balances, the value function satisfies (6) and (7), and the distribution of trading probabilities satisfies (8).

In quantitative implementations of the theory, one can try to compute equilibrium algorithmically, as follows. Guess a path of trading probabilities and use it to solve the system of differential equations (4) with initial condition $\left\{n_{k}(T)\right\}_{k \in \mathbb{K}}$ to obtain a path for the distribution of reserve balances. Then substitute the trading probabilities and distribution of reserves implied by the guess, and solve the system of differential equations (6) and (7) for the implied value function. Then use this value function and (8) to obtain a new guess for the path of trading probabilities and continue iterating until the value function has converged. Instead of 
following this route, here we make a curvature assumption on the vectors $\left\{u_{k}\right\}_{k \in \mathbb{K}}$ and $\left\{U_{k}\right\}_{k \in \mathbb{K}}$ that will allow us to provide an analytical characterization of equilibrium.

Assumption A. For any $i, j \in \mathbb{K}$, and all $(k, s) \in \Pi(i, j)$, the payoff functions satisfy

$$
\begin{gathered}
u_{\left\lceil\frac{i+j}{2}\right\rceil}+u_{\left\lfloor\frac{i+j}{2}\right\rfloor} \geq u_{k}+u_{s} \\
U_{\left\lceil\frac{i+j}{2}\right\rceil}+U_{\left\lfloor\frac{i+j}{2}\right\rfloor} \geq U_{k}+U_{s}, ">\text { " unless } k \in\left\{\left\lfloor\frac{i+j}{2}\right\rfloor,\left\lceil\frac{i+j}{2}\right\rceil\right\},
\end{gathered}
$$

where $\lfloor x\rfloor \equiv \max \{k \in \mathbb{Z}: k \leq x\}$ and $\lceil x\rceil \equiv \min \{k \in \mathbb{Z}: x \leq k\}$ for any $x \in \mathbb{R}$.

In Appendix A (Section A.3, Lemma 3) we show that conditions (DMC) and (DMSC) are equivalent to requiring that the payoff functions $\left\{u_{k}\right\}_{k \in \mathbb{K}}$ and $\left\{U_{k}\right\}_{k \in \mathbb{K}}$ satisfy discrete midpoint concavity and discrete midpoint strict concavity, respectively. ${ }^{10}$ These conditions are reasonable in the context of the fed funds market because central banks typically do not offer payment schemes that are convex in reserve balances. The following result provides a full characterization of equilibrium under Assumption A.

Proposition 2 Let the payoff functions satisfy Assumption A. Then:

(i) An equilibrium exists, and the equilibrium paths for the maximum attainable payoffs, $\boldsymbol{V}(\tau)$, and the distribution of reserve balances, $\boldsymbol{n}(\tau)$, are uniquely determined.

(ii) The equilibrium path for the distribution of trading probabilities, $\phi(\tau)=\left\{\phi_{i j}^{k s}(\tau)\right\}_{i, j, k, s \in \mathbb{K}}$, is given by

$$
\phi_{i j}^{k s}(\tau) \begin{cases}\geq 0 & \text { if }(k, s) \in \Omega_{i j}^{*} \\ =0 & \text { if }(k, s) \notin \Omega_{i j}^{*}\end{cases}
$$

for all $i, j, k, s \in \mathbb{K}$ and all $\tau \in[0, T]$, with $\sum_{(k, s) \in \Omega_{i j}^{*}} \phi_{i j}^{k s}(\tau)=1$, and

$$
\Omega_{i j}^{*}= \begin{cases}\left\{\left(\frac{i+j}{2}, \frac{i+j}{2}\right)\right\} & \text { if } i+j \text { is even } \\ \left\{\left(\left\lfloor\frac{i+j}{2}\right\rfloor,\left\lceil\frac{i+j}{2}\right\rceil\right),\left(\left\lceil\frac{i+j}{2}\right\rceil,\left\lfloor\frac{i+j}{2}\right\rfloor\right)\right\} & \text { if } i+j \text { is odd }\end{cases}
$$

\footnotetext{
${ }^{10}$ These are the natural discrete approximations to the notions of midpoint concavity and midpoint strict concavity of ordinary functions defined on convex sets. Let $X$ be a convex subset of $\mathbb{R}^{n}$, then a function $g: X \rightarrow \mathbb{R}$ is said to be concave if $g(\epsilon x+(1-\epsilon) y) \geq \epsilon g(x)+(1-\epsilon) g(y)$ for all $x, y \in X$, and all $\epsilon \in[0,1]$. The function $g$ is midpoint concave if $2 g\left(\frac{x+y}{2}\right) \geq g(x)+g(y)$ for all $x, y \in X$. Clearly, if $g$ is concave then it is midpoint concave. The converse is true provided $g$ is continuous. The function $g: \mathbb{K} \rightarrow \mathbb{R}$ satisfies the discrete midpoint concavity property if $g\left(\left\lceil\frac{i+j}{2}\right\rceil\right)+g\left(\left\lfloor\frac{i+j}{2}\right\rfloor\right) \geq u_{i}+u_{j}$ for all $i, j \in \mathbb{K}$. See Murota (2003) for more on the midpoint concavity property and the role that it plays in the modern theory of discrete convex analysis.
} 
The equilibrium distribution of trading probabilities (10) can be described intuitively as follows. If at any point during the trading session, a bank with balance $i$ contacts a bank with balance $j$, then the post-trade balance is $\left\lfloor\frac{i+j}{2}\right\rfloor$ for one of the banks and $\left\lceil\frac{i+j}{2}\right\rceil$ for the other. This property, and the uniqueness of the equilibrium paths for the distribution of reserve balances and maximum payoffs, hold under Assumption A. In Appendix A (Section A.3, Corollary 1) we show that if we instead assume that $u$ satisfies discrete midpoint strict concavity and $U$ satisfies discrete midpoint concavity, then the existence and uniqueness results in Proposition 2 still hold. With the path for $\phi(\tau)$ given by (10) in closed form, the equilibrium value function, $\boldsymbol{V}$, is the unique bounded real-valued function that satisfies (6) and (7), and the path for the distribution of balances, $\boldsymbol{n}(\tau)$, is given by (4) with initial condition $\left\{n_{k}(T)\right\}_{k \in \mathbb{K}}$.

\section{Positive implications}

The fed funds market is a mechanism that reallocates reserves among banks. Its performance is typically assessed with empirical measures of the volume of this reallocation and the corresponding interest rates. In this section we derive the theoretical counterparts to these empirical measures and show that the theory is qualitatively consistent with the elementary features of the actual fed funds market. We also identify the determinants of the fed funds rate, trade volume, and trading delays, show that the equilibrium exhibits endogenous intermediation, and propose theory-based measures of the importance of these bank-provided intermediation services in the process of reallocation of reserves.

\subsection{Trade volume and trading delays}

The total volume of fed funds traded during the session is $\bar{v}=\int_{0}^{T} \bar{v}(\tau) d \tau$, where

$$
\bar{v}(\tau)=\alpha \sum_{i \in \mathbb{K}} \sum_{j \in \mathbb{K}} \sum_{k \in \mathbb{K}} \sum_{s \in \mathbb{K}} n_{i}(\tau) n_{j}(\tau) \phi_{i j}^{k s}(\tau)|k-i|
$$

Notice that the arrival rate of specific trading opportunities is endogenous, as it depends on the equilibrium distribution of balances. For example, $\alpha n_{j}(\tau) \phi_{i j}^{k s}(\tau)$ is the rate at which agents with balance $i$ trade a loan of size to $k-i$ with agents with balance $j$ at time $T-\tau$. Thus even though the contact rate, $\alpha$, is exogenous, the trading delays involved in attaining a certain target balance of reserves are determined endogenously, e.g., by agents' trading strategies and the distribution of reserves. 


\subsection{Fed funds rate}

Consider a transaction at time $T-\tau$ between a bank with $i$ balances and a bank with $j$ balances such that the former exits the trade with $k$ balances and the latter with $s=i+j-k$. In this case the bank with $j$ balances gives the bank with $i$ balances a loan of size $b_{j i}(\tau)=k-i=j-s$, and the latter repays $R_{i j}^{k s}(\tau)$ at time $T+\Delta$. Define the (gross) interest rate on this loan as

$$
1+\rho_{i j}^{k s}(\tau)=\frac{R_{i j}^{k s}(\tau)}{j-s} .
$$

Thus in the theory as in the actual fed funds market, there is no such thing as the fed funds rate; rather there is a time-varying distribution of rates. In this context, it is natural to construct a daily average,

$$
\bar{\rho}=\frac{1}{T} \int_{0}^{T} \sum_{i \in \mathbb{K}} \sum_{j \in \mathbb{K}} \sum_{k \in \mathbb{K}} \sum_{s \in \mathbb{K}} \omega_{i j}^{k s}(\tau) \rho_{i j}^{k s}(\tau) d \tau,
$$

where $\omega_{i j}^{k s}(\tau)$ is a weighting function with $\omega_{i j}^{k s}(\tau) \geq 0$ and $\sum_{i, j, k, s \in \mathbb{K}} \omega_{i j}^{k s}(\tau)=1$. For example, if $\omega_{i j}^{k s}(\tau)=v_{i j}^{k s}(\tau) / \bar{v}(\tau)$, then $\bar{\rho}$ is a value-weighted daily average fed funds rate akin to the effective federal funds rate published daily by the Federal Reserve. ${ }^{11}$

\subsection{Intermediation and speculative trades}

Consider a bank $B$ that starts the day with a zero balance of reserves and has two trade opportunities during the whole trading session: the first with bank $A$ that holds 20 units of reserves and the second with bank $C$ that holds 0 . Then according to Proposition 2, $B$ holds 10 units after trading with $A$ and 5 units after trading with $C$. Notice that $B$ buys 10 units from $A$ early in the trading session and resells 5 of these 10 units to $C$ later in the day, i.e., $B$ acted as an intermediary between $A$ and $C$. The equilibrium exhibits endogenous intermediation in the sense that banks act as dealers, buying and selling funds on their own account and channeling them from banks with larger balances to banks with smaller balances. From an applied standpoint, this kind of intermediation is an important feature of the fed funds market. ${ }^{12}$ From a theoretical standpoint, it is interesting that intermediation emerges

\footnotetext{
${ }^{11}$ The actual daily effective federal funds rate is a volume-weighted average of rates on trades arranged by major brokers. The Federal Reserve Bank of New York receives summary reports from the brokers and every morning publishes the effective federal funds rate for the previous day.

${ }^{12}$ This theoretical finding is consistent with a striking aspect of the fed funds market that was pointed out by Ashcraft and Duffie (2007): "A significant number of loans in our data are made by lenders in the lower deciles by relative balances. Many of these lenders are presumably themselves in relative need of funds but agree to lend
} 
as an equilibrium phenomenon even though all banks are fundamentally identical (i.e., they have the same contact rate, the same payoffs, and the bargaining power). Intermediation is a natural consequence of two elementary forces: random sequencing of meetings among banks with different holdings and the tendency of banks to want to equate their marginal utilities from reserve holdings formalized in Proposition $2 .{ }^{13}$

We propose a theory-based empirical measure of the importance of intermediation in the process of reallocation of reserves among banks. Consider a bank that starts the day with balance $k_{0}$ and then gets $N \in\{0,1,2, \ldots\}$ trading opportunities during the whole trading session. Let $k_{n}$ denote the bank's post-trade balance after the $n^{\text {th }}$ trade, for $n=1, \ldots, N$. Define the bank's accumulated volume of purchases $O^{p}=\sum_{n=1}^{N} \max \left\{k_{n}-k_{n-1}, 0\right\}$, the accumulated volume of sales, $O^{s}=-\sum_{n=1}^{N} \min \left\{k_{n}-k_{n-1}, 0\right\}$, and the (signed) net trade, $O^{p}-O^{s}=k_{N}-k_{0}$. Then $\min \left\{O^{p}, O^{s}\right\}$ measures the volume of funds intermediated by the bank. Alternatively, $O^{p}+O^{s}$ is the gross volume of funds traded by the bank, and $\left|O^{p}-O^{s}\right|$ is the size of the bank's net daily trade, so $X=O^{p}+O^{s}-\left|O^{p}-O^{s}\right|$ is a bank-level measure of excess funds reallocation, i.e., the volume of funds traded over and above what is required to accommodate the daily net trade. ${ }^{14}$ The statistic $X$ is an index of simultaneous buying and selling at the individual bank level that suggests $X /\left(O^{p}+O^{s}\right)$ as a natural measure of the proportion of the total volume of funds traded by a bank that the bank intermediated during the trading session.

\section{Quantitative analysis}

In this section we calibrate and simulate the model and show that it captures the salient features of the fed funds market in the United States. We then use the model as a laboratory to study a key issue in contemporary central banking, namely, the effectiveness of policies that use the interest rate on banks' reserves as a tool to manage the overnight interbank rate.

at a sufficiently high rate, planning to borrow later in the day at a lower rate. In any OTC market, the borrower does not generally know the most attractive rates available from other counterparties, or which counterparties are offering them, and may have an incentive to accept the rate offered by such a lender."

${ }^{13}$ In contrast, existing models of financial OTC markets, e.g., Duffie et al. (2005) and Lagos and Rocheteau (2009), feature intermediation by assuming that there are two types of agents: "investors" who get utility from holding the asset and "dealers" who have a superior (faster) trading technology and intermediate trade between investors with different asset valuations.

${ }^{14}$ Our measure of excess funds reallocation is reminiscent of the notion of excess job reallocation used in empirical studies of job creation and destruction (e.g., Davis, Haltiwanger, and Schuh, 1996). 


\subsection{Calibration}

The motives for trading fed funds and the payoffs from holding reserve balances are different for different types of market participants. Since commercial banks account for the bulk of the trade volume in the fed funds market, we focus on their trading motives and payoffs. ${ }^{15}$ The Federal Reserve imposes a minimum level of reserves on commercial banks and other depository institutions. ${ }^{16}$ End-of-day balances within a maintenance period may vary but generally remain positive as overnight overdrafts are considered unauthorized extensions of credit and penalized. On October 9, 2008, the Federal Reserve began remunerating banks' positive end-of-day balances. In the theory, all of these policy considerations are represented by $\left\{U_{k}\right\}_{k \in \mathbb{K}}$. The Fed has traditionally not paid interest on intraday reserve balances, but it charges interest on uncollateralized daylight overdrafts. In the theory, the flow payoff to a bank from holding intraday balances is captured by $\left\{u_{k}\right\}_{k \in \mathbb{K}}$.

For the quantitative work, we adopt the following formulation of banks' end-of-day payoffs:

$$
U_{k}=e^{-r \Delta_{f}}\left(k-\bar{k}_{0}+F_{k}\right),
$$

where

$$
F_{k}=\max _{k^{w} \in \mathbb{K}}\left\{\bar{F}\left(k^{w}\right)-i_{f}^{w}\left[k^{w}-\left(k-\bar{k}_{0}\right)\right]\right\} \text { s.t. } k-\bar{k}_{0} \leq k^{w}
$$

with

$$
\bar{F}\left(k^{w}\right)= \begin{cases}i_{f}^{r} \bar{k}+i_{f}^{e}\left(k^{w}-\bar{k}\right) & \text { if } \bar{k} \leq k^{w} \\ i_{f}^{r} k^{w}-i_{f}^{c}\left(\bar{k}-k^{w}\right) & \text { if } 0 \leq k^{w}<\bar{k} \\ -i_{f}^{c} \bar{k}+i_{f}^{o} k^{w} & \text { if } k^{w}<0 .\end{cases}
$$

This formulation captures the essential institutional arrangements currently in place in the United States. The parameter $\Delta_{f} \in \mathbb{R}_{+}$represents the length of the period between the end of the trading session and the beginning of the following trading session, when the bank's reserves held overnight at the Federal Reserve become available (in practice, this period consists of the 2.5 hours between 6:30 pm and 9:00 pm). The parameter $\bar{k}_{0} \in\{0, \ldots, K-1\}$ indexes

\footnotetext{
${ }^{15}$ Ashcraft and Duffie (2007) report that commercial banks account for over 80 percent of the volume of federal funds traded in 2005, while 15 percent involves GSEs, and 5 percent corresponds to special situations involving nonbanks that hold reserve balances at the Federal Reserve. Their estimates are based on the Furfine algorithm, from a sample of the top 100 institutions ranked by monthly volume of fed funds sent, including commercial banks, GSEs, and excluding transactions involving accounts held by central banks, federal or state governments, or other settlement systems.

${ }^{16}$ The reserve balance requirement applies to the average level of a bank's end-of-day balances during a twoweek maintenance period. For an explanation of how these required operating balances are calculated, see Bennett and Hilton (1997) and Federal Reserve (2009, 2010b).
} 
translations of the set $\mathbb{K}$, which afford us a more flexible interpretation of the elements of $\mathbb{K}$. Intuitively, $\bar{k}_{0}$ can be thought of as the overdraft threshold, which allows us to interpret a bank with $k<\bar{k}_{0}$ as having an overdraft in its Fed account. ${ }^{17}$ Thus according to (13), the end-of-day payoff of a bank that holds net-of-overdraft-threshold balance $k-\bar{k}_{0}$ at the end of the trading session is the discounted value of this balance net of interest payments from or to the Fed, denoted $F_{k}$. Specifically, $F_{k}$ contemplates that in practice, at the end of the trading day banks have the option to borrow from the Federal Reserve discount window an amount of reserves $k^{w}-\left(k-\bar{k}_{0}\right) \geq 0$. The parameter $\bar{k} \in\left\{1, \ldots, K-\bar{k}_{0}\right\}$ represents the reserve requirement imposed on each bank. The cost of overnight borrowing from the discount window is denoted $i_{f}^{w}$. The overnight interest rates that a bank earns on required and excess reserves are denoted $i_{f}^{r}$ and $i_{f}^{e}$, respectively, with $i_{f}^{e}<i_{f}^{w}$. The deficiency per-dollar cost of failing to meet the reserve requirement is denoted $i_{f}^{c}$, and $i_{f}^{o}$ is the overnight overdraft penalty rate. The flow payoff to a bank from holding intraday balances is given by

$$
u_{k}= \begin{cases}i_{+}^{d}\left(k-\bar{k}_{0}\right)^{1-\epsilon} & \text { if } 0 \leq k-\bar{k}_{0} \\ -i_{-}^{d}\left(\bar{k}_{0}-k\right)^{1+\epsilon} & \text { if } k-\bar{k}_{0}<0 .\end{cases}
$$

The interest rate that a bank earns from the Fed on positive intraday balances is $i_{+}^{d}$, and $i_{-}^{d}$ is the interest rate it pays the Fed on daylight overdraft. The curvature parameter $\epsilon \in[0,1)$ will be set to a negligible positive value. ${ }^{18}$

We measure time in days. The model is meant to capture trade dynamics in the last 2.5 hours of the daily trading session, so we set $T=2.5 / 24$. The parametrization of the initial distribution of reserve balances, $\left\{n_{k}(T)\right\}_{k \in \mathbb{K}}$, is guided by identifying $n_{k}(T)$ in the theory with the empirical proportion of commercial banks whose balances at 4:00 pm are $k / \bar{k}$ times their average daily reserve requirement over a typical two-week holding period in 2007. Specifically, $\left\{n_{k}(T)\right\}_{k \in \mathbb{K}}$ was estimated from data using the following procedure. First, we identified 136 commercial banks that traded fed funds at the end of the second quarter of 2007 (according to their FR Y9-C regulatory filings) and for which we have been able to

\footnotetext{
${ }^{17}$ For example, in a parametrization with $\bar{k}_{0}=0, \mathbb{K}$ can be interpreted as the set of reserve balances that can be held by an individual bank. More generally, we can instead regard $k \in \mathbb{K}$ as an abstract index and interpret $k^{\prime} \equiv k-\bar{k}_{0}$ as a bank's actual reserve balance. Under this interpretation, reserve balances (i.e., $k^{\prime}$ ) held by banks are in the set $\mathbb{K}^{\prime} \equiv\left\{k^{\prime}: k^{\prime}=k-\bar{k}_{0}\right.$ for some $\left.k \in \mathbb{K}\right\}$. Then since $\mathbb{K}^{\prime}=\left\{-\bar{k}_{0}, \ldots, K-\bar{k}_{0}\right\}$, this formulation allows the payoff functions to accommodate the possibility of negative reserve balances. In line with this more general interpretation, $\bar{k}$ represents the reserve requirement imposed on reserve balances, $k^{\prime} \equiv k-\bar{k}_{0}$. (The reserve requirement stated in terms of the index $k$ would be $\bar{k}+\bar{k}_{0}$.)

${ }^{18}$ Together with $i_{-}^{d}$ large enough relative to $i_{+}^{d}$, this will ensure that $\left\{u_{k}\right\}_{k \in \mathbb{K}}$ satisfies the discrete midpoint strict concavity property.
} 
obtain information on their required operating balance. Second, we obtained the empirical cross-sectional distribution of closing balances of these 136 banks for each day of a two-week maintenance period in the same quarter. Third, for every day in the sample, we constructed a measure of each bank's imputed reserve balance at 4:00 pm, as follows. Given each bank's closing balance on a given day, we subtracted the bank's net payments activity from 4:00 pm until Fedwire Funds Service closing time (typically 6:30 pm) as well as the discount window activity for that day. Fourth, for each bank we calculated the average (over days in the twoweek maintenance period) imputed reserve balance at 4:00 pm and normalized it by dividing it by the bank's daily average required operating balance over the same maintenance period. ${ }^{19}$ At this stage we detected two outliers and removed them from the sample to obtain the final sample, $\mathcal{B}$, of 134 banks. ${ }^{20}$ The distribution of average imputed normalized reserve balances across this sample of 134 banks had a mean equal to 4.5. For our baseline experiments we translated this distribution so that the mean would match the empirical mean of the ratio of seasonally adjusted reserves to required reserves of all depository institutions during the second quarter of 2007, i.e., 1.04 as reported in the H.3 Federal Reserve Statistical Release. Let $h^{i}$ denote this average imputed normalized translated reserve balance for bank $i \in \mathcal{B}$. Finally, we let $\mathbb{K}=\{0, \ldots, 250\}, \bar{k}_{0}=100$, and set $n_{k}(T)=\frac{1}{134} \sum_{i \in \mathcal{B}} \mathbb{I}_{\left\{h^{i} \in\left[k-\bar{k}_{0}, k-\bar{k}_{0}+1\right)\right\}}$ for $k=0, \ldots, 249$, and $n_{250}(T)=1-\sum_{k=0}^{249} n_{k}(T)$. We normalize $\bar{k}=1$, so $k$ can be interpreted as a multiple of the reserve requirement.

Since the results are insensitive to small values of $r$, we set $r=0$. Most transactions are settled through Fedwire, and Fedwire does not operate for 2.5 hours between 6:30 pm and 9:00 pm, so the settlement lags $\Delta$ and $\Delta_{f}$ are set to $\Delta=\Delta_{f}=2.5 / 24$, which means that banks regard all loans (to other banks or to the Fed) as being repaid at the beginning of the following working day. The values of the policy rates $i_{-}^{d}, i_{+}^{d}, i_{f}^{r}, i_{f}^{e}, i_{f}^{w}, i_{f}^{c}$, and $i_{f}^{o}$ are chosen to mimic policies in the United States during the second quarter of 2007. The interest rate charged on daylight overdrafts, $i_{-}^{d}$, is set to $0.0036 / 360 .^{21}$ The interest rate paid on positive intraday

\footnotetext{
${ }^{19}$ The information on reserve balances is from Daylight Overdraft Reporting and Pricing System (DORPS) and two other internal Federal Reserve data sets: Discount window primary credit lending program and Required operating balances.

${ }^{20}$ See Section C.1 in Appendix C for details on our treatment of outliers.

${ }^{21}$ In practice, when an institution has insufficient funds in its Federal Reserve account to cover its settlement obligations during the operating day, it can incur a daylight overdraft up to an individual maximum amount known as net debit cap. (This cap is equal to zero for some institutions.) On March 24, 2011, the Federal Reserve Board implemented major revisions to the Payment System Risk policy, which include a zero fee for collateralized daylight overdrafts and an increased fee for uncollateralized daylight overdrafts to 50 basis points (annual rate)
} 
balances, $i_{+}^{d}$, is set to $10^{-7} / 360$ (one-thousandth of a basis point, annualized). ${ }^{22}$ The Federal Reserve did not pay interest on reserves prior to October 2008, so $i_{f}^{r}=i_{f}^{e}=0$. The total per-dollar cost of borrowing from the discount window is $i_{f}^{w}=i^{w}+P^{w}$, where $i^{w}$ is the window discount rate and $P^{w}$ represents the pecuniary value of the additional costs associated with discount window borrowing (such as administrative costs and stigma). The deficiency charge for failing to meet the reserve requirement is $i_{f}^{c}=i^{c}+P^{c}$, where $i^{c}$ is the overnight interest rate charged on the shortfall and $P^{c}$ represents the pecuniary value of additional penalties that the bank may suffer for failing to meet reserve requirements. The overnight overdraft penalty rate is $i_{f}^{o}=i^{o}+P^{o}$, where $i^{o}$ is the interest rate on the overdraft and $P^{o}$ represents additional penalties resulting from the use of unauthorized overnight credit. The interest rate on discount window loans under the Primary Credit Facility was 6.25 percent per annum in the second quarter of 2007 , so we set $i^{w}=0.0625 / 360$. The penalty rate charged for reserve deficiencies is 100 basis points above the Primary Credit Facility discount window lending rate on the first day of the calendar month in which the deficiency occurred, so we set $i^{c}=0.0725 / 360$. The interest penalty on overnight overdrafts is 400 basis points above the effective fed funds rate. The average daily effective fed funds rate during the second quarter of 2007 was 5.25 percent per annum, so we set $i^{o}=0.0925 / 360$. In the baseline we set $P^{c}=P^{o}=P^{w}$. ${ }^{23}$ We calibrate $P^{w}$ and $\alpha$, so that the equilibrium of the model is consistent with the following two targets: (a) the fed funds rate during the second quarter of 2007, which was 0.0525 per annum, and $(b)$ the standard deviation of the empirical end-of-day distribution of average normalized reserve balances (for the two-week holding period used to estimate the initial distribution), which was 1.1. This calibration strategy implies $P^{w}=0.0525 / 360$ and $\alpha=115 .^{24}$

from the prior level of 36 basis points that we use in our baseline (see Federal Reserve, 2010a).

${ }^{22}$ The interest that a bank receives for holding positive intraday reserves has actually been zero in the United States. We set $i_{+}^{d}$ to a small positive number and $\epsilon=10^{-6}$, a negligible positive number, only to ensure that $\left\{u_{k}\right\}_{k \in \mathbb{K}}$ satisfies the discrete midpoint strict concavity property, which significantly simplifies our solution algorithm. A negligible $i_{+}^{d}$ has only a negligible effect on the equilibrium rates.

${ }^{23}$ Corollary 2 (in Appendix A, Section A.4) reports a simple closed-form expression for $U_{k}$ for parametrizations such as this one, which satisfy $i_{f}^{e}<i_{f}^{w} \leq i_{f}^{o}$ and $i_{f}^{w}<i_{f}^{c}+i_{f}^{r}$. None of the quantitative results are sensitive to the specific values of $P^{c}$ or $P^{o}$ provided these inequalities are satisfied.

${ }^{24}$ With these values the equilibrium value-weighted daily average fed funds rate implied by the model $(\bar{\rho}$ as defined in Section 5.2) is 0.052 per annum, and the standard deviation of the end-of-day distribution of balances implied by the model is 1.1. The value $\alpha=115$ implies that banks have an average of about 12 meetings during the trading session, i.e., a trading opportunity every 12.5 minutes, on average. The implied equilibrium mean and median numbers of trading partners per bank during the session are 7.7 and 8 , respectively. The implied equilibrium proportion of intermediated funds in the theory (i.e., as defined in Section 5.3) is 0.65. 


\subsection{Simulation}

With the parameter values reported in Section 6.1, we simulated the equilibrium paths of one million banks. The results are presented in two figures. Figure 1 displays the behavior of the distribution of reserve balances and the fed funds rate. The top row describes the evolution of the distribution of reserves. The left panel shows the opening and the end-of-day distribution of reserve balances across banks. The middle panel describes the intraday evolution of the distribution of reserves by depicting box plots of the distribution at 15-minute intervals throughout the trading session. The distribution of banks' reserves follows a clear pattern of convergence. $^{25}$ The right panel shows that the standard deviation of the cross-sectional distribution of reserves falls over time - another indication that the market is continuously reallocating reserves from banks with larger balances to banks with smaller balances. The bottom row describes the behavior of the (distribution of) fed funds rate(s). The left panel plots in chronological time, $t=T-\tau$, at each minute $t$ during the trading session, the valueweighted average of the cross-sectional distribution of rates, $\sum_{i, j, k, s \in \mathbb{K}} \omega_{i j}^{k s}(\tau) \rho_{i j}^{k s}(\tau)$. The middle panel shows the histogram of $\left\{\left[\rho_{i j}^{k s}(\tau)\right]_{\tau \in[0, T]}\right\}_{i, j, k, s \in \mathbb{K}^{4}}$. The right panel exhibits a box plot every 15 minutes of the spread between the theoretical rates on loans traded at minute $t=T-\tau$, i.e., $\rho_{i j}^{k s}(\tau)$, and the value-weighted average of the cross-sectional distribution of rates on all transactions traded in that minute.

Figure 2 reports several dimensions of trade volume, such as the intraday time path of the volume of trade, the distribution of loan sizes, the distribution of transactions per bank, and intermediation. The top left panel shows the proportion of the daily volume (the solid line) and the proportion of the daily number of loans (the dashed line) traded by time $t=T-\tau$. Notice that neither the volume of trade nor the number of trades is distributed uniformly throughout the day; rather, trading activity tends to be higher earlier in the session. The top middle panel shows the daily distribution of loan sizes, and the top right panel uses box plots every 15 minutes to describe the evolution of the distribution of loan sizes during the day. In the bottom row, the left panel shows the distribution of the number of counterparties per bank, and the middle and right panels show the distribution of excess funds reallocation and the distribution of the proportion of intermediated funds - the two measures of intermediation introduced in

\footnotetext{
${ }^{25}$ The data display a similar pattern of convergence during the last 2.5 hours of the typical trading day. Empirical analogues of these box plots of the intraday distributions of reserve balances can be found in Afonso and Lagos (2014) and Ashcraft and Duffie (2007).
} 
Section 5.3. The equilibrium exhibits a substantial amount of endogenous intermediation. ${ }^{26}$

In order to assess the model fit, Figure 3 shows the box plots (at 15-minute intervals throughout the trading session) of the distribution of normalized reserves generated by the calibrated model and the distribution of average imputed normalized translated reserves from the data. The initial distribution and standard deviation of the end-of-day distribution from the model match the data by construction (the initial distribution is estimated from data, and $\alpha$ is calibrated so that the standard deviation of the end-of-day distribution in the model matches its empirical counterpart). The figure shows the degree to which the model is able to track the whole intraday path of the empirical distribution of reserves, i.e., the degree to which the theory can successfully capture the dynamics of the reallocation of reserves during the last stretch of a typical trading day. The rate of convergence of reserve balances in the model is uniform over time, while in the data convergence appears to be faster in the last hour of the trading session (it speeds up some time between 5:15 pm and 5:30 pm). Thus the model may be better suited for capturing trade dynamics during the last 60 to 90 minutes of the trading session (rather than during the last 150 minutes). Focusing on that time frame would significantly improve the fit. Alternatively, a more general model in which the contact rate is allowed to be time dependent (either exogenously or if banks could choose search intensity) may have a better chance at capturing the acceleration in the convergence of reserve balances that we see in the data.

\subsection{Policy evaluation}

During the five years prior to the onset of the 2008-2009 financial crisis, total reserve balances held by depository institutions in the United States fluctuated between $\$ 38$ billion and $\$ 56$ billion, and required reserves stood between 80 percent and 99 percent of total reserves. Total reserves increased dramatically from about $\$ 41.5$ billion in the months prior to September 2008 to more than $\$ 900$ billion in January 2009. Most of the increase was accounted for by a sharp

\footnotetext{
${ }^{26}$ We have also studied the distributions of fed funds purchased throughout the trading day every 15 minutes by banks whose adjusted balance, $k-\bar{k}_{0}-\bar{k}$, at the time of the trade are in the top 70 percent of the distribution of nonnegative adjusted balances, as well as the distributions of fed funds sold throughout the trading day every 15 minute by banks whose adjusted balances at the time of the trade are in the bottom 70 percent of the distribution of negative adjusted balances. We have found that according to the theory, it is common for banks with relatively large balances to borrow, as well as for banks with relatively low balances to lend, which has been interpreted as prima facie evidence of the presence of over-the-counter trading frictions in the fed funds market. Ashcraft and Duffie (2007) were the first to point out that this type of trading activity is present in the loan estimates obtained with the Furfine algorithm. Afonso and Lagos (2014) report similar findings.
} 
rise in excess reserves, which represented more than 93 percent of total reserves in January 2009 (up from less than 3 percent in the months prior to September 2008). This context of large excess reserves still persists today, six years later. On the policy front, the Emergency Economic Stabilization Act of 2008 authorized the Federal Reserve to pay interest on reserve balances held by or on behalf of depository institutions beginning October 1, 2008. With this authority, the Federal Reserve Board approved a rule to amend its Regulation D, and the Federal Reserve Banks began paying interest on reserves on October 9, 2008.

The unprecedented scale of excess reserves and the new policy instruments at the disposal of the Federal Reserve raise important questions regarding the Fed's ability to adjust its policy stance. For example, how large an open market operation would be necessary to increase the fed funds rate by 25 basis points in a context with excess reserves standing above $\$ 1$ trillion? Is it possible to uncouple the quantity of reserves from the implementation of the interest rate target? And if so, what is the elasticity of the fed funds rate to changes in the interest on reserves? These issues have been receiving much attention in policy circles. ${ }^{27}$ We perceive a growing need for quantitative models that can be used to explore the effectiveness of the interest rate on reserves as a tool to manage the fed funds rate. In this section we take steps toward meeting this demand.

As in Section 6.1, we think of $n_{k}(T)$ as the model counterpart of the empirical proportion of commercial banks whose balances at the beginning of the trading session are $k / \bar{k}$ times larger than their average daily reserve requirement over a two-week holding period. In order to conduct policy and counterfactual experiments, it is useful to work with a parametric distribution of balances, so instead of working with the empirical frequency of balances as in Section 6.1, here we estimate the initial distribution with 2011 data by maximum likelihood using a Gaussian mixture model with 2 components. ${ }^{28}$ Let $\Phi$ denote the cumulative distribution function of the Gaussian mixture with parameters $\mu_{1}=3.19$ and $\mu_{2}=36.2$ (the means), $\sigma_{1}=3.9$ and $\sigma_{2}=34$ (the standard deviations), and $p_{1}=1-p_{2}=0.56$ (the probability of drawing from the first

\footnotetext{
${ }^{27}$ See Ennis and Wolman (2010), Goodfriend (2002), and Keister et al. (2008) for policy discussions. Keister et al. (2008) conclude, "While the floor system has received a fair amount of attention in policy circles recently, there are important open questions about how well such a system will work in practice. Going forward, it will be useful to develop theoretical models of the monetary policy implementation process that can address these questions." Ennis and Wolman (2010) stress, "In contrast to the predictions of simple theories, the interest on reserves (IOR) rate has not acted as a floor on the federal funds rate. It is now well-understood why certain institutional features of the fed funds market and the IOR program should prevent the IOR rate from acting as a floor, but the precise determination of the fed funds rate in this environment remains poorly understood."

${ }^{28}$ See Appendix C (Section C.2) for a detailed description of our estimation procedure.
} 
component), which we use to represent the distribution of average imputed normalized translated reserve balances at 4:00 pm during the first quarter of 2011. Notice that $\bar{\mu} \equiv p_{1} \mu_{1}+p_{2} \mu_{2}=17.6$, which is the empirical mean of the ratio of seasonally adjusted reserves to required reserves of all depository institutions during the first quarter of 2011 reported in the H.3 Federal Reserve Statistical Release. ${ }^{29}$ In order to feed this distribution into the model, we let $\bar{k}=1$ (so $k$ can be interpreted as a multiple of the reserve requirement), $\mathbb{K}=\{0, \ldots, 250\}, \bar{k}_{0}=100$, and $n_{k}(T)=$ $\Phi\left(k-\bar{k}_{0}+1\right)-\Phi\left(k-\bar{k}_{0}\right)$ for $k=1, \ldots, 249, n_{0}(T)=\Phi(-100)$, and $n_{250}(T)=1-\Phi(150)$. By construction, $Q \equiv \sum_{k=0}^{250}\left(k-\bar{k}_{0}\right) n_{k}(T) \approx \bar{\mu}=17.6$.

For the policy experiments that follow, we recalibrate the model so that the equilibrium is in line with market conditions on a typical day in $2011 .{ }^{30}$ The values of the policy rates $i_{-}^{d}$, $i_{f}^{w}, i_{f}^{c}, i_{f}^{o}, i_{f}^{r}$, and $i_{f}^{e}$ are all chosen to mimic the policies in place in the United States during the first quarter of 2011. Specifically, $i_{-}^{d}=0.0036 / 360, i_{f}^{w}=0.0075 / 360, i_{f}^{c}=i_{f}^{w}+0.01 / 360$, and $i_{f}^{r}=i_{f}^{e} \equiv i_{f}=0.0025 / 360$. The effective fed funds rate was about 15 basis points, and the overnight overdraft rate, $i_{f}^{o}$, was set at 400 basis points above the effective fed funds rate during 2011, so $i_{f}^{o}=0.0415 / 360$.

We set $P^{c}=P^{o}=P^{w}=0$ and $\alpha=1$ so the equilibrium is consistent with: (a) an upper band of the fed funds rate target of about 0.0025 per annum and $(b)$ the standard deviation of the empirical end-of-day distribution of average normalized reserve balances (for the two-week holding period used to estimate the initial distribution), which was 26.9. ${ }^{31}$ All other parameter values, i.e., $r, T, \Delta, \Delta_{f}$, and $i_{+}^{d}$, are set as in the calibration of Section 6.1. Figures 4 and 5 are the 2011 counterparts of Figures 1 and 2.

The policy experiments consist of varying either $i_{f}$ or $i_{f}^{w}$ for different values of $Q$. In the theory, $Q \equiv \sum_{k=0}^{250}\left(k-\bar{k}_{0}\right) n_{k}(T)$ is the quantity of reserves held by the banking system as a whole, while $\bar{k}$ is the reserve requirement of the consolidated banking system. Hence $Q / \bar{k}$

\footnotetext{
${ }^{29}$ As was the case in Section 6.1 for 2007, our sample of banks for 2011 has an average ratio of reserve balances to required operating balances that is somewhat higher than the ratio for all banks, so we translate the estimated distribution so that its mean matches the empirical mean of the ratio of seasonally adjusted reserves to required reserves of all depository institutions during the first quarter of 2011 as reported in the H.3 Federal Reserve Statistical Release.

${ }^{30}$ Section D.1 in Appendix D reports the results of similar counterfactual policy experiments for 2007.

${ }^{31}$ With this parametrization, the equilibrium of the model delivers a value-weighted daily average fed funds rate of 0.0029 per annum and a standard deviation of the end-of-day distribution of balances equal to 27 . While $P^{w}=0$ allows the model to replicate the much lower fed funds rate prevailing in 2011 relative to 2007, a lower value of $P^{w}$ for 2011 than for 2007 is also in line with recent efforts by the Federal Reserve to make the discount window more accessible and less stigmatic. The small value of $\alpha$ allows the model to capture a context in which there is little trade between banks, as has been the case since excess reserves sharply increased in 2009.
} 
indicates whether total reserve balances are scarce or abundant relative to the total amount of required reserves on a given day, and we can represent different market conditions by varying $Q .{ }^{32}$ For example, a situation with $Q / \bar{k}$ small may result from an open market sale at the onset of the trading session. We conduct three types of policy experiments, and for each we consider seven scenarios depending on the value of $Q / \bar{k}$, namely, $0.1,0.5,1,5,10,15$, and 30 .

The first experiment consists of increasing $i_{f}$ by 25 basis points from 0 to 75 basis points while leaving $i_{f}^{w}$ fixed at its baseline value (75 basis points). The second experiment consists of increasing $i_{f}^{w}$ by 25 basis points from 25 to 150 basis points while leaving $i_{f}$ at its baseline value (25 basis points). The implied values of the equilibrium (value-weighted) daily average fed funds rate, $\bar{\rho}$, for the first and second experiments are summarized in Table 1 and Table 2, respectively. In both tables, the first scenario, $Q / \bar{k}=0.1$, represents a day in which reserves are very scarce in the sense that the consolidated banking system holds balances that are only one-tenth of the required reserves. In the seventh scenario, $Q / \bar{k}=30$, the quantity of reserves in the system is very large relative to the quantity of required reserves, similar to what is the case on a typical day nowadays. In this case, the equilibrium fed funds rate essentially varies one-for-one with the interest on reserves, $i_{f}$, and is insensitive to the discount window rate, $i_{f}^{w}$. The fed funds rate is sensitive to both policy rates when market conditions are less extreme (in terms of the size of the total reserves relative to required reserves). For example, if the market is "balanced," e.g., if $Q / \bar{k}=1$, then an increase of 25 basis points in either policy rate increases the equilibrium fed funds rate roughly by a half of 25 basis points. ${ }^{33}$ Other intermediate market conditions give different intermediate results; for example, if $Q / \bar{k}=10$, then an increase of 25 basis points in the interest rate paid on reserves increases the fed funds rate by about 20 basis points, while an increase of 25 basis points in the discount window rate would increase the fed funds rate by about 5 basis points. The responsiveness of the equilibrium fed funds rate with respect to $i_{f}$ increases with $Q / \bar{k}$, while the opposite is true for $i_{f}^{w}$.

For a given policy, the equilibrium fed funds rate is decreasing in the overall quantity of funds in the system, $Q / \bar{k}$, as can be seen by following any of the rows in Table 1 or Table 2 from

\footnotetext{
${ }^{32}$ Since for a large enough grid, $\mathbb{K}$, our procedure ensures $Q \approx \bar{\mu}$, we vary $Q$ by varying $\bar{\mu}$. The desired value of $Q$ for each experiment is achieved by using a Gaussian mixture with parameters $\left(\mu_{1}(Q), \mu_{2}(Q), \sigma_{1}, \sigma_{1}, p_{1}\right)$, where $\mu_{i}(Q) \equiv Q \mu_{i} / \bar{\mu}$, and cumulative distribution function denoted by $\Phi(\cdot ; Q)$, and then setting the initial distribution of balances to $n_{k}(T)=\Phi\left(k-\bar{k}_{0}+1 ; Q\right)-\Phi\left(k-\bar{k}_{0} ; Q\right)$ for $k=1, \ldots, 249, n_{0}(T)=\Phi(-100 ; Q)$, and $n_{250}(T)=1-\Phi(150 ; Q)$.

${ }^{33}$ As we explain below, the "half" results from the fact that in our baseline calibration, the bargaining power of all banks is equal to one-half.
} 
left to right. Notice that the equilibrium fed funds rate typically lies in an interval $\left[i_{f}+\varepsilon, i_{f}^{w}+\varepsilon\right]$. Such an interval is often referred to as a channel or corridor by central bankers. ${ }^{34}$ In Table 1 the corridor gets narrower as $i_{f}$ increases, and in the limit when $i_{f} \rightarrow i_{f}^{w}=0.0075$ (the last row), the interval collapses to a point: the equilibrium rate can only equal $0.0075+\varepsilon$ and therefore becomes insensitive to $Q / \bar{k}$. Similarly, the equilibrium rate tends to remain equal to $0.0025+\varepsilon$ for any value of $Q / \bar{k}$ as $i_{f}^{w} \rightarrow i_{f}=0.0025$ (first row of Table 2).

For the third experiment we set $i_{f}^{w}=i_{f}+w$, where $w$ denotes a number of basis points per annum, and increase $i_{f}$ by 25 basis points from 0 to 100 basis points. The implied values of $\bar{\rho}$ for $w=0.0025 / 360$ are reported in Table 3. The equilibrium fed funds rate is always inside a corridor $\left[i_{f}+\varepsilon, i_{f}+w+\varepsilon\right]$ (the value of $\varepsilon$ is slightly above half a basis point). These experiments amount to shifting the whole corridor, keeping its width, $w$, constant. As before, the exact position of the equilibrium fed funds rate within this corridor depends on the amount of reserves relative to required reserves, $Q / \bar{k}$. For example, from the last column of Table 3, it is clear that if reserves are very abundant, the equilibrium fed funds rate coincides with the lower limit of the corridor, $i_{f}+\varepsilon$. As the market becomes more balanced, i.e., as $Q / \bar{k}$ gets closer to 1 , the equilibrium fed funds rate approaches the middle of the corridor. Finally, notice that shifting the whole corridor up by $x$ basis points (keeping the corridor width, $w$, fixed) increases the equilibrium fed funds rate by $x$ basis points.

Figure 6 illustrates the equilibrium value-weighted daily average fed funds rate, $\bar{\rho}$, as a function of the ratio of overall reserves to required reserves, $Q / \bar{k}$. This figure was generated using the parametrization corresponding to the third row of Table 2 (i.e., the baseline calibration with the policy rates in place in the first quarter of 2011, $i_{f}=0.0025 / 360$ and $i_{f}^{w}=0.0075$ ). Each panel in Figure 7 shows how $\bar{\rho}$ changes with $Q / \bar{k}$ for a different policy stance defined by a pair of policy rates $i_{f}$ and $i_{f}^{w}$. If one thinks of open-market operations as interventions that change the marketwide availability of reserves relative to the reserve requirement, the curves displayed in Figures 6 and 7 show the effect that —all else equal—open market sales or

\footnotetext{
${ }^{34}$ The value of $\varepsilon$ is slightly above half a basis point in our calculations. (It is not exactly zero, because in the baseline calibration, banks have a small yet positive, concave intraday payoff from holding reserves.) Many central banks, e.g., the European Central Bank and the central banks of Australia, Canada, and England, use a channel or corridor system to implement monetary policy. The system consists of a lending facility that resembles the discount window in the United States, from which banks are allowed to borrow freely (typically against acceptable collateral) at an interest rate equal to the target rate plus a fixed number of basis points. There is also a deposit facility that allows banks to earn overnight interest on reserves at a rate equal to the target rate minus a fixed number of basis points. Hence interest rates at the two standing facilities form a channel or corridor around the target rate.
} 
purchases of various sizes would have on the equilibrium fed funds rate when carried out against the background of different interest-on-reserves or Discount-Window rates.

Discussion Tables 1 and 2 show that if excess reserves are abundant, then $i_{f}$ is a powerful tool for managing $\bar{\rho}$ but $i_{f}^{w}$ is relatively ineffective, while the opposite is true if total reserves are small relative to the aggregate reserve requirement. The experiments also show that if either $i_{f}$ or $i^{w}$ is increased by $x$ basis points in a balanced market, then $\bar{\rho}$ will increase by about one-half of $x$. Table 3 shows that $\bar{\rho}$ will be very close to $i_{f}$ (the floor of the corridor) if excess reserves are abundant, that it lies almost exactly in the middle of the corridor if the market is balanced, and that it tends to get closer to $i^{w}$ (the corridor ceiling) as reserves become scarce. This table also shows that if both $i_{f}$ and $i^{w}$ are increased by $x$ basis points, then $\bar{\rho}$ will increase by exactly $x$ basis points.

In order to explain these findings and to show explicitly what are the key determinants of the equilibrium distribution of fed funds rates negotiated between banks throughout the day, consider the special case of the theory with $\mathbb{K}=\{0,1,2\}$. This case is simple because there can only be mutually beneficial trade between a bank with $i=2$ and a bank with $j=0$ balances, so the loan size must equal 1 in every trade. Hence, from (12), there is a single bilateral interest rate, $1+\rho(\tau)=R(\tau)$, at each point in time. In this context it is natural to refer to a bank with $i=2$ and a bank with $j=0$ as the lender and borrower, respectively, and to let $\theta \in[0,1]$ be the bargaining power of the borrower. If we let the end-of-day parameters satisfy $\bar{k}_{0}=0$, $\bar{k}=1, \Delta_{f}=\Delta$ and $i_{f}^{e}<i_{f}^{w}<i_{f}^{r}+i_{f}^{c}$ (a condition on policy rates that is satisfied in our baseline calibration), (13) reduces to

$$
U_{k}= \begin{cases}-e^{-r \Delta}\left(i_{f}^{w}-i_{f}^{r}\right) & \text { if } k=0 \\ e^{-r \Delta}\left(1+i_{f}^{r}\right) & \text { if } k=1 \\ e^{-r \Delta}\left(2+i_{f}^{r}+i_{f}^{e}\right) & \text { if } k=2 .\end{cases}
$$

We can interpret a bank with $k=1$ as being "on target" (holding the level of required reserves), a bank with $k=2$ as being "above target" (holding excess reserves), and a bank with $k=0$ as being "below target" (unable to meet the reserve requirement). In this setting the quantity of reserves in the market, $Q$, equals $n_{1}(T)+2 n_{2}(T)$, so $Q \leq 1$ if and only if $n_{2}(T) \leq n_{0}(T)$, i.e., since the total amount of required reserves is $\bar{k}=1$, the consolidated banking system is short of reserves if $n_{2}(T) \leq n_{0}(T)$ and holds excess reserves otherwise. If we set $u_{k}=0$ (which is 
essentially true in our calibration) the equilibrium interest rate can be solved for explicitly:

$$
\rho(\tau)=\Theta(\tau) i_{f}^{e}+[1-\Theta(\tau)] i_{f}^{w},
$$

where

$$
\Theta(\tau) \equiv \frac{\theta\left[n_{2}(T)-e^{-\alpha\left[n_{2}(T)-n_{0}(T)\right](T-\tau)} n_{0}(T)\right] e^{-\alpha \theta\left[n_{2}(T)-n_{0}(T)\right] \tau}+\left[1-e^{-\alpha \theta\left[n_{2}(T)-n_{0}(T)\right] \tau}\right] n_{2}(T)}{n_{2}(T)-e^{-\alpha\left[n_{2}(T)-n_{0}(T)\right] T} n_{0}(T)} .
$$

Notice that $\Theta(\tau) \in[0,1]$, with $\Theta(0)=\theta$, and $\partial \Theta(\tau) / \partial \theta>0$ for all $\tau$. It is possible to show that if $n_{2}(T)<n_{0}(T)$, then $0 \leq \Theta(\tau) \leq \theta$ with $\Theta^{\prime}(\tau)<0$, and conversely, if $n_{0}(T)<n_{2}(T)$, then $\theta \leq \Theta(\tau) \leq 1$ with $\Theta^{\prime}(\tau)>0$. Thus $\Theta(\tau)$ can be thought of as a borrower's effective bargaining power at time $T-\tau$, determined by the borrower's fundamental bargaining power, $\theta$, as well as his ability to realize gains from trade in the time remaining until the end of the trading session, which depends on the evolution of the endogenous distribution of balances across banks. For example, if $n_{0}(T)<n_{2}(T)$, it is relatively difficult for banks with excess balances to find potential borrowers, and $\Theta(\tau)$ is larger than $\theta$ throughout the trading session. In this case the lenders' effective bargaining power, $1-\Theta(\tau)$, increases toward their fundamental bargaining power, $1-\theta$, as the trading session progresses, reflecting the fact that although borrowers face a favorable distribution of potential trading partners throughout the session, their chances to execute the desired trade diminish as the end of the session draws closer. In the special case where the market is "balanced," i.e., if $n_{0}(T)=n_{2}(T)$, we have $\Theta(\tau)=\theta$ for all $\tau$. According to (16), the fed funds rate is a time-varying weighted average of the lender's end-of-day return on the second unit of balances, $i_{f}^{e}$, and the borrower's end-of-day reservation value for the first unit of balances, $i_{f}^{w}$. The weight on the former at time $T-\tau$ is $\Theta(\tau)$, i.e., the borrower's effective bargaining power at time $T-\tau$. Notice that a 1 percent increase in the overnight interest rate that the central bank pays on excess reserves, $i_{f}^{e}$, causes a $\Theta(\tau)$ percent increase in the fed funds rate at time $T-\tau$. A 1 percent increase in the overnight cost of a deficient balance, $i_{f}^{w}$, causes a $1-\Theta(\tau)$ percent increase in the fed funds rate at time $T-\tau$. It is possible to show that if $n_{2}(T)$ is very large relative to $n_{0}(T)$ (i.e., if $Q / \bar{k}$ is very large), then $\Theta(\tau)$ is very close to 1 for most of the trading session, which explains why $\bar{\rho}$ is very close to the floor of the corridor in the last column of Table 3 as well as why it moves basis point for basis point with the floor of the corridor in the last column of Table 1 . And clearly, if $Q / \bar{k}=1$ and $\theta=1 / 2$, then $\rho(\tau)=\bar{\rho}=(1 / 2)\left(i_{f}^{e}+i_{f}^{w}\right)$, consistent with the experiments reported in the middle columns of Tables 1,2 and 3). Since policy discussion is often organized around 
the competitive static model of Poole (1968), it is interesting to point out that the curves in Figures 6 and 7 are reminiscent of those that would be traced out by the equilibrium points resulting from progressively shifting the standard vertical supply of reserves in the popular "Poole model" (see, e.g., Ennis and Keister, 2008 or Keister et al., 2008).

\section{Conclusion}

The model we have developed is strikingly simple: banks randomly contact other banks over time and bargain the terms of the loans. Given the wide range of theoretical and quantitative results that the model delivers, we regard its simplicity as a virtue. We recognize, however, that there are several aspects of the real-world market for federal funds that our theory abstracts from, and we think that this opens up several interesting avenues for future work.

Available estimates suggest that the bulk of fed funds trade is direct trade between banks. But there is a segment of the market intermediated by specialized brokers that are not themselves commercial banks, so it would be interesting to incorporate them into the model.

The model is well suited to describe the last 2.5 hours of the typical trading session, when unexpected payment shocks are rare. In order to model trade dynamics throughout the whole day, the theory could be extended to allow for random payment shocks that induce exogenous reallocations of reserves among banks. Also, we have focused on trade dynamics within a typical day, but the theory could be extended to encompass a sequence of trading sessions like the one we have modeled.

The baseline model has banks that only differ in their initial holdings of reserves. Our perusal of available data suggests that it would be a fruitful task to extend the quantitative work to allow for heterogeneity among banks in terms of their relative bargaining strengths, the rates at which they can contact potential trading partners, and the payoffs from holding reserve balances.

We have assumed random search, which may be a reasonable assumption for settings in which banks are completely uninformed about potential counterparties' balances before a contact takes place. However, in reality some banks may have some information about which counterparties are more likely to be long or short on any given day, so for some questions it may be useful to extend the model to incorporate some degree of directedness in search.

We have abstracted from default risk. This may be an interesting feature to add, e.g., to study interbank markets during times of financial stress. Other natural extensions involve 
incorporating private information, e.g., regarding the reserve balances held by each bank or about the likelihood that a counterparty may fail to repay at the stipulated time. 


\section{A Proofs}

\section{A.1 Value function}

Let the function $J_{k}(x, \tau): \mathbb{K} \times \mathbb{R} \times[0, T] \rightarrow \mathbb{R}$ denote the maximum attainable payoff to a bank that holds $k \in \mathbb{K}$ units of reserve balances and whose net credit position is $x \in \mathbb{R}$ when the time until the end of the trading session is $\tau \in[0, T]$. Let $s=(k, x) \in \mathbb{K} \times \mathbb{R}$ denote the bank's individual state. Then,

$$
\begin{aligned}
J_{k}(x, \tau) & =\mathbb{E}\left\{\int_{0}^{\min \left(\tau_{\alpha}, \tau\right)} e^{-r z} u_{k} d z+\mathbb{I}_{\left\{\tau_{\alpha}>\tau\right\}} e^{-r \tau}\left(U_{k}+e^{-r \Delta} x\right)\right. \\
& \left.+\mathbb{I}_{\left\{\tau_{\alpha} \leq \tau\right\}} e^{-r \tau_{\alpha}} \int J_{k-b_{s s^{\prime}}\left(\tau-\tau_{\alpha}\right)}\left(x+R_{\boldsymbol{s}^{\prime} \boldsymbol{s}}\left(\tau-\tau_{\alpha}\right), \tau-\tau_{\alpha}\right) \mu\left(d \boldsymbol{s}^{\prime}, \tau-\tau_{\alpha}\right)\right\},
\end{aligned}
$$

where $\mathbb{E}$ is an expectation operator over the exponentially distributed random time until the next trading opportunity, $\tau_{\alpha}$, and $\mathbb{I}_{\left\{\tau_{\alpha} \leq \tau\right\}}$ is an indicator function that equals 1 if $\tau_{\alpha} \leq \tau$ and 0 otherwise. For each time $\tau \in[0, T]$ until the end of the trading session, $\mu(\cdot, \tau)$ is a probability measure (on the Borel $\sigma$-field of the subsets of $\mathbb{K} \times \mathbb{R}$ ) that describes the heterogeneity of potential trading partners over individual states, $\boldsymbol{s}^{\prime}=\left(k^{\prime}, x^{\prime}\right)$. The pair $\left(b_{s s^{\prime}}\left(\tau-\tau_{\alpha}\right), R_{\boldsymbol{s}^{\prime} \boldsymbol{s}}\left(\tau-\tau_{\alpha}\right)\right)$ denotes the bilateral terms of trade between a bank with state $s$ and a (randomly drawn) bank with state $\boldsymbol{s}^{\prime}$, when the remaining time is $\tau-\tau_{\alpha}$. That is, $b_{\boldsymbol{s} \boldsymbol{s}^{\prime}}\left(\tau-\tau_{\alpha}\right)$ is the amount of balances that the bank with state $s$ lends to the bank with state $\boldsymbol{s}^{\prime}$, and $R_{\boldsymbol{s}^{\prime} \boldsymbol{s}}\left(\tau-\tau_{\alpha}\right)$ is the amount of balances that the latter commits to repay at time $T+\Delta$.

For all $\tau \in[0, T]$ and any $\left(\boldsymbol{s}, \boldsymbol{s}^{\prime}\right)$ with $\boldsymbol{s}, \boldsymbol{s}^{\prime} \in \mathbb{K} \times \mathbb{R}$, we take $\left(b_{\boldsymbol{s s}^{\prime}}(\tau), R_{\boldsymbol{s}^{\prime} \boldsymbol{s}}(\tau)\right)$ to be the outcome corresponding to the symmetric Nash solution to a bargaining problem. ${ }^{35}$ Thus the bargaining outcome, $\left(b_{\boldsymbol{s s}^{\prime}}(\tau), R_{\boldsymbol{s}^{\prime} \boldsymbol{s}}(\tau)\right)$, is the pair $(b, R)$ that solves

$$
\max _{b \in \Gamma\left(k, k^{\prime}\right), R \in \mathbb{R}}\left[J_{k-b}(x+R, \tau)-J_{k}(x, \tau)\right]^{\frac{1}{2}}\left[J_{k^{\prime}+b}\left(x^{\prime}-R, \tau\right)-J_{k^{\prime}}\left(x^{\prime}, \tau\right)\right]^{\frac{1}{2}} .
$$

Below, in Lemma 2, we show that

$$
J_{k}(x, \tau)=V_{k}(\tau)+e^{-r(\tau+\Delta)} x
$$

\footnotetext{
${ }^{35}$ This axiomatic Nash solution can also be obtained from a strategic bargaining game in which, upon contact, Nature selects one of the banks with probability one-half to make a take-it-or-leave-it offer, which the other bank must either accept or reject on the spot. It is easy to verify that the expected equilibrium outcome of this game coincides with the solution to the Nash bargaining problem, subject to the obvious reinterpretation of $R_{\boldsymbol{s}^{\prime} \boldsymbol{s}}(\tau)$ as an expected repayment, which is inconsequential. See Appendix C in Lagos and Rocheteau (2009).
} 
satisfies (17), if and only if $V_{k}(\tau): \mathbb{K} \times[0, T] \rightarrow \mathbb{R}$ satisfies (1) for all $(k, \tau) \in \mathbb{K} \times[0, T]$, with (2) and (3). Note that in $(2)$ and (3) we use $\left(b_{k k^{\prime}}(\tau), R_{k^{\prime} k}(\tau)\right)$ (rather than $\left.\left(b_{\boldsymbol{s s}^{\prime}}(\tau), R_{\boldsymbol{s}^{\prime} \boldsymbol{s}}(\tau)\right)\right)$ to denote the bargaining outcome between a bank with individual state $s \in \mathbb{K} \times \mathbb{R}$ and a bank with individual state $s^{\prime} \in \mathbb{K} \times \mathbb{R}$, in order to stress that this outcome is independent of the banks' net credit positions, $x$ and $x^{\prime}$. Before proving Lemma 2, we establish the following preliminary result.

Lemma 1 For any $\left(k, k^{\prime}\right) \in \mathbb{K} \times \mathbb{K}$ and any $\tau \in[0, T]$, consider the following problem:

$$
\max _{b \in \Gamma\left(k, k^{\prime}\right), R \in \mathbb{R}}\left[V_{k-b}(\tau)-V_{k}(\tau)+e^{-r(\tau+\Delta)} R\right]^{\theta_{k k^{\prime}}}\left[V_{k^{\prime}+b}(\tau)-V_{k^{\prime}}(\tau)-e^{-r(\tau+\Delta)} R\right]^{1-\theta_{k k^{\prime}}},
$$

where $\theta_{k k^{\prime}}=1-\theta_{k^{\prime} k} \in[0,1]$, and $V_{k}(\tau): \mathbb{K} \times[0, T] \rightarrow \mathbb{R}$ is bounded. The correspondence

$$
\begin{aligned}
H^{*}\left(k, k^{\prime}, \tau ; V\right)=\arg \max _{b \in \Gamma\left(k, k^{\prime}\right), R \in \mathbb{R}}\left\{\left[V_{k-b}(\tau)-V_{k}(\tau)+e^{-r(\tau+\Delta)} R\right]^{\theta_{k k^{\prime}}}\right. \\
{\left.\left[V_{k^{\prime}+b}(\tau)-V_{k^{\prime}}(\tau)-e^{-r(\tau+\Delta)} R\right]^{1-\theta_{k k^{\prime}}}\right\} }
\end{aligned}
$$

is nonempty. Moreover, $\left(b_{k k^{\prime}}(\tau), R_{k^{\prime} k}(\tau)\right) \in H^{*}\left(k, k^{\prime}, \tau ; V\right)$ if and only if

$$
\begin{aligned}
b_{k k^{\prime}}(\tau) & \in \arg \max _{b \in \Gamma\left(k, k^{\prime}\right)}\left[V_{k^{\prime}+b}(\tau)+V_{k-b}(\tau)-V_{k^{\prime}}(\tau)-V_{k}(\tau)\right] \text {, and } \\
e^{-r(\tau+\Delta)} R_{k^{\prime} k}(\tau) & =\theta_{k k^{\prime}}\left[V_{k^{\prime}+b_{k k^{\prime}}(\tau)}(\tau)-V_{k^{\prime}}(\tau)\right]+\left(1-\theta_{k k^{\prime}}\right)\left[V_{k}(\tau)-V_{k-b_{k k^{\prime}}(\tau)}(\tau)\right] .
\end{aligned}
$$

Proof of Lemma 1. Define

$$
\begin{aligned}
& \bar{R}=e^{r(\tau+\Delta)} \max _{b \in \Gamma\left(k, k^{\prime}\right)}\left\{\theta_{k k^{\prime}}\left[V_{k^{\prime}+b}(\tau)-V_{k^{\prime}}(\tau)\right]+\left(1-\theta_{k k^{\prime}}\right)\left[V_{k}(\tau)-V_{k-b}(\tau)\right]\right\} \\
& \underline{R}=e^{r(\tau+\Delta)} \min _{b \in \Gamma\left(k, k^{\prime}\right)}\left\{\theta_{k k^{\prime}}\left[V_{k^{\prime}+b}(\tau)-V_{k^{\prime}}(\tau)\right]+\left(1-\theta_{k k^{\prime}}\right)\left[V_{k}(\tau)-V_{k-b}(\tau)\right]\right\}
\end{aligned}
$$

and consider

$$
\max _{(b, R) \in \tilde{\boldsymbol{\Gamma}}\left(k, k^{\prime}\right)}\left[V_{k-b}(\tau)-V_{k}(\tau)+e^{-r(\tau+\Delta)} R\right]^{\theta_{k k^{\prime}}}\left[V_{k^{\prime}+b}(\tau)-V_{k^{\prime}}(\tau)-e^{-r(\tau+\Delta)} R\right]^{1-\theta_{k k^{\prime}}},
$$

where $\tilde{\boldsymbol{\Gamma}}\left(k, k^{\prime}\right)=\left\{(b, R) \in \Gamma\left(k, k^{\prime}\right) \times[\underline{R}, \bar{R}]\right\}$. Since $V_{k}(\tau)$ is bounded, $-\infty<\underline{R} \leq \bar{R}<\infty$, so $(24)$ has at least one solution. Let $\left(b^{*}, R^{*}\right)$ denote a solution to (24). If we ignore the constraints $\underline{R} \leq R \leq \bar{R}$, then $\left(b^{*}, R^{*}\right)$ must satisfy the following first-order condition:

$$
e^{-r(\tau+\Delta)} R^{*}=\theta_{k k^{\prime}}\left[V_{k^{\prime}+b^{*}}(\tau)-V_{k^{\prime}}(\tau)\right]+\left(1-\theta_{k k^{\prime}}\right)\left[V_{k}(\tau)-V_{k-b^{*}}(\tau)\right]
$$


But then (22) and (23) imply $\underline{R} \leq R^{*} \leq \bar{R}$, and therefore $\left(b^{*}, R^{*}\right)$ solves (24) if and only if it solves (19). Suppose that $\left(b^{*}, R^{*}\right)$ is a solution to $(24)$ such that

$$
b^{*} \notin \arg \max _{b \in \Gamma\left(k, k^{\prime}\right)}\left[V_{k^{\prime}+b}(\tau)+V_{k-b}(\tau)-V_{k^{\prime}}(\tau)-V_{k}(\tau)\right] .
$$

Condition (25) implies

$$
\begin{aligned}
V_{k-b^{*}}(\tau)-V_{k}(\tau)+e^{-r(\tau+\Delta)} R^{*} & =\theta_{k k^{\prime}}\left[V_{k^{\prime}+b^{*}}(\tau)+V_{k-b^{*}}(\tau)-V_{k^{\prime}}(\tau)-V_{k}(\tau)\right] \\
V_{k^{\prime}+b^{*}}(\tau)-V_{k^{\prime}}(\tau)-e^{-r(\tau+\Delta)} R^{*} & =\left(1-\theta_{k k^{\prime}}\right)\left[V_{k^{\prime}+b^{*}}(\tau)+V_{k-b^{*}}(\tau)-V_{k^{\prime}}(\tau)-V_{k}(\tau)\right],
\end{aligned}
$$

so the value of (24) achieved by $\left(b^{*}, R^{*}\right)$ is

$$
\theta_{k k^{\prime}}^{\theta_{k k^{\prime}}}\left(1-\theta_{k k^{\prime}}\right)^{1-\theta_{k k^{\prime}}}\left[V_{k^{\prime}+b^{*}}(\tau)+V_{k-b^{*}}(\tau)-V_{k^{\prime}}(\tau)-V_{k}(\tau)\right] \equiv \xi^{*}
$$

But (26) implies that there exists $b^{\prime} \in \Gamma\left(k, k^{\prime}\right)$ such that

$$
\xi^{*}<\theta_{k k^{\prime}}^{\theta_{k k^{\prime}}}\left(1-\theta_{k k^{\prime}}\right)^{1-\theta_{k k^{\prime}}}\left[V_{k^{\prime}+b^{\prime}}(\tau)+V_{k-b^{\prime}}(\tau)-V_{k^{\prime}}(\tau)-V_{k}(\tau)\right]
$$

Then since

$$
R^{\prime}=e^{r(\tau+\Delta)}\left\{\theta_{k k^{\prime}}\left[V_{k^{\prime}+b^{\prime}}(\tau)-V_{k^{\prime}}(\tau)\right]+\left(1-\theta_{k k^{\prime}}\right)\left[V_{k}(\tau)-V_{k-b^{\prime}}(\tau)\right]\right\} \in[\underline{R}, \bar{R}],
$$

it follows that $\left(b^{\prime}, R^{\prime}\right)$ achieves a higher value than $\left(b^{*}, R^{*}\right)$, so $\left(b^{*}, R^{*}\right)$ is not a solution to (24), a contradiction. Hence, a solution $\left(b^{*}, R^{*}\right)$ to $(24)$, or equivalently to (19), must satisfy (25) and

$$
b^{*} \in \arg \max _{b \in \Gamma\left(k, k^{\prime}\right)}\left[V_{k^{\prime}+b}(\tau)+V_{k-b}(\tau)-V_{k^{\prime}}(\tau)-V_{k}(\tau)\right] .
$$

To conclude, we show that any $\left(b^{*}, R^{*}\right)$ that satisfies $(25)$ and $(27)$ is a solution to (19). To see this, notice that for all $(b, R) \in \Gamma\left(k, k^{\prime}\right) \times \mathbb{R}$,

$$
\begin{aligned}
& {\left[V_{k-b}(\tau)-V_{k}(\tau)+e^{-r(\tau+\Delta)} R\right]^{\theta_{k k^{\prime}}}\left[V_{k^{\prime}+b}(\tau)-V_{k^{\prime}}(\tau)-e^{-r(\tau+\Delta)} R\right]^{1-\theta_{k k^{\prime}}}} \\
& \leq \max _{R \in \mathbb{R}}\left[V_{k-b}(\tau)-V_{k}(\tau)+e^{-r(\tau+\Delta)} R\right]^{\theta_{k k^{\prime}}}\left[V_{k^{\prime}+b}(\tau)-V_{k^{\prime}}(\tau)-e^{-r(\tau+\Delta)} R\right]^{1-\theta_{k k^{\prime}}} \\
& =\theta_{k k^{\prime}}^{\theta_{k k^{\prime}}}\left(1-\theta_{k k^{\prime}}\right)^{1-\theta_{k k^{\prime}}}\left[V_{k^{\prime}+b}(\tau)+V_{k-b}(\tau)-V_{k^{\prime}}(\tau)-V_{k}(\tau)\right] \\
& \leq \theta_{k k^{\prime}}^{\theta_{k k^{\prime}}}\left(1-\theta_{k k^{\prime}}\right)^{1-\theta_{k k^{\prime}}} \max _{b \in \Gamma\left(k, k^{\prime}\right)}\left[V_{k^{\prime}+b}(\tau)+V_{k-b}(\tau)-V_{k^{\prime}}(\tau)-V_{k}(\tau)\right]=\xi^{*} .
\end{aligned}
$$

Lemma 2 The function $J_{k}(x, \tau)$ given in (18) satisfies (17) if and only if $V_{k}(\tau)$ satisfies (1), with (2) and (3). 
Proof of Lemma 2. Let $\boldsymbol{B}$ denote the space of bounded real-valued functions defined on $\mathbb{K} \times[0, T]$. Let $\boldsymbol{B}^{\prime}$ denote the space of functions obtained by adding $e^{-r(\tau+\Delta)} x$ for some $x \in \mathbb{R}$, to each element of $\boldsymbol{B}$. That is,

$$
\boldsymbol{B}^{\prime}=\left\{g: \mathbb{S} \rightarrow \mathbb{R} \mid g(k, x, \tau)=w(k, \tau)+e^{-r(\tau+\Delta)} x \text { for some } w \in \boldsymbol{B}\right\},
$$

where $\mathbb{S}=\mathbb{K} \times \mathbb{R} \times[0, T]$. Let $s=(k, x)$ and $\boldsymbol{s}^{\prime}=\left(k^{\prime}, x^{\prime}\right)$ denote two elements of $\mathbb{K} \times \mathbb{R}$. For any $g \in \boldsymbol{B}^{\prime}$ and any $\left(\boldsymbol{s}, \boldsymbol{s}^{\prime}, \tau\right) \in \mathbb{K} \times \mathbb{R} \times \mathbb{S}$, let

$$
\begin{gathered}
\tilde{H}\left(s, s^{\prime}, \tau ; g\right)=\arg \max _{b \in \Gamma\left(k, k^{\prime}\right), R \in \mathbb{R}}\left\{[g(k-b, x+R, \tau)-g(k, x, \tau)]^{\theta_{k k^{\prime}}}\right. \\
\left.\left[g\left(k^{\prime}+b, x^{\prime}-R, \tau\right)-g\left(k^{\prime}, x^{\prime}, \tau\right)\right]^{1-\theta_{k k^{\prime}}}\right\},
\end{gathered}
$$

where $\theta_{k k^{\prime}}=1-\theta_{k^{\prime} k} \in[0,1]$ for any $k, k^{\prime} \in \mathbb{K}$. Since $g \in \boldsymbol{B}^{\prime}, \tilde{H}\left(\boldsymbol{s}, \boldsymbol{s}^{\prime}, \tau ; g\right)=H^{*}\left(k, k^{\prime}, \tau ; w\right)$, where

$$
\begin{gathered}
H^{*}\left(k, k^{\prime}, \tau ; w\right)=\arg \max _{b \in \Gamma\left(k, k^{\prime}\right), R \in \mathbb{R}}\left\{\left[w(k-b, \tau)-w(k, \tau)+e^{-r(\tau+\Delta)} R\right]^{\theta_{k k^{\prime}}}\right. \\
\left.\left[w\left(k^{\prime}+b, \tau\right)-w\left(k^{\prime}, \tau\right)-e^{-r(\tau+\Delta)} R\right]^{1-\theta_{k k^{\prime}}}\right\}
\end{gathered}
$$

for some $w \in \boldsymbol{B}$, as defined in Lemma 1. By Lemma $1, H^{*}\left(k, k^{\prime}, \tau ; w\right)$ is nonempty, and $\left(b\left(k, k^{\prime}, \tau\right), R\left(k^{\prime}, k, \tau\right)\right) \in H^{*}\left(k, k^{\prime}, \tau ; w\right)$ if and only if

$$
b\left(k, k^{\prime}, \tau\right) \in \arg \max _{b \in \Gamma\left(k, k^{\prime}\right)}\left[w\left(k^{\prime}+b, \tau\right)+w(k-b, \tau)-w\left(k^{\prime}, \tau\right)-w(k, \tau)\right]
$$

and

$$
\begin{aligned}
e^{-r(\tau+\Delta)} R\left(k^{\prime}, k, \tau\right) & =\theta_{k k^{\prime}}\left\{w\left[k^{\prime}+b\left(k, k^{\prime}, \tau\right), \tau\right]-w\left(k^{\prime}, \tau\right)\right\} \\
& +\left(1-\theta_{k k^{\prime}}\right)\left\{w(k, \tau)-w\left[k-b\left(k, k^{\prime}, \tau\right), \tau\right]\right\} .
\end{aligned}
$$

The right side of (17) defines a mapping $\mathcal{T}$ on $\boldsymbol{B}^{\prime}$. That is, for any $g \in \boldsymbol{B}^{\prime}$ and all $(k, x, \tau) \in \mathbb{S}$,

$$
\begin{aligned}
(\mathcal{T} g)(k, x, \tau) & =\mathbb{E}\left[\int_{0}^{\min \left(\tau_{\alpha}, \tau\right)} e^{-r z} u_{k} d z+\mathbb{I}_{\left\{\tau_{\alpha}>\tau\right\}} e^{-r \tau}\left(U_{k}+e^{-r \Delta} x\right)\right. \\
& \left.+\mathbb{I}_{\left\{\tau_{\alpha} \leq \tau\right\}} e^{-r \tau_{\alpha}} \int g\left[k-b\left(k, k^{\prime}, \tau-\tau_{\alpha}\right), x+R\left(k^{\prime}, k, \tau-\tau_{\alpha}\right), \tau-\tau_{\alpha}\right] \mu\left(d \boldsymbol{s}^{\prime}, \tau-\tau_{\alpha}\right)\right]
\end{aligned}
$$

where $b\left(k, k^{\prime}, \tau\right)$ satisfies $(28)$ and $R\left(k^{\prime}, k, \tau\right)$ satisfies (29) (for the special case $\theta_{k k^{\prime}}=1 / 2$ for all $\left.k, k^{\prime} \in \mathbb{K}\right)$, for $w \in \boldsymbol{B}$ defined by $w(k, \tau)=g(k, x, \tau)-e^{-r(\tau+\Delta)} x$ for all $(k, \tau) \in \mathbb{K} \times[0, T]$. Substitute $g(k, x, \tau)=w(k, \tau)+e^{-r(\tau+\Delta)} x$ on the right side of $(\mathcal{T} g)(k, x, \tau)$ to obtain

$$
(\mathcal{T} g)(k, x, \tau)=(\mathcal{M} w)(k, \tau)+e^{-r(\tau+\Delta)} x,
$$


where $\mathcal{M}$ is a mapping on $\boldsymbol{B}$ defined by

$$
\begin{aligned}
(\mathcal{M} w)(k, \tau) & =\mathbb{E}\left[\int_{0}^{\min \left(\tau_{\alpha}, \tau\right)} e^{-r z} u_{k} d z+\mathbb{I}_{\left\{\tau_{\alpha}>\tau\right\}} e^{-r \tau} U_{k}\right. \\
& +\mathbb{I}_{\left\{\tau_{\alpha} \leq \tau\right\}} e^{-r \tau_{\alpha}} \int w\left[k-b\left(k, k^{\prime}, \tau-\tau_{\alpha}\right), \tau-\tau_{\alpha}\right] \mu\left(d \boldsymbol{s}^{\prime}, \tau-\tau_{\alpha}\right) \\
& \left.+\mathbb{I}_{\left\{\tau_{\alpha} \leq \tau\right\}} e^{-r \tau_{\alpha}} \int e^{-r\left(\tau+\Delta-\tau_{\alpha}\right)} R\left(k^{\prime}, k, \tau-\tau_{\alpha}\right) \mu\left(d \boldsymbol{s}^{\prime}, \tau-\tau_{\alpha}\right)\right]
\end{aligned}
$$

for all $(k, \tau) \in \mathbb{K} \times[0, T]$. Since the right side of (31) is independent of the net credit position $x$, after recognizing that $\mu\left(\left\{\left(k^{\prime}, x\right) \in \mathbb{K} \times \mathbb{R}: k^{\prime}=k\right\}, \tau\right)=n_{k}(\tau),(31)$ can be written as

$$
\begin{aligned}
(\mathcal{M} w)(k, \tau) & =\mathbb{E}\left[\int_{0}^{\min \left(\tau_{\alpha}, \tau\right)} e^{-r z} u_{k} d z+\mathbb{I}_{\left\{\tau_{\alpha}>\tau\right\}} e^{-r \tau} U_{k}\right] \\
& +\mathbb{E}\left[\mathbb{I}_{\left\{\tau_{\alpha} \leq \tau\right\}} e^{-r \tau_{\alpha}} \sum_{k^{\prime} \in \mathbb{K}} n_{k^{\prime}}\left(\tau-\tau_{\alpha}\right) w\left[k-b\left(k, k^{\prime}, \tau-\tau_{\alpha}\right), \tau-\tau_{\alpha}\right]\right. \\
& \left.+\mathbb{I}_{\left\{\tau_{\alpha} \leq \tau\right\}} e^{-r \tau_{\alpha}} \sum_{k^{\prime} \in \mathbb{K}} n_{k^{\prime}}\left(\tau-\tau_{\alpha}\right) e^{-r\left(\tau+\Delta-\tau_{\alpha}\right)} R\left(k^{\prime}, k, \tau-\tau_{\alpha}\right)\right],
\end{aligned}
$$

for all $(k, \tau) \in \mathbb{K} \times[0, T]$. From (32), it is clear that $\mathcal{M}$ is the mapping defined by the right side of (1). Since $w \in \boldsymbol{B}$, and $\left(b\left(k, k^{\prime}, \tau\right), R\left(k^{\prime}, k, \tau\right)\right)$ satisfy (28) and (29), it follows that $\mathcal{M}: \boldsymbol{B} \rightarrow \boldsymbol{B}$, and together with (30), this implies $\mathcal{T}: \boldsymbol{B}^{\prime} \rightarrow \boldsymbol{B}^{\prime}$. Notice that $g^{*}=w^{*}+e^{-r(\tau+\Delta)} x \in \boldsymbol{B}^{\prime}$ is a fixed point of $\mathcal{T}$ if and only if $w^{*} \in \boldsymbol{B}$ is a fixed point of $\mathcal{M}$. In the statement of the lemma and in the body of the paper, the fixed points $g^{*}(k, x, \tau)$ and $w^{*}(k, \tau)$ are denoted $J_{k}(x, \tau)$ and $V_{k}(\tau)$, respectively.

\section{A.2 Proposition 1}

Proof of Proposition 1. Start with the mapping (32), and notice that after writing out the expectation explicitly and performing a change of variable, it becomes

$(\mathcal{M} w)(k, \tau)=v_{k}(\tau)+\alpha \int_{0}^{\tau} \sum_{k^{\prime} \in \mathbb{K}} n_{k^{\prime}}(z)\left\{w\left[k-b\left(k, k^{\prime}, z\right), z\right]+e^{-r(z+\Delta)} R\left(k^{\prime}, k, z\right)\right\} e^{-(r+\alpha)(\tau-z)} d z$, for all $(k, \tau) \in \mathbb{K} \times[0, T]$, where

$$
v_{k}(\tau) \equiv \mathbb{E}\left[\int_{0}^{\min \left(\tau_{\alpha}, \tau\right)} e^{-r z} u_{k} d z+\mathbb{I}_{\left\{\tau_{\alpha}>\tau\right\}} e^{-r \tau} U_{k}\right],
$$

which can be integrated to obtain

$$
v_{k}(\tau)=\left[1-e^{-(r+\alpha) \tau}\right] \frac{u_{k}}{r+\alpha}+e^{-(r+\alpha) \tau} U_{k}
$$


Since $b\left(k, k^{\prime}, \tau\right)$ and $R\left(k^{\prime}, k, \tau\right)$ satisfy (28) and (29), the previous expression for the mapping $\mathcal{M}$ can be written as

$$
\begin{aligned}
(\mathcal{M} w)(k, \tau) & =v_{k}(\tau)+\alpha \int_{0}^{\tau} w(k, z) e^{-(r+\alpha)(\tau-z)} d z \\
& +\alpha \int_{0}^{\tau}\left[\sum _ { k ^ { \prime } \in \mathbb { K } } n _ { k ^ { \prime } } ( z ) \theta _ { k k ^ { \prime } } \left\{w\left[k^{\prime}+b\left(k, k^{\prime}, z\right), z\right]+w\left[k-b\left(k, k^{\prime}, z\right), z\right]\right.\right. \\
& \left.\left.-w\left(k^{\prime}, z\right)-w(k, z)\right\}\right] e^{-(r+\alpha)(\tau-z)} d z .
\end{aligned}
$$

In turn, since

$$
\begin{aligned}
& w\left[k^{\prime}+b\left(k, k^{\prime}, z\right), z\right]+w\left[k-b\left(k, k^{\prime}, z\right), z\right]-w\left(k^{\prime}, z\right)-w(k, z) \\
& =\max _{b \in \Gamma\left(k, k^{\prime}\right)}\left[w\left(k^{\prime}+b, z\right)+w(k-b, z)-w\left(k^{\prime}, z\right)-w(k, z)\right] \\
& =\max _{(i, j) \in \Pi\left(k, k^{\prime}\right)}\left[w(j, z)+w(i, z)-w\left(k^{\prime}, z\right)-w(k, z)\right],
\end{aligned}
$$

we have

$$
\begin{aligned}
(\mathcal{M} w)(k, \tau) & =v_{k}(\tau)+\alpha \int_{0}^{\tau} w(k, z) e^{-(r+\alpha)(\tau-z)} d z \\
& +\alpha \int_{0}^{\tau} \sum_{k^{\prime} \in \mathbb{K}} n_{k^{\prime}}(z) \theta_{k k^{\prime}} \max _{(i, j) \in \Pi\left(k, k^{\prime}\right)}\left[w(i, z)+w(j, z)-w(k, z)-w\left(k^{\prime}, z\right)\right] e^{-(r+\alpha)(\tau-z)} d z,
\end{aligned}
$$

for all $(k, \tau) \in \mathbb{K} \times[0, T]$. With relabeling, this mapping can be rewritten as

$$
\begin{aligned}
(\mathcal{M} w)(i, \tau) & =v_{i}(\tau)+\alpha \int_{0}^{\tau} w(i, z) e^{-(r+\alpha)(\tau-z)} d z \\
& +\alpha \int_{0}^{\tau} \sum_{j \in \mathbb{K}} \sum_{k \in \mathbb{K}} \sum_{s \in \mathbb{K}} n_{j}(z) \theta_{i j} \phi_{i j}^{k s}(z)[w(k, z)+w(s, z)-w(i, z)-w(j, z)] e^{-(r+\alpha)(\tau-z)} d z,
\end{aligned}
$$

for all $(i, \tau) \in \mathbb{K} \times[0, T]$, with

$$
\phi_{i j}^{k s}(z) \begin{cases}\geq 0 & \text { if }(k, s) \in \Omega_{i j}[w(\cdot, z)] \\ =0 & \text { if }(k, s) \notin \Omega_{i j}[w(\cdot, z)],\end{cases}
$$

for all $i, j, k, s \in \mathbb{K}$ and all $z \in[0, T]$, where $\sum_{k \in \mathbb{K}} \sum_{s \in \mathbb{K}} \phi_{i j}^{k s}(z)=1$, and

$$
\Omega_{i j}[w(\cdot, z)] \equiv \arg \max _{\left(k^{\prime}, s^{\prime}\right) \in \Pi(i, j)}\left[w\left(k^{\prime}, z\right)+w\left(s^{\prime}, z\right)-w(i, z)-w(j, z)\right] .
$$

From (34) (with $\theta_{k k^{\prime}}=1 / 2$ ), it is clear that $\boldsymbol{V}=\mathcal{M} \boldsymbol{V}$ can be written as

$$
\begin{aligned}
V_{i}(\tau) & =v_{i}(\tau)+\alpha \int_{0}^{\tau} V_{i}(z) e^{-(r+\alpha)(\tau-z)} d z \\
& +\frac{\alpha}{2} \int_{0}^{\tau} \sum_{j \in \mathbb{K}} \sum_{k \in \mathbb{K}} \sum_{s \in \mathbb{K}} n_{j}(z) \phi_{i j}^{k s}(z)\left[V_{k}(z)+V_{s}(z)-V_{i}(z)-V_{j}(z)\right] e^{-(r+\alpha)(\tau-z)} d z,
\end{aligned}
$$


for all $(i, \tau) \in \mathbb{K} \times[0, T]$. Notice that (35) implies (7). Differentiate both sides of (35) with respect to $\tau$, and rearrange terms to obtain

$\dot{V}_{i}(\tau)+r V_{i}(\tau)=\dot{v}_{i}(\tau)+(r+\alpha) v_{i}(\tau)+\frac{\alpha}{2} \sum_{j \in \mathbb{K}} \sum_{k \in \mathbb{K}} \sum_{s \in \mathbb{K}} n_{j}(\tau) \phi_{i j}^{k s}(\tau)\left[V_{k}(\tau)+V_{s}(\tau)-V_{i}(\tau)-V_{j}(\tau)\right]$, which together with the fact that $\dot{v}_{i}(\tau)=u_{i}-(r+\alpha) v_{i}(\tau)$ implies $(6)$.

\section{A.3 Proposition 2}

The following lemma establishes the equivalence between property (DMC) and discrete midpoint concavity.

Lemma 3 Let $g$ be a real-valued function on $\mathbb{K}$. Then $g$ satisfies

$$
g\left(\left\lceil\frac{i+j}{2}\right\rceil\right)+g\left(\left\lfloor\frac{i+j}{2}\right\rfloor\right) \geq g(k)+g(s)
$$

for any $i, j \in \mathbb{K}$ and all $(k, s) \in \Pi(i, j)$, if and only if it satisfies the discrete midpoint concavity property,

$$
g\left(\left\lceil\frac{i+j}{2}\right\rceil\right)+g\left(\left\lfloor\frac{i+j}{2}\right\rfloor\right) \geq g(i)+g(j)
$$

for all $i, j \in \mathbb{K}$.

Proof of Lemma 3. Suppose that $g$ satisfies (36). Since the condition holds for all $(k, s) \in$ $\Pi(i, j)$, and we know that $(i, j) \in \Pi(i, j)$, it holds for the special case $(k, s)=(i, j)$, so $g$ satisfies (37). To show the converse, notice that since (37) holds for all $i, j \in \mathbb{K}$, it also holds for all $i, j \in \mathbb{K}$ such that $(i, j) \in \Pi(k, s)$ for any $k, s \in \mathbb{K}$. But for any such $(i, j)$, we know that $i+j=k+s$, so $(37)$ implies

$$
g\left(\left\lceil\frac{k+s}{2}\right\rceil\right)+g\left(\left\lfloor\frac{k+s}{2}\right\rfloor\right) \geq g(i)+g(j)
$$

for any $k, s \in \mathbb{K}$ and all $(i, j) \in \Pi(k, s)$, which is the same as (36) up to a relabeling.

The following two lemmas are used in the proof of Proposition 2.

Lemma 4 For any given path $\boldsymbol{n}(\tau)$, there exists a unique $w^{*} \in \boldsymbol{B}$ that satisfies $w^{*}=\mathcal{M} w^{*}$, and a unique $g^{*} \in \boldsymbol{B}^{\prime}$ that satisfies $g^{*}=\mathcal{T} g^{*}$, defined by $g^{*}(k, x, \tau)=w^{*}(k, \tau)+e^{-r(\tau+\Delta)} x$ for all $(k, x, \tau) \in \mathbb{S}$. 
Proof of Lemma 4. Write the mapping $\mathcal{M}$ defined in the proof of Proposition 1 (with $\left.\theta_{k k^{\prime}}=1 / 2\right)$, as

$$
\begin{aligned}
(\mathcal{M} w)(i, \tau) & =v_{i}(\tau)+\alpha \int_{0}^{\tau} w(i, z) e^{-(r+\alpha)(\tau-z)} d z \\
& +\frac{\alpha}{2} \int_{0}^{\tau} \sum_{j \in \mathbb{K}} n_{j}(z) \max _{(k, s) \in \Pi(i, j)}[w(k, z)+w(s, z)-w(i, z)-w(j, z)] e^{-(r+\alpha)(\tau-z)} d z,
\end{aligned}
$$

for all $(i, \tau) \in \mathbb{K} \times[0, T]$. For any $w, w^{\prime} \in \boldsymbol{B}$, define the metric $D: \boldsymbol{B} \times \boldsymbol{B} \rightarrow \mathbb{R}$, by

$$
D\left(w, w^{\prime}\right)=\sup _{(i, \tau) \in \mathbb{K} \times[0, T]}\left[e^{-\beta \tau}\left|w(i, \tau)-w^{\prime}(i, \tau)\right|\right],
$$

where $\beta \in \mathbb{R}$ satisfies

$$
\max \{0,2 \alpha-r\}<\beta<\infty \text {. }
$$

For the case with $\beta=0, D$ reduces to the standard sup metric, $d_{\infty}$. The metric space $\left(\boldsymbol{B}, d_{\infty}\right)$ is complete, and since $(\boldsymbol{B}, D)$ and $\left(\boldsymbol{B}, d_{\infty}\right)$ are strongly equivalent, it follows that $(\boldsymbol{B}, D)$ is also a complete metric space (see Ok, 2007, pp. 136 and 167). For any $w, w^{\prime} \in \boldsymbol{B}$, and any $(i, \tau) \in \mathbb{K} \times[0, T]$

$$
\begin{aligned}
e^{-\beta \tau} \mid & (\mathcal{M} w)(i, \tau)-\left(\mathcal{M} w^{\prime}\right)(i, \tau) \mid= \\
& =e^{-\beta \tau} \mid \alpha \int_{0}^{\tau} w(i, z) e^{-(r+\alpha)(\tau-z)} d z-\alpha \int_{0}^{\tau} w^{\prime}(i, z) e^{-(r+\alpha)(\tau-z)} d z \\
& +\frac{\alpha}{2} \int_{0}^{\tau} \sum_{j \in \mathbb{K}} n_{j}(z) \max _{(k, s) \in \Pi(i, j)}[w(k, z)+w(s, z)-w(i, z)-w(j, z)] e^{-(r+\alpha)(\tau-z)} d z \\
& -\frac{\alpha}{2} \int_{0}^{\tau} \sum_{j \in \mathbb{K}} n_{j}(z) \max _{(k, s) \in \Pi(i, j)}\left[w^{\prime}(k, z)+w^{\prime}(s, z)-w^{\prime}(i, z)-w^{\prime}(j, z)\right] e^{-(r+\alpha)(\tau-z)} d z \mid \\
& \leq \alpha e^{-\beta \tau} \int_{0}^{\tau}\left|w(i, z)-w^{\prime}(i, z)\right| e^{-(r+\alpha)(\tau-z)} d z \\
& +\frac{\alpha}{2} e^{-\beta \tau} \int_{0}^{\tau} \sum_{j \in \mathbb{K}} n_{j}(z) \mid \max _{(k, s) \in \Pi(i, j)}[w(k, z)+w(s, z)-w(i, z)-w(j, z)] \\
& -\max _{(k, s) \in \Pi(i, j)}\left[w^{\prime}(k, z)+w^{\prime}(s, z)-w^{\prime}(i, z)-w^{\prime}(j, z)\right] \mid e^{-(r+\alpha)(\tau-z)} d z .
\end{aligned}
$$

Use $\left(k_{i j}^{*}(z), s_{i j}^{*}(z)\right)$ to denote a solution to the maximization on the right side of $\mathcal{M} w$, that is,

$$
\left(k_{i j}^{*}(z), s_{i j}^{*}(z)\right) \in \max _{(k, s) \in \Pi(i, j)}[w(k, z)+w(s, z)-w(i, z)-w(j, z)] .
$$

A solution exists because $w \in \boldsymbol{B}$, and $\Pi(i, j)$ is a finite set for all $(i, j) \in \mathbb{K} \times \mathbb{K}$. Then 


$$
\begin{aligned}
& e^{-\beta \tau}\left|(\mathcal{M} w)(i, \tau)-\left(\mathcal{M} w^{\prime}\right)(i, \tau)\right| \leq \\
& \leq \alpha \int_{0}^{\tau} e^{-\beta z}\left|w(i, z)-w^{\prime}(i, z)\right| e^{-(r+\alpha+\beta)(\tau-z)} d z \\
& +\frac{\alpha}{2} \int_{0}^{\tau} \sum_{j \in \mathbb{K}} n_{j}(z)\left\{e^{-\beta z}\left|w\left(k_{i j}^{*}(z), z\right)-w^{\prime}\left(k_{i j}^{*}(z), z\right)\right|+e^{-\beta z}\left|w\left(s_{i j}^{*}(z), z\right)-w^{\prime}\left(s_{i j}^{*}(z), z\right)\right|\right. \\
& \left.+e^{-\beta z}\left|w^{\prime}(i, z)-w(i, z)\right|+e^{-\beta z}\left|w^{\prime}(j, z)-w(j, z)\right|\right\} e^{-(r+\alpha+\beta)(\tau-z)} d z \\
& \leq \frac{3 \alpha}{r+\alpha+\beta}\left[1-e^{-(r+\alpha+\beta) \tau}\right] D\left(w, w^{\prime}\right) \\
& \leq \frac{3 \alpha}{r+\alpha+\beta} D\left(w, w^{\prime}\right) .
\end{aligned}
$$

Since this last inequality holds for all $(i, \tau) \in \mathbb{K} \times[0, T]$, and $w$ and $w^{\prime}$ are arbitrary,

$$
D\left(\mathcal{M} w, \mathcal{M} w^{\prime}\right) \leq \frac{3 \alpha}{r+\alpha+\beta} D\left(w, w^{\prime}\right), \quad \text { for all } w, w^{\prime} \in \boldsymbol{B} .
$$

Notice that (38) implies $\frac{3 \alpha}{r+\alpha+\beta} \in(0,1)$, so $\mathcal{M}$ is a contraction mapping on the complete metric space $(\boldsymbol{B}, D)$. By the Contraction Mapping Theorem (Theorem 3.2 in Stokey and Lucas, 1989), for any given path $\boldsymbol{n}(\tau)$, there exists a unique $w^{*} \in \boldsymbol{B}$ that satisfies $w^{*}=\mathcal{M} w^{*}$, and therefore, by (30), there exists a unique $g^{*} \in \boldsymbol{B}^{\prime}$ that satisfies $g^{*}=\mathcal{T} g^{*}$, and it is defined by $g^{*}(k, x, \tau)=w^{*}(k, \tau)+e^{-r(\tau+\Delta)} x$ for all $(k, x, \tau) \in \mathbb{S}$.

Lemma 5 Let $i, j, q \in \mathbb{K}$, and $(k, s) \in \Pi(i, j)$.

(i) If either $i+j$ or $s+q$ is even, then

$$
\left(\left\lceil\frac{k+q}{2}\right\rceil,\left\lfloor\frac{s+q}{2}\right\rfloor\right) \in \Pi\left(\left\lceil\frac{i+j}{2}\right\rceil, q\right) \quad \text { and } \quad\left(\left\lfloor\frac{k+q}{2}\right\rfloor,\left\lceil\frac{s+q}{2}\right\rceil\right) \in \Pi\left(\left\lfloor\frac{i+j}{2}\right\rfloor, q\right) .
$$

(ii) If $i+j$ and $s+q$ are odd, then

$$
\left(\left\lfloor\frac{k+q}{2}\right\rfloor,\left\lceil\frac{s+q}{2}\right\rceil\right) \in \Pi\left(\left\lceil\frac{i+j}{2}\right\rceil, q\right) \quad \text { and } \quad\left(\left\lceil\frac{k+q}{2}\right\rceil,\left\lfloor\frac{s+q}{2}\right\rfloor\right) \in \Pi\left(\left\lfloor\frac{i+j}{2}\right\rfloor, q\right) .
$$

Proof of Lemma 5. Notice that for any $i, j, q \in \mathbb{K}$,

$$
\Pi(i, j)=\{(i+j-y, y) \in \mathbb{K} \times \mathbb{K}: y \in\{0,1, \ldots, i+j\}\},
$$

so

$$
\begin{aligned}
& \Pi\left(\left\lceil\frac{i+j}{2}\right\rceil, q\right)=\left\{\left(\left\lceil\frac{i+j}{2}\right\rceil+q-y, y\right) \in \mathbb{K} \times \mathbb{K}: y \in\left\{0,1, \ldots,\left\lceil\frac{i+j}{2}\right\rceil+q\right\}\right\} \\
& \Pi\left(\left\lfloor\frac{i+j}{2}\right\rfloor, q\right)=\left\{\left(\left\lfloor\frac{i+j}{2}\right\rfloor+q-y, y\right) \in \mathbb{K} \times \mathbb{K}: y \in\left\{0,1, \ldots,\left\lfloor\frac{i+j}{2}\right\rfloor+q\right\}\right\} .
\end{aligned}
$$


For any $i, j, q \in \mathbb{K}$, define

$$
\begin{aligned}
& \tilde{\Pi}(i, j, q)=\left\{\left(\left\lceil\frac{k+q}{2}\right\rceil,\left\lfloor\frac{s+q}{2}\right\rfloor\right) \in \mathbb{K} \times \mathbb{K}:(k, s) \in \Pi(i, j)\right\} \\
& \hat{\Pi}(i, j, q)=\left\{\left(\left\lfloor\frac{k+q}{2}\right\rfloor,\left\lceil\frac{s+q}{2}\right\rceil\right) \in \mathbb{K} \times \mathbb{K}:(k, s) \in \Pi(i, j)\right\},
\end{aligned}
$$

and recall that $(k, s) \in \Pi(i, j)$ implies $k+s=i+j$.

(i) Assume that either $i+j$ or $s+q$ is even. We first show that given any $i, j, q \in \mathbb{K},(k, s) \in$ $\Pi(i, j)$ implies $\left(\left\lceil\frac{k+q}{2}\right\rceil,\left\lfloor\frac{s+q}{2}\right\rfloor\right) \in \Pi\left(\left\lceil\frac{i+j}{2}\right\rceil, q\right)$. Notice that if either $i+j$ or $s+q$ is even, then

$$
\left\lceil\frac{k+q}{2}\right\rceil+\left\lfloor\frac{s+q}{2}\right\rfloor=\left\lceil\frac{i+j}{2}\right\rceil+q \text {. }
$$

With (42),

$$
\begin{aligned}
\tilde{\Pi}(i, j, q) & =\left\{\left(\left\lceil\frac{k+q}{2}\right\rceil,\left\lceil\frac{i+j}{2}\right\rceil+q-\left\lceil\frac{k+q}{2}\right\rceil\right) \in \mathbb{K} \times \mathbb{K}:(k, i+j-k) \in \Pi(i, j)\right\} \\
& =\left\{\left(y,\left\lceil\frac{i+j}{2}\right\rceil+q-y\right) \in \mathbb{K} \times \mathbb{K}: y \in\left\{\left\lceil\frac{q}{2}\right\rceil,\left\lceil\frac{q+1}{2}\right\rceil, \ldots,\left\lceil\frac{q+i+j}{2}\right\rceil\right\}\right\} \\
& \equiv \tilde{\Pi}^{e}\left(\left\lceil\frac{i+j}{2}\right\rceil, q\right) .
\end{aligned}
$$

By construction, given any $i, j, q \in \mathbb{K},\left(\left\lceil\frac{k+q}{2}\right\rceil,\left\lfloor\frac{s+q}{2}\right\rfloor\right) \in \tilde{\Pi}^{e}\left(\left\lceil\frac{i+j}{2}\right\rceil, q\right)$ for all $(k, s) \in \Pi(i, j)$. Since $0 \leq\left\lceil\frac{q}{2}\right\rceil$, and $\left\lceil\frac{q+i+j}{2}\right\rceil \leq\left\lceil\frac{i+j}{2}\right\rceil+q$, it follows from (40) and (43) that $\tilde{\Pi}^{e}\left(\left\lceil\frac{i+j}{2}\right\rceil, q\right) \subseteq$ $\Pi\left(\left\lceil\frac{i+j}{2}\right\rceil, q\right)$ for all $i, j, q \in \mathbb{K}$, which implies $\left(\left\lceil\frac{k+q}{2}\right\rceil,\left\lfloor\frac{s+q}{2}\right\rfloor\right) \in \Pi\left(\left\lceil\frac{i+j}{2}\right\rceil, q\right)$ for all $(k, s) \in$ $\Pi(i, j)$, and any $i, j, q \in \mathbb{K}$.

Next, we show that given any $i, j, q \in \mathbb{K},(k, s) \in \Pi(i, j)$ implies $\left(\left\lfloor\frac{k+q}{2}\right\rfloor,\left\lceil\frac{s+q}{2}\right\rceil\right) \in$ $\Pi\left(\left\lfloor\frac{i+j}{2}\right\rfloor, q\right)$. Notice that if either $i+j$ or $s+q$ is even, then

$$
\left\lfloor\frac{k+q}{2}\right\rfloor+\left\lceil\frac{s+q}{2}\right\rceil=\left\lfloor\frac{i+j}{2}\right\rfloor+q .
$$

With (44),

$$
\begin{aligned}
\hat{\Pi}(i, j, q) & =\left\{\left(\left\lfloor\frac{k+q}{2}\right\rfloor,\left\lfloor\frac{i+j}{2}\right\rfloor+q-\left\lfloor\frac{k+q}{2}\right\rfloor\right) \in \mathbb{K} \times \mathbb{K}:(k, i+j-k) \in \Pi(i, j)\right\} \\
& =\left\{\left(y,\left\lfloor\frac{i+j}{2}\right\rfloor+q-y\right) \in \mathbb{K} \times \mathbb{K}: y \in\left\{\left\lfloor\frac{q}{2}\right\rfloor,\left\lfloor\frac{q+1}{2}\right\rfloor, \ldots,\left\lfloor\frac{q+i+j}{2}\right\rfloor\right\}\right\} \\
& \equiv \hat{\Pi}^{e}\left(\left\lfloor\frac{i+j}{2}\right\rfloor, q\right) .
\end{aligned}
$$

By construction, given any $i, j, q \in \mathbb{K},\left(\left\lfloor\frac{k+q}{2}\right\rfloor,\left\lceil\frac{s+q}{2}\right\rceil\right) \in \hat{\Pi}^{e}\left(\left\lfloor\frac{i+j}{2}\right\rfloor, q\right)$ for all $(k, s) \in \Pi(i, j)$. Since $0 \leq\left\lfloor\frac{q}{2}\right\rfloor$, and $\left\lfloor\frac{q+i+j}{2}\right\rfloor \leq\left\lfloor\frac{i+j}{2}\right\rfloor+q$, it follows from (41) and (45) that $\hat{\Pi}^{e}\left(\left\lfloor\frac{i+j}{2}\right\rfloor, q\right) \subseteq$ 
$\Pi\left(\left\lfloor\frac{i+j}{2}\right\rfloor, q\right)$ for all $i, j, q \in \mathbb{K}$, which implies $\left(\left\lfloor\frac{k+q}{2}\right\rfloor,\left\lceil\frac{s+q}{2}\right\rceil\right) \in \Pi\left(\left\lfloor\frac{i+j}{2}\right\rfloor, q\right)$ for all $(k, s) \in$ $\Pi(i, j)$, and any $i, j, q \in \mathbb{K}$.

(ii) Suppose that $i+j$ and $s+q$ are odd. We first show that given any $i, j, q \in \mathbb{K},(k, s) \in \Pi(i, j)$ implies $\left(\left\lfloor\frac{k+q}{2}\right\rfloor,\left\lceil\frac{s+q}{2}\right\rceil\right) \in \Pi\left(\left\lceil\frac{i+j}{2}\right\rceil, q\right)$. Notice that if $i+j$ and $s+q$ are odd, then

$$
\left\lfloor\frac{k+q}{2}\right\rfloor+\left\lceil\frac{s+q}{2}\right\rceil=\left\lceil\frac{i+j}{2}\right\rceil+q .
$$

With (46),

$$
\begin{aligned}
\hat{\Pi}(i, j, q) & =\left\{\left(\left\lceil\frac{i+j}{2}\right\rceil+q-\left\lceil\frac{s+q}{2}\right\rceil,\left\lceil\frac{s+q}{2}\right\rceil\right) \in \mathbb{K} \times \mathbb{K}:(k, s) \in \Pi(i, j)\right\} \\
& =\left\{\left(\left\lceil\frac{i+j}{2}\right\rceil+q-y, y\right) \in \mathbb{K} \times \mathbb{K}: y \in\left\{\left\lceil\frac{q}{2}\right\rceil,\left\lceil\frac{q+1}{2}\right\rceil, \ldots,\left\lceil\frac{q+i+j}{2}\right\rceil\right\}\right\} \\
& \equiv \hat{\Pi}^{o}\left(\left\lceil\frac{i+j}{2}\right\rceil, q\right) .
\end{aligned}
$$

By construction, given any $i, j, q \in \mathbb{K},\left(\left\lfloor\frac{k+q}{2}\right\rfloor,\left\lceil\frac{s+q}{2}\right\rceil\right) \in \hat{\Pi}^{o}\left(\left\lceil\frac{i+j}{2}\right\rceil, q\right)$ for all $(k, s) \in \Pi(i, j)$. Since $0 \leq\left\lceil\frac{q}{2}\right\rceil$, and $\left\lceil\frac{q+i+j}{2}\right\rceil \leq\left\lceil\frac{i+j}{2}\right\rceil+q$, it follows from (40) and (47) that $\hat{\Pi}^{o}\left(\left\lceil\frac{i+j}{2}\right\rceil, q\right) \subseteq$ $\Pi\left(\left\lceil\frac{i+j}{2}\right\rceil, q\right)$ for all $i, j, q \in \mathbb{K}$, which implies $\left(\left\lfloor\frac{k+q}{2}\right\rfloor,\left\lceil\frac{s+q}{2}\right\rceil\right) \in \Pi\left(\left\lceil\frac{i+j}{2}\right\rceil, q\right)$ for all $(k, s) \in$ $\Pi(i, j)$, and any $i, j, q \in \mathbb{K}$.

Finally, we show that given any $i, j, q \in \mathbb{K},(k, s) \in \Pi(i, j)$ implies $\left(\left\lceil\frac{k+q}{2}\right\rceil,\left\lfloor\frac{s+q}{2}\right\rfloor\right) \in$ $\Pi\left(\left\lfloor\frac{i+j}{2}\right\rfloor, q\right)$. Notice that if $i+j$ and $s+q$ are odd, then

$$
\left\lceil\frac{k+q}{2}\right\rceil+\left\lfloor\frac{s+q}{2}\right\rfloor=\left\lfloor\frac{i+j}{2}\right\rfloor+q
$$

With (48),

$$
\begin{aligned}
\tilde{\Pi}(i, j, q) & =\left\{\left(\left\lfloor\frac{i+j}{2}\right\rfloor+q-\left\lfloor\frac{s+q}{2}\right\rfloor,\left\lfloor\frac{s+q}{2}\right\rfloor\right) \in \mathbb{K} \times \mathbb{K}:(k, s) \in \Pi(i, j)\right\} \\
& =\left\{\left(\left\lfloor\frac{i+j}{2}\right\rfloor+q-y, y\right) \in \mathbb{K} \times \mathbb{K}: y \in\left\{\left\lfloor\frac{q}{2}\right\rfloor,\left\lfloor\frac{q+1}{2}\right\rfloor, \ldots,\left\lfloor\frac{q+i+j}{2}\right\rfloor\right\}\right\} \\
& \equiv \tilde{\Pi}^{o}\left(\left\lfloor\frac{i+j}{2}\right\rfloor, q\right) .
\end{aligned}
$$

By construction, given any $i, j, q \in \mathbb{K},\left(\left\lceil\frac{k+q}{2}\right\rceil,\left\lfloor\frac{s+q}{2}\right\rfloor\right) \in \tilde{\Pi}^{o}\left(\left\lfloor\frac{i+j}{2}\right\rfloor, q\right)$ for all $(k, s) \in \Pi(i, j)$. Since $0 \leq\left\lfloor\frac{q}{2}\right\rfloor$, and $\left\lfloor\frac{q+i+j}{2}\right\rfloor \leq\left\lfloor\frac{i+j}{2}\right\rfloor+q$, it follows from (41) and (49) that $\tilde{\Pi}^{o}\left(\left\lfloor\frac{i+j}{2}\right\rfloor, q\right) \subseteq$ $\left(\left\lfloor\frac{i+j}{2}\right\rfloor, q\right)$ for all $i, j, q \in \mathbb{K}$, which implies $\left(\left\lceil\frac{k+q}{2}\right\rceil,\left\lfloor\frac{s+q}{2}\right\rfloor\right) \in \Pi\left(\left\lfloor\frac{i+j}{2}\right\rfloor, q\right)$ for all $(k, s) \in$ $\Pi(i, j)$, and any $i, j, q \in \mathbb{K}$. 
Proof of Proposition 2. Consider the metric space $(\boldsymbol{B}, D)$ used in the proof of Lemma 4. A function $w \in \boldsymbol{B}$ satisfies the bilateral-trade asset-holding Equalization Property (EP) if for all $(i, j, \tau) \in \mathbb{K} \times \mathbb{K} \times[0, T]$,

$$
\begin{aligned}
\max _{(k, s) \in \Pi(i, j)}[w & (k, \tau)+w(s, \tau)-w(i, \tau)-w(j, \tau)] \\
= & w\left(\left\lceil\frac{i+j}{2}\right\rceil, \tau\right)+w\left(\left\lfloor\frac{i+j}{2}\right\rfloor, \tau\right)-w(i, \tau)-w(j, \tau) .
\end{aligned}
$$

A function $w \in \boldsymbol{B}$ satisfies the bilateral-trade asset-holding Strict Equalization Property (SEP) if for all $(i, j, \tau) \in \mathbb{K} \times \mathbb{K} \times[0, T]$,

$$
\arg \max _{(k, s) \in \Pi(i, j)}[w(k, \tau)+w(s, \tau)-w(i, \tau)-w(j, \tau)]=\Omega_{i j}^{*},
$$

where $\Omega_{i j}^{*}$ is defined in (11). Let

$$
\begin{aligned}
\boldsymbol{B}^{\prime \prime} & =\{w \in \boldsymbol{B}: w \text { satisfies }(\mathrm{EP})\} \\
\boldsymbol{B}^{\prime \prime \prime} & =\{w \in \boldsymbol{B}: w \text { satisfies (SEP) }\} .
\end{aligned}
$$

Clearly, $\boldsymbol{B}^{\prime \prime \prime} \subseteq \boldsymbol{B}^{\prime \prime} \subseteq \boldsymbol{B}$.

We first establish that $\boldsymbol{B}^{\prime \prime}$ is a closed subset of $\boldsymbol{B}$. Let $\left\{w_{n}\right\}_{n=0}^{\infty}$ be a sequence of functions in $\boldsymbol{B}^{\prime \prime}$, with $\lim _{n \rightarrow \infty} w_{n}=\bar{w}$. If $\bar{w} \notin \boldsymbol{B}^{\prime \prime}$, then there exists some $(k, s) \in \Pi(i, j)$ and $\varsigma \in \mathbb{R}$ such that

$$
0<\varsigma=\bar{w}(k, \tau)+\bar{w}(s, \tau)-\left[\bar{w}\left(\left\lceil\frac{i+j}{2}\right\rceil, \tau\right)+\bar{w}\left(\left\lfloor\frac{i+j}{2}\right\rfloor, \tau\right)\right],
$$

for some $(i, j, \tau) \in \mathbb{K} \times \mathbb{K} \times[0, T]$. This implies

$$
\begin{aligned}
w_{n}(k, \tau)+w_{n}(s, \tau) & =w_{n}\left(\left\lceil\frac{i+j}{2}\right\rceil, \tau\right)+w_{n}\left(\left\lfloor\frac{i+j}{2}\right\rfloor, \tau\right)+\varsigma \\
& -\left\{\bar{w}(k, \tau)+\bar{w}(s, \tau)-\left[w_{n}(k, \tau)+w_{n}(s, \tau)\right]\right\} \\
& +\bar{w}\left(\left\lceil\frac{i+j}{2}\right\rceil, \tau\right)+\bar{w}\left(\left\lfloor\frac{i+j}{2}\right\rfloor, \tau\right)-\left[w_{n}\left(\left\lceil\frac{i+j}{2}\right\rceil, \tau\right)+w_{n}\left(\left\lfloor\frac{i+j}{2}\right\rfloor, \tau\right)\right\rfloor .
\end{aligned}
$$

For this particular $(i, j, \tau) \in \mathbb{K} \times \mathbb{K} \times[0, T]$, for all $n$ large enough we can ensure that

$$
\left|\bar{w}(k, \tau)+\bar{w}(s, \tau)-\left[w_{n}(k, \tau)+w_{n}(s, \tau)\right]\right|<\frac{\varsigma}{4}
$$

and

$$
\left|\bar{w}\left(\left\lceil\frac{i+j}{2}\right\rceil, \tau\right)+\bar{w}\left(\left\lfloor\frac{i+j}{2}\right\rfloor, \tau\right)-\left[w_{n}\left(\left\lceil\frac{i+j}{2}\right\rceil, \tau\right)+w_{n}\left(\left\lfloor\frac{i+j}{2}\right\rfloor, \tau\right)\right]\right|<\frac{\varsigma}{4},
$$


but then

$$
0<\varsigma / 2<w_{n}(k, \tau)+w_{n}(s, \tau)-\left[w_{n}\left(\left\lceil\frac{i+j}{2}\right\rceil, \tau\right)+w_{n}\left(\left\lfloor\frac{i+j}{2}\right\rfloor, \tau\right)\right],
$$

which contradicts the fact that $w_{n} \in \boldsymbol{B}^{\prime \prime}$. Thus, we conclude that $\bar{w} \in \boldsymbol{B}^{\prime \prime}$, so $\boldsymbol{B}^{\prime \prime}$ is closed.

The second step is to show that the mapping $\mathcal{M}$ defined in (31) preserves property (EP), i.e., that $\mathcal{M}\left(\boldsymbol{B}^{\prime \prime}\right) \subseteq \boldsymbol{B}^{\prime \prime}$. That is, we wish to show that for any $w \in \boldsymbol{B}^{\prime \prime}, w^{\prime}=\mathcal{M} w \in \boldsymbol{B}^{\prime \prime}$, or equivalently, that

$$
w\left(\left\lceil\frac{i+j}{2}\right\rceil, \tau\right)+w\left(\left\lfloor\frac{i+j}{2}\right\rfloor, \tau\right) \geq w(k, \tau)+w(s, \tau) \text { for all }(k, s) \in \Pi(i, j),
$$

for any $(i, j, \tau) \in \mathbb{K} \times \mathbb{K} \times[0, T]$, implies that

$$
w^{\prime}\left(\left\lceil\frac{i+j}{2}\right\rceil, \tau\right)+w^{\prime}\left(\left\lfloor\frac{i+j}{2}\right\rfloor, \tau\right)-w^{\prime}(k, \tau)-w^{\prime}(s, \tau) \geq 0 \text { for all }(k, s) \in \Pi(i, j),
$$

for any $(i, j, \tau) \in \mathbb{K} \times \mathbb{K} \times[0, T]$. Since $w \in \boldsymbol{B}^{\prime \prime}$, using (34) (with $\theta_{k k^{\prime}}=1 / 2$ for all $\left.k, k^{\prime} \in \mathbb{K}\right)$,

$$
\begin{aligned}
(\mathcal{M} w)(i, \tau) & =v_{i}(\tau)+\alpha \int_{0}^{\tau} w(i, z) e^{-(r+\alpha)(\tau-z)} d z \\
& +\frac{\alpha}{2} \int_{0}^{\tau} \sum_{q \in \mathbb{K}} n_{q}(z)\left[w\left(\left\lceil\frac{i+q}{2}\right\rceil, z\right)+w\left(\left\lfloor\frac{i+q}{2}\right\rfloor, z\right)-w(i, z)-w(q, z)\right] e^{-(r+\alpha)(\tau-z)} d z
\end{aligned}
$$

for all $(i, \tau) \in \mathbb{K} \times[0, T]$. For any $(i, j, \tau) \in \mathbb{K} \times \mathbb{K} \times[0, T]$ and $(k, s) \in \Pi(i, j)$, let $G(i, j, k, s, \tau)$ denote the left side of inequality (50). Then,

$$
\begin{aligned}
& G(i, j, k, s, \tau)=v_{\left\lceil\frac{i+j}{2}\right\rceil}(\tau)+v_{\left\lfloor\frac{i+j}{2}\right\rfloor}(\tau)-v_{k}(\tau)-v_{s}(\tau) \\
& +\alpha \int_{0}^{\tau}\left[w\left(\left\lceil\frac{i+j}{2}\right\rceil, z\right)+w\left(\left\lfloor\frac{i+j}{2}\right\rfloor, z\right)-w(k, z)-w(s, z)\right] e^{-(r+\alpha)(\tau-z)} d z \\
& +\frac{\alpha}{2} \int_{0}^{\tau} \sum_{q \in \mathbb{K}} n_{q}(z)\left[w\left(\left\lceil\frac{\left\lceil\frac{i+j}{2}\right\rceil+q}{2}\right\rceil, z\right)+w\left(\left\lfloor\frac{\left\lceil\frac{i+j}{2}\right\rceil+q}{2}\right\rfloor, z\right)\right. \\
& \left.-w\left(\left\lceil\frac{i+j}{2}\right\rceil, z\right)-w(q, z)\right] e^{-(r+\alpha)(\tau-z)} d z \\
& +\frac{\alpha}{2} \int_{0}^{\tau} \sum_{q \in \mathbb{K}} n_{q}(z)\left[w\left(\left\lfloor\frac{\left\lfloor\frac{i+j}{2}\right\rfloor+q}{2}\right\rfloor, z\right)+w\left(\left\lfloor\frac{\left\lfloor\frac{i+j}{2}\right\rfloor+q}{2}\right\rfloor, z\right)\right. \\
& \left.-w\left(\left\lfloor\frac{i+j}{2}\right\rfloor, z\right)-w(q, z)\right] e^{-(r+\alpha)(\tau-z)} d z \\
& -\frac{\alpha}{2} \int_{0}^{\tau} \sum_{q \in \mathbb{K}} n_{q}(z)\left[w\left(\left\lceil\frac{k+q}{2}\right\rceil, z\right)+w\left(\left\lfloor\frac{k+q}{2}\right\rfloor, z\right)-w(k, z)-w(q, z)\right] e^{-(r+\alpha)(\tau-z)} d z \\
& -\frac{\alpha}{2} \int_{0}^{\tau} \sum_{q \in \mathbb{K}} n_{q}(z)\left[w\left(\left\lceil\frac{s+q}{2}\right\rceil, z\right)+w\left(\left\lfloor\frac{s+q}{2}\right\rfloor, z\right)-w(s, z)-w(q, z)\right] e^{-(r+\alpha)(\tau-z)} d z .
\end{aligned}
$$


With (33) and after deleting redundant terms, this expression can be rearranged to yield

$$
\begin{aligned}
& G(i, j, k, s, \tau)=\frac{1-e^{-(r+\alpha) \tau}}{r+\alpha}\left(u_{\left\lceil\frac{i+j}{2}\right\rceil}+u_{\left\lfloor\frac{i+j}{2}\right\rfloor}-u_{k}-u_{s}\right) \\
& +e^{-(r+\alpha) \tau}\left[U_{\left\lceil\frac{i+j}{2}\right\rceil}+U_{\left\lfloor\frac{i+j}{2}\right\rfloor}-U_{k}-U_{s}\right] \\
& +\frac{\alpha}{2} \int_{0}^{\tau}\left[w\left(\left\lceil\frac{i+j}{2}\right\rceil, z\right)+w\left(\left\lfloor\frac{i+j}{2}\right\rfloor, z\right)-w(k, z)-w(s, z)\right] e^{-(r+\alpha)(\tau-z)} d z \\
& +\frac{\alpha}{2} \int_{0}^{\tau} \sum_{q \in \mathbb{K}} n_{q}(z)\left\{w\left(\left\lceil\frac{\left\lceil\frac{i+j}{2}\right\rceil+q}{2}\right\rceil, z\right)+w\left(\left\lfloor\frac{\left\lceil\frac{i+j}{2}\right\rceil+q}{2}\right\rfloor, z\right)\right. \\
& -w\left(\left\lceil\frac{k+q}{2}\right\rceil, z\right)-w\left(\left\lfloor\frac{s+q}{2}\right\rfloor, z\right) \\
& -w\left(\left\lfloor\frac{k+q}{2}\right\rfloor, z\right)-w\left(\left\lceil\frac{s+q}{2}\right\rceil, z\right) \\
& \left.+w\left(\left\lceil\frac{\left\lfloor\frac{i+j}{2}\right\rfloor+q}{2}\right\rceil, z\right)+w\left(\left\lfloor\frac{\left\lfloor\frac{i+j}{2}\right\rfloor+q}{2}\right\rfloor, z\right)\right\} e^{-(r+\alpha)(\tau-z)} d z .
\end{aligned}
$$

What needs to be shown is that $w \in \boldsymbol{B}^{\prime \prime}$ implies that for any $(i, j, \tau) \in \mathbb{K} \times \mathbb{K} \times[0, T]$, $G(i, j, k, s, \tau) \geq 0$ for all $(k, s) \in \Pi(i, j)$. The fact that $w \in \boldsymbol{B}^{\prime \prime}$ immediately implies that the first integral in the last expression is nonnegative. By Lemma $5, w \in \boldsymbol{B}^{\prime \prime}$ also implies that the second integral in the last expression is nonnegative. Together with Assumption A, these observations imply

$$
\begin{aligned}
0 & <\frac{1-e^{-(r+\alpha) \tau}}{r+\alpha}\left(u_{\left\lceil\frac{i+j}{2}\right\rceil}+u_{\left\lfloor\frac{i+j}{2}\right\rfloor}-u_{k}-u_{s}\right)+e^{-(r+\alpha) \tau}\left[U_{\left\lceil\frac{i+j}{2}\right\rceil}+U_{\left\lfloor\frac{i+j}{2}\right\rfloor}-U_{k}-U_{s}\right] \\
& \leq G(i, j, k, s, \tau),
\end{aligned}
$$

so we conclude that $\mathcal{M}\left(\boldsymbol{B}^{\prime \prime}\right) \subseteq \boldsymbol{B}^{\prime \prime \prime} \subseteq \boldsymbol{B}^{\prime \prime}$.

The third step is to show that (10) is the equilibrium distribution of trading probabilities. From Lemma 4 , we know that $\mathcal{M}$ is a contraction mapping on the complete metric space $(\boldsymbol{B}, D)$, so it has a unique fixed point $w^{*}(k, \tau) \equiv V_{k}(\tau) \in \boldsymbol{B}$. In addition, we have now established that $\boldsymbol{B}^{\prime \prime}$ is a closed subset of $\boldsymbol{B}$, and that $\mathcal{M}\left(\boldsymbol{B}^{\prime \prime}\right) \subseteq \boldsymbol{B}^{\prime \prime \prime} \subseteq \boldsymbol{B}^{\prime \prime}$. Therefore, by Corollary 1 in Stokey and Lucas (1989, p. 52), we conclude that $V_{k}(\tau) \in \boldsymbol{B}^{\prime \prime \prime}$. This implies that the set $\Omega_{i j}[\boldsymbol{V}(\tau)]$ defined in $(9)$ reduces to $\Omega_{i j}^{*}$ for all $(i, j, \tau) \in \mathbb{K} \times \mathbb{K} \times[0, T]$, and consequently, that (8) reduces to (10) for all $(i, j, \tau) \in \mathbb{K} \times \mathbb{K} \times[0, T]$. This establishes part (ii) in the statement of the proposition.

We can now show that the paths $\boldsymbol{n}(\tau)$ and $\boldsymbol{V}(\tau)$ are uniquely determined. Since (by Lemma 4) the fixed point $V_{k}(\tau) \in \boldsymbol{B}^{\prime \prime \prime}$ is unique given any path for the distribution of reserve 
balances, $\boldsymbol{n}(\tau)$, all that has to be shown is that given the initial condition $\left\{n_{k}(T)\right\}_{k \in \mathbb{K}}$, and given that the path $\phi(\tau)$ satisfies (10), the system of first-order ordinary differential equations, $\dot{\boldsymbol{n}}(\tau)=f[\boldsymbol{n}(\tau), \boldsymbol{\phi}(\tau)]$, has a unique solution. But since $f$ is continuously differentiable, this follows from Propositions 6.3 and 7.6 in Amann (1990). This establishes part $(i)$ in the statement of the proposition.

Corollary 1 Assume that $\left\{U_{k}\right\}_{k \in \mathbb{K}}$ satisfies the discrete midpoint concavity property and $\left\{u_{k}\right\}_{k \in \mathbb{K}}$ satisfies the discrete midpoint strict concavity property. An equilibrium exists, and the equilibrium paths for the distribution of reserve balances, $\boldsymbol{n}(\tau)$, and maximum attainable payoffs, $\boldsymbol{V}(\tau)$, are uniquely determined and identical to those in Proposition 2. The equilibrium distribution of trading probabilities is

$$
\phi_{i j}^{k s}(\tau)= \begin{cases}\tilde{\phi}_{i j}^{k s}(\tau) & \text { if }(k, s) \in \Omega_{i j}^{*}(\tau) \\ 0 & \text { if }(k, s) \notin \Omega_{i j}^{*}(\tau)\end{cases}
$$

for all $i, j, k, s \in \mathbb{K}$ and $\tau \in[0, T]$, with $\tilde{\phi}_{i j}^{k s}(\tau) \geq 0$ and $\sum_{(k, s) \in \Omega_{i j}^{*}(\tau)} \tilde{\phi}_{i j}^{k s}(\tau)=1$, and where $\Omega_{i j}^{*}(\tau)=\Omega_{i j}^{*}$, with $\Omega_{i j}^{*}$ given by (11) for all $\tau \in(0, T]$, and $\Omega_{i j}^{*}(0)=\Omega_{i j}^{*} \cup \Omega_{i j}^{0}$, where

$$
\Omega_{i j}^{0}=\left\{(k, s) \in \Pi(i, j): U_{k}+U_{s}=U_{\left\lceil\frac{i+j}{2}\right\rceil}+U_{\left\lfloor\frac{i+j}{2}\right\rfloor}\right\} .
$$

Proof of Corollary 1. The proof proceeds exactly as the proof of Proposition 2 up to (51). Notice that under Assumption A, (51) holds for all $\tau \in[0, T]$. Instead, under the assumption that $\left\{U_{k}\right\}_{k \in \mathbb{K}}$ satisfies discrete midpoint concavity and $\left\{u_{k}\right\}_{k \in \mathbb{K}}$ satisfies discrete midpoint strict concavity, the inequality in (51) holds as a strict inequality for all $\tau \in(0, T]$, but only as a weak inequality for $\tau=0$. As before, the unique fixed point $V_{k}(\tau) \in \boldsymbol{B}^{\prime \prime}$, but now $V_{k}(\tau) \notin \boldsymbol{B}^{\prime \prime \prime}$, since $V_{k}(\tau)$ satisfies (SEP) for all $(i, j, \tau) \in \mathbb{K} \times \mathbb{K} \times(0, T]$, rather than for all $(i, j, \tau) \in \mathbb{K} \times \mathbb{K} \times[0, T]$. However, it is clear from (51) that in this case $\mathcal{M} V_{k}(\tau)=V_{k}(\tau) \in \boldsymbol{B}_{0}^{\prime \prime \prime}$, where $\boldsymbol{B}_{0}^{\prime \prime \prime}$ is the subset of elements of $\boldsymbol{B}$ that satisfy (SEP) for all $(i, j, \tau) \in \mathbb{K} \times \mathbb{K} \times(0, T]$. This implies that the set $\Omega_{i j}[\boldsymbol{V}(\tau)]$ defined in (9) now reduces to the set $\Omega_{i j}^{*}(\tau)$ defined in the statement of the corollary for all $\tau \in[0, T]$, and consequently, that (8) reduces to (52) for all $\tau \in[0, T]$. Notice that despite the potential multiplicity of optimal post-trade portfolios in bilateral meetings at $\tau=0$ (which is the only difference between this case and the one treated in Proposition 2), as can be seen from (34) and (52), the mapping $\mathcal{M}$ is unaffected by this multiplicity, and hence so is its fixed point. Therefore, (by Lemma 2) the fixed point $V_{k}(\tau) \in \boldsymbol{B}_{0}^{\prime \prime \prime}$ is unique given any 
path for $\boldsymbol{n}(\tau)$. Finally, if we cast (4) in integral equation form,

$$
n_{k}(\tau)=n_{k}(T)-\alpha \int_{\tau}^{T} \sum_{i \in \mathbb{K}} \sum_{j \in \mathbb{K}} \sum_{s \in \mathbb{K}} n_{i}(z)\left[n_{k}(z) \phi_{k i}^{s j}(z)-n_{j}(z) \phi_{i j}^{k s}(z)\right] d z
$$

for all $k \in \mathbb{K}$, then it becomes clear that for all $k \in \mathbb{K}$ and all $\tau \in[0, T], n_{k}(\tau)$ is independent of $\phi_{i j}^{k s}(0)$ (changing the integral at a single point leaves the right side of (53) unaffected). Therefore, by the same arguments used in the final step of the proof of Proposition 2, there exists a unique $\boldsymbol{n}(\tau)$ that solves the system (53), and it is the same solution that obtains under Assumption A.

\section{A.4 End-of-day payoffs}

The specification of end-of-day payoffs, (13), contemplates the fact that at the end of the trading day banks have the option to borrow from the Federal Reserve discount window. The following lemma characterizes the solution to this end-of-day problem.

Lemma 6 Assume $i_{f}^{e}<i_{f}^{w} \leq i_{f}^{o}$. Consider a bank with end-of-day balance $k$ that has the option to borrow from the discount window right after the end of the trading session, and let $k^{w}$ denote the bank's balance after having borrowed from the window.

(i) If $\bar{k} \leq k-\bar{k}_{0}$, then $k^{w}=k-\bar{k}_{0}$ and the bank's maximum terminal payoff is given by (13) with $F_{k}=i_{f}^{r} \bar{k}+i_{f}^{e}\left(k-\bar{k}_{0}-\bar{k}\right)$.

(ii) If $0 \leq k-\bar{k}_{0}<\bar{k}$, then

$$
k^{w} \begin{cases}=\bar{k} & \text { if } i_{f}^{w}<i_{f}^{c}+i_{f}^{r} \\ \in\left[k-\bar{k}_{0}, \bar{k}\right] \cap \mathbb{K} & \text { if } i_{f}^{w}=i_{f}^{c}+i_{f}^{r} \\ =k-\bar{k}_{0} & \text { if } i_{f}^{c}+i_{f}^{r}<i_{f}^{w}\end{cases}
$$

and the bank's maximum terminal payoff is given by (13) with

$$
F_{k}= \begin{cases}i_{f}^{r} \bar{k}-i_{f}^{w}\left[\bar{k}-\left(k-\bar{k}_{0}\right)\right] & \text { if } i_{f}^{w} \leq i_{f}^{r}+i_{f}^{c} \\ i_{f}^{r}\left(k-\bar{k}_{0}\right)-i_{f}^{c}\left[\bar{k}-\left(k-\bar{k}_{0}\right)\right] & \text { if } i_{f}^{r}+i_{f}^{c}<i_{f}^{w}\end{cases}
$$

(iii) If $k-\bar{k}_{0}<0$, then

$$
k^{w} \begin{cases}=\bar{k} & \text { if } i_{f}^{w}<i_{f}^{c}+i_{f}^{r} \\ \in[0, \bar{k}] \cap \mathbb{K} & \text { if } i_{f}^{w}=i_{f}^{c}+i_{f}^{r} \\ =0 & \text { if } i_{f}^{c}+i_{f}^{r}<i_{f}^{w}\end{cases}
$$


and the bank's maximum terminal payoff is given by (13) with

$$
F_{k}= \begin{cases}i_{f}^{r} \bar{k}-i_{f}^{w}\left[\bar{k}-\left(k-\bar{k}_{0}\right)\right] & \text { if } i_{f}^{w}<i_{f}^{c}+i_{f}^{r} \\ i_{f}^{w}\left(k-\bar{k}_{0}\right)-i_{f}^{c} \bar{k} & \text { if } i_{f}^{c}+i_{f}^{o} \leq i_{f}^{w}\end{cases}
$$

Proof of Lemma 6. Notice that $F_{k}$ can be written more compactly as

$$
\begin{aligned}
F_{k} & =\max _{k-\bar{k}_{0} \leq k^{w}}\left\{i_{f}^{r} \max \left[0, \min \left(k^{w}, \bar{k}\right)\right]+i_{f}^{e} \max \left(k^{w}-\bar{k}, 0\right)\right. \\
& \left.-i_{f}^{c} \max \left[\min \left(\bar{k}-k^{w}, \bar{k}\right), 0\right]-i_{f}^{o} \max \left(-k^{w}, 0\right)-i_{f}^{w}\left[k^{w}-\left(k-\bar{k}_{0}\right)\right]\right\} .
\end{aligned}
$$

A bank that ends the trading session with balance $k$ chooses $k^{w}$ by solving (58).

(i) Given $\bar{k} \leq k-\bar{k}_{0},(58)$ reduces to

$$
F_{k}=\max _{k-\bar{k}_{0} \leq k^{w}}\left\{\left(i_{f}^{r}-i_{f}^{e}\right) \bar{k}+i_{f}^{w}\left(k-\bar{k}_{0}\right)+\left(i_{f}^{e}-i_{f}^{w}\right) k^{w}\right\}
$$

The assumption $i_{f}^{e}<i_{f}^{w}$ implies the solution is $k^{w}=k-\bar{k}_{0}$, and substituting it into the objective function yields $F_{k}=i_{f}^{r} \bar{k}+i_{f}^{e}\left(k-\bar{k}_{0}-\bar{k}\right)$.

(ii) Given $0 \leq k-\bar{k}_{0}<\bar{k}$ and part (i), (58) reduces to

$$
F_{k}=\max _{k-\bar{k}_{0} \leq k^{w} \leq \bar{k}}\left\{i_{f}^{w}\left(k-\bar{k}_{0}\right)-i_{f}^{c} \bar{k}+\left(i_{f}^{c}+i_{f}^{r}-i_{f}^{w}\right) k^{w}\right\},
$$

which implies that the solution is given by (54), and substituting this solution into the objective function yields (55).

(iii) Given $k-\bar{k}_{0}<0$ and part (i), (58) becomes

$$
\begin{aligned}
F_{k} & =i_{f}^{w}\left(k-\bar{k}_{0}\right)+\max _{k-\bar{k}_{0} \leq k^{w} \leq \bar{k}}\left\{i_{f}^{r} \max \left(0, k^{w}\right)-i_{f}^{c} \max \left[\min \left(\bar{k}-k^{w}, \bar{k}\right), 0\right]-i_{f}^{o} \max \left(-k^{w}, 0\right)-i_{f}^{w} k^{w}\right\} \\
& =i_{f}^{w}\left(k-\bar{k}_{0}\right)-i_{f}^{c} \bar{k}+\max \left\{\max _{k-\bar{k}_{0} \leq k^{w} \leq 0}\left(i_{f}^{o}-i_{f}^{w}\right) k^{w}, \max _{0 \leq k^{w} \leq \bar{k}}\left(i_{f}^{c}+i_{f}^{r}-i_{f}^{w}\right) k^{w}\right\} \\
& =i_{f}^{w}\left(k-\bar{k}_{0}\right)-i_{f}^{c} \bar{k}+\max _{0 \leq k^{w} \leq \bar{k}}\left(i_{f}^{c}+i_{f}^{r}-i_{f}^{w}\right) k^{w},
\end{aligned}
$$

where the last equality follows from $i_{f}^{w} \leq i_{f}^{o}$. Thus the solution is given by (56), and this yields the value given in (57).

Corollary 2 Assume $i_{f}^{e}<i_{f}^{w} \leq i_{f}^{o}$ and $i_{f}^{w}<i_{f}^{c}+i_{f}^{r}$. Then

$$
U_{k}= \begin{cases}e^{-r \Delta_{f}}\left[k-\bar{k}_{0}+i_{f}^{r} \bar{k}+i_{f}^{e}\left(k-\bar{k}_{0}-\bar{k}\right)\right] & \text { if } \bar{k} \leq k-\bar{k}_{0} \\ e^{-r \Delta_{f}}\left\{k-\bar{k}_{0}+i_{f}^{r} \bar{k}-i_{f}^{w}\left[\bar{k}-\left(k-\bar{k}_{0}\right)\right]\right\} & \text { if } k-\bar{k}_{0}<\bar{k}\end{cases}
$$




\section{B Efficiency}

In this section we use our theory to characterize the optimal process of reallocation of reserve balances in the fed funds market. The spirit of the exercise is to take as given the market structure, including the contact rate $\alpha$ and the regulatory variables $\left\{u_{k}, U_{k}\right\}_{k \in \mathbb{K}}$, and to ask whether decentralized trade in the over-the-counter market structure reallocates reserve balances efficiently, given these institutions. To this end, we study the problem of a social planner who solves

$$
\begin{aligned}
& \max _{[\chi(t)]_{t=0}^{T}} {\left[\int_{0}^{T} \sum_{k \in \mathbb{K}} m_{k}(t) u_{k} e^{-r t} d t+e^{-r T} \sum_{k \in \mathbb{K}} m_{k}(T) U_{k}\right] } \\
& \text { s.t. } \dot{m}_{k}(t)=-f[\boldsymbol{m}(t), \chi(t)], \\
& \chi_{i j}^{k s}(t) \in[0,1], \text { with } \chi_{i j}^{k s}(t)=0 \text { if }(k, s) \notin \Pi(i, j), \\
& \chi_{i j}^{k s}(t)=\chi_{j i}^{s k}(t), \text { and } \sum_{k \in \mathbb{K}} \sum_{s \in \mathbb{K}} \chi_{i j}^{k s}(t)=1,
\end{aligned}
$$

for all $t \in[0, T]$, and all $i, j, k, s \in \mathbb{K}$. We have formulated the planner's problem in chronological time, so $m_{k}(t)$ denotes the measure of banks with balance $k$ at time $t$. Since $\tau \equiv T-t$, we have $m_{k}(t)=m_{k}(T-\tau) \equiv n_{k}(\tau)$, and therefore $\dot{m}_{k}(t)=-\dot{n}_{k}(\tau)$. Hence the flow constraint is the real-time law of motion for the distribution of balances implied by the bilateral stochastic trading process. The control variable, $\chi(t)=\left\{\chi_{i j}^{k s}(t)\right\}_{i, j, k, s \in \mathbb{K}}$, represents the planner's choice of reallocation of balances between any pair of banks that have contacted each other at time $t$. The first, second, and fourth constraints on $\chi(t)$ ensure that $\left\{\chi_{i j}^{k s}(t)\right\}_{k, s \in \mathbb{K}}$ is a probability distribution for each $i, j \in \mathbb{K}$, and that the planner only chooses among feasible reallocations of balances between a pair of banks. We look for a solution that does not depend on the identities or "names" of banks, so the third constraint on $\chi(t)$ recognizes the fact that $\chi_{i j}^{k s}(t)$ and $\chi_{j i}^{s k}(t)$ represent the same decision for the planner. That is, $\chi_{i j}^{k s}(t)$ and $\chi_{j i}^{s k}(t)$ both represent the probability that a pair of banks with balances $i$ and $j$ who contact each other at time $t$ exit the meeting with balances $k$ and $s$, respectively.

Proposition 3 A solution to the planner's problem is a path for the distribution of balances, $\boldsymbol{n}(\tau)$, a path for the vector of co-states associated with the law of motion for the distribution of balances, $\boldsymbol{\lambda}(\tau)=\left\{\lambda_{k}(\tau)\right\}_{k \in \mathbb{K}}$, and a path for the distribution of trading probabilities, $\boldsymbol{\psi}(\tau)=$ 
$\left\{\psi_{i j}^{k s}(\tau)\right\}_{i, j, k, s \in \mathbb{K}}$. The necessary conditions for optimality are

$$
r \lambda_{i}(\tau)+\dot{\lambda}_{i}(\tau)=u_{i}+\alpha \sum_{j \in \mathbb{K}} \sum_{k \in \mathbb{K}} \sum_{s \in \mathbb{K}} n_{j}(\tau) \psi_{i j}^{k s}(\tau)\left[\lambda_{k}(\tau)+\lambda_{s}(\tau)-\lambda_{i}(\tau)-\lambda_{j}(\tau)\right]
$$

for all $(i, \tau) \in \mathbb{K} \times[0, T]$, with

$$
\lambda_{i}(0)=U_{i} \quad \text { for all } i \in \mathbb{K},
$$

with the path for $\boldsymbol{n}(\tau)$ given by $\dot{\boldsymbol{n}}(\tau)=f[\boldsymbol{n}(\tau), \boldsymbol{\psi}(\tau)]$, and with

$$
\psi_{i j}^{k s}(\tau)= \begin{cases}\tilde{\psi}_{i j}^{k s}(\tau) & \text { if }(k, s) \in \Omega_{i j}[\boldsymbol{\lambda}(\tau)] \\ 0 & \text { if }(k, s) \notin \Omega_{i j}[\boldsymbol{\lambda}(\tau)]\end{cases}
$$

for all $i, j, k, s \in \mathbb{K}$ and all $\tau \in[0, T]$, where $\tilde{\psi}_{i j}^{k s}(\tau) \geq 0$ and $\sum_{k \in \mathbb{K}} \sum_{s \in \mathbb{K}} \tilde{\psi}_{i j}^{k s}(\tau)=1$.

Proof of Proposition 3. The planner's current-value Hamiltonian can be written as

$$
L=\sum_{k \in \mathbb{K}} m_{k}(t) u_{k}+\alpha \sum_{i \in \mathbb{K}} \sum_{j \in \mathbb{K}} \sum_{k \in \mathbb{K}} \sum_{s \in \mathbb{K}} m_{i}(t) m_{j}(t) \chi_{i j}^{k s}(t)\left[\mu_{k}(t)-\mu_{i}(t)\right],
$$

where $\boldsymbol{\mu}(t)=\left\{\mu_{k}(t)\right\}_{k \in \mathbb{K}}$ is the vector of co-states associated with the law of motion for the distribution of banks across reserve balances. In an optimum, the co-states and the controls must satisfy $\frac{\partial L}{\partial m_{i}(t)}=r \mu_{i}(t)-\dot{\mu}_{i}(t)$, and

$$
\chi_{i j}^{k s}(t) \begin{cases}=1 & \text { if }\left.\frac{\partial L}{\partial \chi_{i j}^{k s}(t)}\right|_{\chi_{j i}^{s k}(t)=\chi_{i j}^{k s}(t)}>0 \\ \in[0,1] & \text { if }\left.\frac{\partial L}{\partial \chi_{i j}^{k s}(t)}\right|_{\chi_{j i}^{s k}(t)=\chi_{i j}^{k s}(t)}=0 \\ 0 & \text { if }\left.\frac{\partial L}{\partial \chi_{i j}^{k s}(t)}\right|_{\chi_{j i}^{s k}(t)=\chi_{i j}^{k s}(t)}<0 .\end{cases}
$$

Notice that

$$
\left.\frac{\partial L}{\partial \chi_{i j}^{k s}(t)}\right|_{\chi_{j i}^{s k}(t)=\chi_{i j}^{k s}(t)}=\alpha m_{i}(t) m_{j}(t)\left[\mu_{k}(t)+\mu_{s}(t)-\mu_{i}(t)-\mu_{j}(t)\right],
$$

and that given $\chi_{j i}^{s k}(t)=\chi_{i j}^{k s}(t)$

$$
\frac{\partial L}{\partial m_{i}}=u_{i}+\alpha \sum_{j \in \mathbb{K}} \sum_{k \in \mathbb{K}} \sum_{s \in \mathbb{K}} m_{j}(t) \chi_{i j}^{k s}(t)\left[\mu_{k}(t)+\mu_{s}(t)-\mu_{i}(t)-\mu_{j}(t)\right] .
$$


Thus the necessary conditions for optimality are

$$
\chi_{i j}^{k s}(t)= \begin{cases}\tilde{\chi}_{i j}^{k s}(t) & \text { if }(k, s) \in \Omega_{i j}[\boldsymbol{\mu}(t)] \\ 0 & \text { if }(k, s) \notin \Omega_{i j}[\boldsymbol{\mu}(t)]\end{cases}
$$

for all $i, j, k, s \in \mathbb{K}$ and all $t \in[0, T]$, where $\tilde{\chi}_{i j}^{k s}(t) \geq 0$ and $\sum_{k \in \mathbb{K}} \sum_{s \in \mathbb{K}} \tilde{\chi}_{i j}^{k s}(t)=1$, the Euler equations,

$$
r \mu_{i}(t)-\dot{\mu}_{i}(t)=u_{i}+\alpha \sum_{j \in \mathbb{K}} \sum_{k \in \mathbb{K}} \sum_{s \in \mathbb{K}} m_{j}(t) \chi_{i j}^{k s}(t)\left[\mu_{k}(t)+\mu_{s}(t)-\mu_{i}(t)-\mu_{j}(t)\right]
$$

for all $i \in \mathbb{K}$, with the path for $\boldsymbol{m}(t)$ given by (59), and

$$
\mu_{i}(T)=U_{i} \quad \text { for all } i \in \mathbb{K}
$$

In summary, the necessary conditions are (59), (63), (64), and (65). Next, we use the fact that $\tau \equiv T-t$ to define $m_{k}(t)=m_{k}(T-\tau) \equiv n_{k}(\tau), \chi_{i j}^{k s}(t)=\chi_{i j}^{k s}(T-\tau) \equiv \psi_{i j}^{k s}(\tau)$, and $\mu_{i}(t)=\mu_{i}(T-\tau) \equiv \lambda_{i}(\tau)$. With these new variables, (64) leads to (60), (59) leads to $\dot{\boldsymbol{n}}(\tau)=f[\boldsymbol{n}(\tau), \boldsymbol{\psi}(\tau)],(65)$ leads to (61), and (63) leads to (62).

The following result provides a full characterization of the solution to the planner's problem under Assumption A.

Proposition 4 Let the payoff functions satisfy Assumption A. Then:

(i) The optimal path for the distribution of trading probabilities, $\boldsymbol{\psi}(\tau)=\left\{\psi_{i j}^{k s}(\tau)\right\}_{i, j, k, s \in \mathbb{K}}$, is given by

$$
\psi_{i j}^{k s}(\tau)= \begin{cases}\tilde{\psi}_{i j}^{k s}(\tau) & \text { if }(k, s) \in \Omega_{i j}^{*} \\ 0 & \text { if }(k, s) \notin \Omega_{i j}^{*}\end{cases}
$$

for all $i, j, k, s \in \mathbb{K}$ and all $\tau \in[0, T]$, where $\tilde{\psi}_{i j}^{k s}(\tau) \geq 0$ and $\sum_{(k, s) \in \Omega_{i j}^{*}} \tilde{\psi}_{i j}^{k s}(\tau)=1$.

(ii) Along the optimal path, the shadow value of a bank with $i$ reserve balances is given by (60) and (61), with the path for $\boldsymbol{\psi}(t)$ given by (66), and the path for $\boldsymbol{n}(\tau)$ given by $\dot{\boldsymbol{n}}(\tau)=f[\boldsymbol{n}(\tau), \boldsymbol{\psi}(\tau)]$.

Notice the similarity between the equilibrium conditions and the planner's optimality conditions. First, from (8) and (62), we see that the equilibrium loan sizes are privately efficient. That is, given the value function $\boldsymbol{V}$, the equilibrium distribution of trading probabilities is the 
one that would be chosen by the planner. Second, the path for the equilibrium values, $\boldsymbol{V}(\tau)$, satisfies (6) and (7), while the path for the planner's shadow prices satisfies (60) and (61). These pairs of conditions would be identical were it not for the fact that the planner imputes to each agent gains from trade with frequency $2 \alpha$, rather $\alpha$, which is the frequency with which the agent generates gains from trade for himself in the equilibrium. This reflects a composition externality typical of random matching environments. The planner's calculation of the value of a marginal agent in state $i$ includes not only the expected gains from trade to this agent, but also the expected gains from trade that having this marginal agent in state $i$ generates for all other agents by increasing their contact rates with agents in state $i$. In the equilibrium, the individual agent in state $i$ internalizes the former, but not the latter. ${ }^{36}$

Under Assumption A, however, condition (10) is identical to (66), so the equilibrium paths for the distribution of balances and trading probabilities coincide with the optimal paths. This observation is summarized in the following proposition.

Proposition 5 Let the payoff functions satisfy Assumption A. Then, the equilibrium supports an efficient allocation of reserve balances.

Proof of Proposition 4. The function $\boldsymbol{\lambda} \equiv[\lambda(\tau)]_{\tau \in[0, T]}$ satisfies (60) and (61) if and only if it satisfies

$$
\begin{aligned}
\lambda_{i}(\tau) & =v_{i}(\tau)+\alpha \int_{0}^{\tau} \lambda_{i}(z) e^{-(r+\alpha)(\tau-z)} d z \\
& +\alpha \int_{0}^{\tau} \sum_{j \in \mathbb{K}} \sum_{k \in \mathbb{K}} \sum_{s \in \mathbb{K}} n_{j}(z) \psi_{i j}^{k s}(z)\left[\lambda_{k}(z)+\lambda_{s}(z)-\lambda_{i}(z)-\lambda_{j}(z)\right] e^{-(r+\alpha)(\tau-z)} d z .
\end{aligned}
$$

The right side of this functional equation defines a mapping $\mathcal{P}: \boldsymbol{B} \rightarrow \boldsymbol{B}$; that is, for any $w \in \boldsymbol{B}$,

$$
\begin{aligned}
(\mathcal{P} w)(i, \tau) & =v_{i}(\tau)+\alpha \int_{0}^{\tau} w(i, z) e^{-(r+\alpha)(\tau-z)} d z \\
& +\alpha \int_{0}^{\tau} \sum_{j \in \mathbb{K}} \sum_{k \in \mathbb{K}} \sum_{s \in \mathbb{K}} n_{j}(z) \psi_{i j}^{k s}(z)[w(k, z)+w(s, z)-w(i, z)-w(j, z)] e^{-(r+\alpha)(\tau-z)} d z
\end{aligned}
$$

\footnotetext{
${ }^{36}$ In a labor market context, a similar composition externality arises in the competitive matching equilibrium of Kiyotaki and Lagos (2007).
} 
for all $(i, \tau) \in \mathbb{K} \times[0, T]$. Hence a function $\boldsymbol{\lambda}$ satisfies (60) and (61) if and only if it satisfies $\boldsymbol{\lambda}=\mathcal{P} \boldsymbol{\lambda}$. Rewrite the mapping $\mathcal{P}$ as

$$
\begin{aligned}
(\mathcal{P} w)(i, \tau) & =v_{i}(\tau)+\alpha \int_{0}^{\tau} w(i, z) e^{-(r+\alpha)(\tau-z)} d z \\
& +\alpha \int_{0}^{\tau} \sum_{j \in \mathbb{K}} n_{j}(z) \max _{(k, s) \in \Pi(i, j)}[w(k, z)+w(s, z)-w(i, z)-w(j, z)] e^{-(r+\alpha)(\tau-z)} d z,
\end{aligned}
$$

and for any $w, w^{\prime} \in \boldsymbol{B}$, define the metric $D^{*}: \boldsymbol{B} \times \boldsymbol{B} \rightarrow \mathbb{R}$ by

$$
D^{*}\left(w, w^{\prime}\right)=\sup _{(i, \tau) \in \mathbb{K} \times[0, T]}\left[e^{-\kappa \tau}\left|w(i, \tau)-w^{\prime}(i, \tau)\right|\right],
$$

where $\kappa \in \mathbb{R}$ satisfies

$$
\max \{0,5 \alpha-r\}<\kappa<\infty \text {. }
$$

The metric space $\left(\boldsymbol{B}, D^{*}\right)$ is complete (by the same argument used to argue that $(\boldsymbol{B}, D)$ is complete, in the proof of Lemma 4$)$. For any $w, w^{\prime} \in \boldsymbol{B}$, and any $(i, \tau) \in \mathbb{K} \times[0, T]$, the same steps that led to (39) now lead to

$$
D^{*}\left(\mathcal{P} w, \mathcal{P} w^{\prime}\right) \leq \frac{5 \alpha}{r+\alpha+\kappa} D^{*}\left(w, w^{\prime}\right), \quad \text { for all } w, w^{\prime} \in \boldsymbol{B} .
$$

Notice that (68) implies $\frac{5 \alpha}{r+\alpha+\kappa} \in(0,1)$, so $\mathcal{P}$ is a contraction mapping on the complete metric space $\left(\boldsymbol{B}, D^{*}\right)$. By the Contraction Mapping Theorem (Theorem 3.2 in Stokey and Lucas, 1989), for any given path $\boldsymbol{n}(\tau)$, there exists a unique $\boldsymbol{\lambda} \in \boldsymbol{B}$ that satisfies $\boldsymbol{\lambda}=\mathcal{P} \boldsymbol{\lambda}$.

Consider the sets $\boldsymbol{B}^{\prime \prime}$ and $\boldsymbol{B}^{\prime \prime \prime}$ defined in the proof of Proposition 2. By following the same steps as in the first part of that proof, it can be shown that $\boldsymbol{B}^{\prime \prime}$ is closed under $D^{*}$. Next we show that the mapping $\mathcal{P}$ defined in (67) preserves property (EP), i.e., that $\mathcal{P}\left(\boldsymbol{B}^{\prime \prime}\right) \subseteq \boldsymbol{B}^{\prime \prime}$. That is, we wish to show that for any $w \in \boldsymbol{B}^{\prime \prime}, w^{\prime}=\mathcal{P} w \in \boldsymbol{B}^{\prime \prime}$, or equivalently, that

$$
w\left(\left\lceil\frac{i+j}{2}\right\rceil, \tau\right)+w\left(\left\lfloor\frac{i+j}{2}\right\rfloor, \tau\right) \geq w(k, \tau)+w(s, \tau) \text { for all }(k, s) \in \Pi(i, j),
$$

for any $(i, j, \tau) \in \mathbb{K} \times \mathbb{K} \times[0, T]$, implies that

$$
w^{\prime}\left(\left\lceil\frac{i+j}{2}\right\rceil, \tau\right)+w^{\prime}\left(\left\lfloor\frac{i+j}{2}\right\rfloor, \tau\right)-w^{\prime}(k, \tau)-w^{\prime}(s, \tau) \geq 0 \text { for all }(k, s) \in \Pi(i, j),
$$

for any $(i, j, \tau) \in \mathbb{K} \times \mathbb{K} \times[0, T]$. Since $w \in \boldsymbol{B}^{\prime \prime}$,

$$
\begin{aligned}
(\mathcal{P} w)(i, \tau) & =v_{i}(\tau)+\alpha \int_{0}^{\tau} w(i, z) e^{-(r+\alpha)(\tau-z)} d z \\
& +\alpha \int_{0}^{\tau} \sum_{q \in \mathbb{K}} n_{q}(z)\left[w\left(\left\lceil\frac{i+q}{2}\right\rceil, z\right)+w\left(\left\lfloor\frac{i+q}{2}\right\rfloor, z\right)-w(i, z)-w(q, z)\right] e^{-(r+\alpha)(\tau-z)} d z,
\end{aligned}
$$


for any $(i, \tau) \in \mathbb{K} \times[0, T]$. For any $(i, j, \tau) \in \mathbb{K} \times \mathbb{K} \times[0, T]$ and $(k, s) \in \Pi(i, j)$, let $G^{\prime}(i, j, k, s, \tau)$ denote the left side of inequality (69). Then,

$$
\begin{aligned}
G^{\prime}(i, j, k, s, \tau)= & \frac{1-e^{-(r+\alpha) \tau}}{r+\alpha}\left(u_{\left\lceil\frac{i+j}{2}\right\rceil}+u_{\left\lfloor\frac{i+j}{2}\right\rfloor}-u_{k}-u_{s}\right) \\
+ & +e^{-(r+\alpha) \tau}\left[U_{\left\lceil\frac{i+j}{2}\right\rceil}+U_{\left\lfloor\frac{i+j}{2}\right\rfloor}-U_{k}-U_{s}\right] \\
+\alpha \int_{0}^{\tau} \sum_{q \in \mathbb{K}} n_{q}(z) & \left\{\left(\left\lfloor\frac{\left.\frac{i+j}{2}\right\rceil+q}{2}\right\rfloor, z\right)+w\left(\left\lfloor\frac{\left.\frac{i+j}{2}\right\rceil+q}{2}\right\rfloor, z\right)\right. \\
& -w\left(\left\lceil\frac{k+q}{2}\right\rceil, z\right)-w\left(\left\lfloor\frac{s+q}{2}\right\rfloor, z\right) \\
& -w\left(\left\lfloor\frac{k+q}{2}\right\rfloor, z\right)-w\left(\left\lceil\frac{s+q}{2}\right\rceil, z\right) \\
& \left.+w\left(\left\lfloor\frac{\left\lfloor\frac{i+j}{2}\right\rfloor+q}{2}\right\rfloor, z\right)+w\left(\left\lfloor\frac{\left.\frac{i+j}{2}\right\rfloor+q}{2}\right\rfloor, z\right)\right\} e^{-(r+\alpha)(\tau-z)} d z .
\end{aligned}
$$

What needs to be shown is that $w \in \boldsymbol{B}^{\prime \prime}$ implies that for any $(i, j, \tau) \in \mathbb{K} \times \mathbb{K} \times[0, T]$, $G^{\prime}(i, j, k, s, \tau) \geq 0$ for all $(k, s) \in \Pi(i, j)$. By Lemma $5, w \in \boldsymbol{B}^{\prime \prime}$ implies that the integral in the last expression is nonnegative. Together with Assumption A, this implies

$$
\begin{aligned}
0 & <\frac{1-e^{-(r+\alpha) \tau}}{r+\alpha}\left(u_{\left\lceil\frac{i+j}{2}\right\rceil}+u_{\left\lfloor\frac{i+j}{2}\right\rfloor}-u_{k}-u_{s}\right)+e^{-(r+\alpha) \tau}\left[U_{\left\lceil\frac{i+j}{2}\right\rceil}+U_{\left\lfloor\frac{i+j}{2}\right\rfloor}-U_{k}-U_{s}\right] \\
& \leq G^{\prime}(i, j, k, s, \tau),
\end{aligned}
$$

so $\mathcal{M}\left(\boldsymbol{B}^{\prime \prime}\right) \subseteq \boldsymbol{B}^{\prime \prime \prime} \subseteq \boldsymbol{B}^{\prime \prime}$.

At this point, we have shown that $\mathcal{P}$ is a contraction mapping on the complete metric space $\left(\boldsymbol{B}, D^{*}\right)$, so it has a unique fixed point $\boldsymbol{\lambda} \in \boldsymbol{B}$. We have also established that $\boldsymbol{B}^{\prime \prime}$ is a closed subset of $\boldsymbol{B}$ and that $\mathcal{M}\left(\boldsymbol{B}^{\prime \prime}\right) \subseteq \boldsymbol{B}^{\prime \prime \prime} \subseteq \boldsymbol{B}^{\prime \prime}$. Therefore, by Corollary 1 in Stokey and Lucas (1989, p. 52), $\boldsymbol{\lambda}=\mathcal{P} \boldsymbol{\lambda} \in \boldsymbol{B}^{\prime \prime \prime}$, that is, the unique fixed point $\boldsymbol{\lambda}$ satisfies (SEP). This implies that the set $\Omega_{i j}[\boldsymbol{\lambda}(\tau)]$ in (62) reduces to $\Omega_{i j}^{*}$ (as defined in (11)) for all $(i, j, \tau) \in \mathbb{K} \times \mathbb{K} \times[0, T]$, and consequently, that (62) reduces to (66). This establishes part $(i)$ in the statement of the proposition.

Given the initial condition $\left\{n_{k}(T)\right\}_{k \in \mathbb{K}}$, and given that the path $\boldsymbol{\psi}(\tau)$ satisfies (66), the system of first-order ordinary differential equations, $\dot{\boldsymbol{n}}(\tau)=f[\boldsymbol{n}(\tau), \boldsymbol{\psi}(\tau)]$ is identical to the one in part (iii) of Proposition 2 and therefore also has a unique solution. Given the resulting path $\boldsymbol{n}(\tau)$, according to Proposition 3, the path for the vector of co-states must satisfy the necessary condition $\boldsymbol{\lambda}=\mathcal{P} \boldsymbol{\lambda}$, or equivalently, (60) and (61), which establishes part (ii) in the statement of the proposition. 


\section{Data}

\section{C.1 Treatment of outliers}

From the histogram of the variable of interest (i.e., the 4:00 pm imputed balances over required operating balances, averaged over the two-week maintenance period), we identified observations that deviate markedly from the other members of the sample. In the 2007 sample, there are two such observations: the smallest and the largest. In order to assess whether these observations are inconsistent with the remainder of the data, we revisited the identity of both of these institutions. The smallest value corresponds to a commercial bank classified as a Federal Reserve nonmember bank that is regulated by the FDIC and that engages in depositary credit intermediation. The largest value corresponds to a state member bank supervised by the Federal Reserve in conjunction with the state chartering authority. Even though these institutions are commercial banks according to the regulatory definition, this definition is broad enough to include institutions such as these two, whose lines of business do not conform to that of a typical commercial bank that participates in the fed funds market. In the 2011 sample there are three observations that deviate markedly from the rest of the sample: the smallest and the two largest. The smallest observation is the same Federal Reserve nonmember bank that we identified as the smallest outlier in the 2007 sample. The two largest observations correspond to national banks supervised by the Office of the Comptroller of the Currency. Thus, as in the 2007 sample, the outliers correspond to institutions that are technically labeled "commercial banks" but whose business activities are different from those of the typical commercial bank and are therefore supervised by authorities other than the Federal Reserve.

We have also implemented a modified version of Grubbs' test that assumes the data can be fitted by a mixture of Gaussians and detects outliers with respect to the Gaussian distribution with the largest variance. This procedure identifies the same two outliers in 2007 and the same three outliers in 2011 that we identified by plotting the histogram as described in the previous paragraph. To summarize, for 2007 we started with an initial sample of 136 banks, eliminated 2 outliers, and then worked with a sample composed of the remaining 134 banks. For 2011 we started with an initial sample of 103 banks, eliminated 3 outliers, and then worked with a sample composed of the remaining 100 banks. 


\section{C.2 Estimation of initial distribution of balances}

In Section 6.1 we described the procedure to estimate the initial distribution of balances that we used in the 2007 calibration to run the baseline simulations presented in Section 6.2. This procedure is straightforward: it essentially consists of using the data to construct the histogram that we employ as the initial condition for the distribution of reserve balances in the model. In order to conduct policy experiments such as those in Section 6.3 or counterfactual experiments such as those in Appendix D, however, it is convenient to work with a parametric initial distribution of balances rather than an empirical histogram, as this allows one to easily change the mean or the standard deviation of the initial distribution of balances. For this reason, the initial distributions used for the exercises in Section 6.3 and Appendix D were estimated using the following procedure.

\section{C.2.1 Estimation procedure for 2011 policy experiments}

As mentioned in the body of the paper, we think of $n_{k}(T)$ as the model counterpart of the empirical proportion of commercial banks whose balances at the beginning of the trading session are $k / \bar{k}$ times larger than their average daily reserve requirement over a two-week holding period. In order to conduct the policy experiments reported in Section 6.3, we estimate $\left\{n_{k}(T)\right\}_{k \in \mathbb{K}}$ from data using the following procedure.

First, we identified 103 commercial banks that traded fed funds during the first quarter of 2011 (according to their FR Y9-C regulatory filings) and for which we have been able to obtain information on their required operating balance. Second, we obtained the empirical cross-sectional distribution of closing balances of these 103 banks for each day of a two-week maintenance period in the same quarter. Third, for every day in the sample, we constructed a measure of each bank's imputed reserve balance at 4:00 pm, as follows. Given each bank's closing balance on a given day, we subtracted the bank's net payments activity from 4:00 pm until Fedwire Funds Service closing time (typically 6:30 pm) as well as the discount window activity for that day. Fourth, for each bank we calculated the average (over days in the twoweek maintenance period) imputed reserve balance at 4:00 pm and normalized it by dividing it by the bank's daily average required operating balance over the same maintenance period. At this stage we detected three outliers (as described in Section C.1) and removed them from the sample to obtain the final sample of 100 banks. We then used this sample to compute maximum likelihood estimates of the parameters of a Gaussian mixture model with two components. The 
estimated parameters are $\hat{\mu}_{1}=3.55$ and $\hat{\mu}_{2}=40.23$ (the means), $\sigma_{1}=3.9$ and $\sigma_{2}=34$ (the standard deviations), and $p_{1}=1-p_{2}=0.56$ (the probability of drawing from the first component). ${ }^{37}$ We discuss the goodness of fit in Section C.2.3 below.

Notice that the mean of the estimated distribution of average normalized imputed reserve balances for the 100 banks in the sample is $p_{1} \hat{\mu}_{1}+p_{2} \hat{\mu}_{2}=19.6$. In order for the calibrated model to capture typical overall market conditions during the first quarter of 2011 , we translate the estimated Gaussian mixture by choosing its mean to match the empirical mean of the ratio of total seasonally adjusted reserves of depository institutions to total required reserves reported in the H.3 Federal Reserve Statistical Release during the first quarter of 2011, which equals 17.6. This is done by considering a Gaussian mixture with the same $p_{1}, p_{2}, \sigma_{1}$, and $\sigma_{2}$ that were estimated from the sample of 100 banks, but replacing the estimated means, $\hat{\mu}_{1}$ and $\hat{\mu}_{2}$, with $\mu_{i}=0.9 \hat{\mu}_{i}$, for $i=1,2$, i.e., $\mu_{1}=3.19$ and $\mu_{2}=36.2 .{ }^{38}$ This leads to the Gaussian mixture, $\Phi$, with parameters $\mu_{1}=3.19, \mu_{2}=36.2, \sigma_{1}=3.9, \sigma_{2}=34$, and $p_{1}=0.56$ used in Section 6.3.

\section{C.2.2 Estimation procedure for 2007 counterfactuals}

In order to conduct the counterfactual policy experiments for 2007 reported in Appendix D (Section D.1), we estimate $\left\{n_{k}(T)\right\}_{k \in \mathbb{K}}$ from data using the same procedure used for the policy experiments reported in Section 6.3. Below we describe the full procedure for completeness.

First, we identified 136 commercial banks that traded fed funds at the end of the second quarter of 2007 (according to their FR Y9-C regulatory filings) and for which we have been able to obtain information on their required operating balance. Second, we obtained the empirical cross-sectional distribution of closing balances of these 136 banks for each day of a two-week maintenance period in the same quarter. Third, for every day in the sample, we constructed a measure of each bank's imputed reserve balance at 4:00 pm, as follows. Given each bank's closing balance on a given day, we subtracted the bank's net payments activity from 4:00 pm until Fedwire Funds Service closing time (typically 6:30 pm) as well as the discount window activity for that day. Fourth, for each bank we calculated the average (over days in the twoweek maintenance period) imputed reserve balance at 4:00 pm and normalized it by dividing it

\footnotetext{
${ }^{37}$ The corresponding standard errors (bootstrap, based on 10,000 iterations) for $\hat{\mu}_{1}, \hat{\mu}_{2}, \sigma_{1}, \sigma_{2}$, and $p_{1}$ are 0.99 , $6.68,1.02,4.53$, and 0.074 , respectively.

${ }^{38}$ The standard deviation of the Gaussian mixture is a function of the means of the two components, so changes in $\mu_{1}$ affect the variance of the mixture. As a robustness check, we have also conducted experiments changing $\sigma_{1}$ along with $\mu_{1}$ so as to keep the variance constant and found no significant difference in our results.
} 
by the bank's daily average required operating balance over the same maintenance period. At this stage we detected two outliers (as described in Section C.1) and removed them from the sample to obtain the final sample of 134 banks. We then used this sample to compute maximum likelihood estimates of the parameters of a Gaussian mixture model with two components. The estimated parameters are $\hat{\mu}_{1}=0.38$ and $\hat{\mu}_{2}=14.53$ (the means), $\sigma_{1}=3.4$ and $\sigma_{2}=32$ (the standard deviations), and $p_{1}=1-p_{2}=0.71$ (the probability of drawing from the first component). ${ }^{39}$ We discuss the goodness of fit in Section C.2.3 below. The mean of the estimated distribution of average normalized imputed reserve balances for the 134 banks in the sample is $p_{1} \hat{\mu}_{1}+p_{2} \hat{\mu}_{2}=4.47$. In order for the calibrated model to capture typical overall market conditions during the second quarter of 2007, we translate the estimated Gaussian mixture by choosing its mean to match the empirical mean of the ratio of total seasonally adjusted reserves of depository institutions to total required reserves reported in the H.3 Federal Reserve Statistical Release during the second quarter of 2007, which equals 1.04. This is done by considering a Gaussian mixture with the same $p_{1}, p_{2}, \sigma_{1}$, and $\sigma_{2}$ that were estimated from the sample of 134 banks, but replacing the estimated means, $\hat{\mu}_{1}$ and $\hat{\mu}_{2}$, with $\mu_{i}=0.23 \hat{\mu}_{i}$, for $i=1,2$. This leads to the Gaussian mixture, $\Phi$, with parameters $\left(\mu_{1}, \mu_{2}, \sigma_{1}, \sigma_{2}, p_{1}\right)$. In order to feed this distribution into the model we let $\bar{k}=1$ (so $k$ can be interpreted as a multiple of the reserve requirement), $\mathbb{K}=\{0, \ldots, 250\}, \bar{k}_{0}=100$, and $n_{k}(T)=\Phi\left(k-\bar{k}_{0}+1\right)-\Phi\left(k-\bar{k}_{0}\right)$ for $k=1, \ldots, 249, n_{0}(T)=$ $\Phi(-100)$, and $n_{250}(T)=1-\Phi(150)$. By construction, $Q \equiv \sum_{k=0}^{250}\left(k-\bar{k}_{0}\right) n_{k}(T) \approx 1.04$.

\section{C.2.3 Goodness of fit}

As described above, for our policy experiments and counterfactual exercises, we use a Gaussian mixture with parameters estimated by maximum likelihood. In this section we describe the process that led us to choose a Gaussian mixture. We estimated four parametric distributions as well as a mixture of two Gaussians to our initial distribution of balances and used several methods to assess goodness of fit.

The 2007 initial distribution of balances The Kolmogorov-Smirnov goodness-of-fit test does not reject the null hypothesis that the 2007 sample has been drawn from the Gaussian mixture with two components at the 90 percent confidence level. We have also fit a Gaussian, a Logistic, and a Generalized Extreme Value distribution, but the null hypothesis is rejected

\footnotetext{
${ }^{39}$ The corresponding standard errors (boostrap, based on 10,000 iterations) for $\hat{\mu}_{1}, \hat{\mu}_{2}, \sigma_{1}, \sigma_{2}$, and $p_{1}$ are: 0.45 , $8.24,0.99,7.84$, and 0.08 respectively.
} 
by the Kolmogorov-Smirnov goodness-of-fit test at the 1 percent significance level. At the 90 percent confidence level, the test does not reject the null hypothesis that the data have been drawn from a $t$-Location Scale distribution.

The Chi-square goodness-of-fit test does not reject the null hypothesis that the 2007 sample has been drawn from a Gaussian mixture with two components at the 99 percent confidence level. However, it rejects, at the 10 percent significance level, the null hypothesis that the data have been drawn from a Gaussian, a Logistic, a Generalized Extreme Value or a $t$-Location Scale distribution.

We also contructed quantile-quantile plots of the sample quantiles of our distribution of initial balances versus theoretical quantiles from a Gaussian, a Logistic, a Generalized Extreme Value, a $t$-Location Scale distribution, and Gaussian mixture with two components. Visually, the $\mathrm{Q}-\mathrm{Q}$ plot of the Gaussian mixture with two components closely follows a linear trend line, suggesting that the mixture of two Gaussians is a reasonably good fit to the data.

The 2011 initial distribution of balances The Kolmogorov-Smirnov goodness-of-fit test does not reject the null hypothesis that the 2011 sample has been drawn from the Gaussian mixture with two components at the 90 percent confidence level. We have fit a Gaussian, a Logistic, and a $t$-Location Scale distribution, but the null hypothesis is rejected by the KolmogorovSmirnov goodness-of-fit test at the 99 percent confidence level. The test does not reject the null hypothesis that the data have been drawn from a Generalized Extreme Value distribution at the significance level 0.01 .

The Chi-square goodness-of-fit test rejects the null hypothesis that the data have been drawn from the Gaussian mixture with two components, a Gaussian, a Logistic, a Generalized Extreme Value, or a $t$-Location Scale distribution at the 99 percent confidence level.

The Q-Q plot of the Gaussian mixture with two components is relatively close to linear, suggesting that the mixture of two Gaussians is a relatively good fit to the data.

\section{Quantitative exercises}

\section{D.1 Policy counterfactual for 2007}

In this section we use the model calibrated to mimic the salient features of a typical day in 2007 to conduct the types of policy experiments conducted in Section 6.3. Table 4 reports the equilibrium values of $\bar{\rho}$ that result from varying $i_{f}$ from 0 to 6 percent in 1 percent increments 
(as before, each column corresponds to a different value of $Q / \bar{k}$ ). All other parameter values are as in Section 6.1. Table 5 reports the equilibrium values of $\bar{\rho}$ that result from varying $i_{f}^{w}$ from 575 basis points to 700 basis points in 25 basis point increments, while keeping all other parameter values as in Section 6.1.

\section{D.2 Sensitivity analysis}

In this section we carry out additional quantitative experiments to assess the sensitivity of the model predictions to changes in the contact rate, $\alpha$, and the standard deviation of the initial distribution of reserve balances. These exercises show how the results of our policy experiments vary with the values of the key calibrated parameters (notice that Tables 1-5 already show how the equilibrium fed funds rate varies with the mean of the initial distribution of balances).

\section{D.2.1 Changes in the contact rate}

The top row of Figure 8 corresponds to the 2007 calibration with the initial distribution of reserves estimated by a Gaussian mixture as described in Section C.2.2. The top left panel plots the equilibrium value weighted fed funds rate, $\bar{\rho}$, as a function of the aggregate normalized level of reserves, $Q / \bar{k}$, corresponding to five values of $\alpha$. Notice that for any given level of $Q / \bar{k}$, the equilibrium rate $\bar{\rho}$ increases with $\alpha$ if $Q / \bar{k}<1$ and decreases with $\alpha$ if $Q / \bar{k}>1$. The interest rate is independent of $\alpha$ in the "balanced market" with $Q / \bar{k}=1$. The top right panel plots $\bar{\rho}$ as a function of $\alpha$ keeping all other parameters (including $Q / \bar{k}$ ) at their baseline values for the 2007 calibration. These results are in line with the discussion at the end of Section 6.3. The bottom row of Figure 8 does the same exercise for the 2011 calibration.

\section{D.2.2 Mean-preserving spreads of the initial distribution of balances}

Consider a Gaussian mixture with parameters $\left(\mu_{1}, \mu_{2}, \sigma_{1}, \sigma_{2}, p_{1}\right)$. We parametrize a family of mean-preserving spreads of this distribution as follows. For any $\bar{\sigma} \in \mathbb{R}_{+}$, define $\tilde{\mu}_{1}=\mu_{1}+\delta p_{2}$, $\tilde{\mu}_{2}=\mu_{2}-\delta p_{1}$, and $\tilde{\sigma}_{i}=\bar{\sigma} \sigma_{i}$ for $i=1,2$, with $\delta \equiv(1-\bar{\sigma})\left(\mu_{2}-\mu_{1}\right)$. Then it is easy to see that $\bar{\sigma}$ indexes a family of Gaussian mixtures with parameters $\left(\tilde{\mu}_{1}, \tilde{\mu}_{2}, \tilde{\sigma}_{1}, \tilde{\sigma}_{2}, p_{1}\right)$, where each member of the family has the same mean, $p_{1} \mu_{1}+p_{2} \mu_{2}$, and a standard deviation proportional to $\bar{\sigma}$. Thus by varying $\bar{\sigma}$ we can generate mean-preserving spreads of the original Gaussian mixture. Clearly, the special case $\bar{\sigma}=1$ corresponds to the original distribution with parameters $\left(\mu_{1}, \mu_{2}, \sigma_{1}, \sigma_{2}, p_{1}\right)$. 
Figure 9 shows the effects of a mean-preserving spread of the initial distribution of balances. The top row corresponds to the 2007 calibration, with the initial distribution of reserves given by Gaussian mixture with parameters $\left(\mu_{1}, \mu_{2}, \sigma_{1}, \sigma_{2}, p_{1}\right)$ estimated as described in Section C.2.2. The top left panel plots the equilibrium value weighted fed funds rate, $\bar{\rho}$, as a function of the aggregate normalized level of reserves, $Q / \bar{k}$, corresponding to five values of $\bar{\sigma}$. Again, we confirm that the distribution is neutral if the market is balanced, i.e., if $Q / \bar{k}=1$ (notice that $\bar{\rho}$ is invariant to $\bar{\sigma}$ when $Q / \bar{k}=1)$. The top right panel plots $\bar{\rho}$ as a function of $\bar{\sigma}$ keeping all other parameters (including $Q / \bar{k}$ ) at their baseline values for the 2007 calibration. The bottom row of Figure 9 does the same exercise for the 2011 calibration. 


\section{References}

[1] Afonso, Gara. 2011. "Liquidity and Congestion." Journal of Financial Intermediation 20(3) (July): 324-360.

[2] Afonso, Gara, Anna Kovner, and Antoinette Schoar. 2011. "Stressed, Not Frozen: The Federal Funds Market in the Financial Crisis." Journal of Finance 66(4) (August): 11091139 .

[3] Afonso, Gara, and Ricardo Lagos. 2014. "An Empirical Investigation of Trade Dynamics in the Market for Federal Funds." Working Paper 708, Federal Reserve Bank of Minneapolis.

[4] Amann, Herbert. 1990. Ordinary Differential Equations: An Introduction to Nonlinear Analysis. New York: de Gruyter Studies in Mathematics.

[5] Ashcraft, Adam B., and Darrell Duffie. 2007. "Systemic Illiquidity in the Federal Funds Market." American Economic Review 97(2) (May): 221-225.

[6] Bartolini, Leonardo, Svenja Gudell, Spence Hilton, and Krista Schwarz. 2005. "Intraday Trading in the Overnight Federal Funds Market." Federal Reserve Bank of New York Current Issues in Economics and Finance 11(11) (November): 1-7.

[7] Bech, Morten L., and Enghin Atalay. 2008. "The Topology of the Federal Funds Market." Federal Reserve Bank of New York Staff Report 354.

[8] Bech, Morten L., and Elizabeth Klee. 2011. "The Mechanics of a Graceful Exit: Interest on Reserves and Segmentation in the Federal Funds Market." Journal of Monetary Economics 58(5) (July): 415-431.

[9] Bennett, Paul, and Spence Hilton. 1997. "Falling Reserve Balances and the Federal Funds Rate." Federal Reserve Bank of New York Current Issues in Economics and Finance 3(5) (April): 1-6.

[10] Coleman, Wilbur John II, Christian Gilles, and Pamela A. Labadie. 1996. "A Model of the Federal Funds Market." Economic Theory 7(2) (February): 337-357.

[11] Davis, Steven J., John C. Haltiwanger, and Scott Schuh. 1996. Job Creation and Destruction. Cambridge: MIT Press. 
[12] Duffie, Darrell. 2012. Dark Markets: Asset Pricing and Information Transmission in Overthe-Counter Markets. Princeton, NJ: Princeton University Press.

[13] Duffie, Darrell, Nicolae Gârleanu, and Lasse Heje Pedersen. 2005. "Over-the-Counter Markets." Econometrica 73(6) (November): 1815-1847.

[14] Duffie, Darrell, Nicolae Gârleanu, and Lasse Heje Pedersen. 2007. "Valuation in Over-theCounter Markets." Review of Financial Studies 20(6) (November): 1865-1900.

[15] Ennis, Huberto M., and Todd Keister. 2008. "Understanding Monetary Policy Implementation." Federal Reserve Bank of Richmond Economic Quarterly 94(3) (Summer): 235-263.

[16] Ennis, Huberto M., and John A. Weinberg. 2009. "Over-the-Counter Loans, Adverse Selection, and Stigma in the Interbank Market." Federal Reserve Bank of Richmond Working Paper 10-07.

[17] Ennis, Huberto M., and Alexander L. Wolman. 2010. "Excess Reserves and the New Challenges of Monetary Policy." Federal Reserve Bank of Richmond Economic Brief (March).

[18] Federal Reserve. 2009. "Interest on Required Reserve Balances and Excess Balances." http://www.frbservices.org/files/reserves/pdf/calculating_required_reserve_balances_ and_excess_balances.pdf

[19] Federal Reserve. 2010a. Press Release. http://www.federalreserve.gov/newsevents/press/other/20100930a.htm

[20] Federal Reserve. 2010b. "Reserve Maintenance Manual." http://www.frbservices.org/files/regulations/pdf/rmm.pdf

[21] Furfine, Craig H. 1999. "The Microstructure of the Federal Funds Market." Financial Markets, Institutions and Instruments 8(5) (December): 24-44.

[22] Furfine, Craig H. 2003. "Standing Facilities and Interbank Borrowing: Evidence from the Federal Reserve's New Discount Window." International Finance 6(3) (November): 329347. 
[23] Gârleanu, Nicolae. 2009. "Portfolio Choice and Pricing in Illiquid Markets." Journal of Economic Theory 144(2) (March): 532-564.

[24] Goodfriend, Marvin. 2002. "Interest on Reserves and Monetary Policy." Federal Reserve Bank of New York Economic Policy Review (May): 13-29.

[25] Hamilton, James D. 1996. "The Daily Market for Federal Funds." Journal of Political Economy 104(1) (February): 26-56.

[26] Hamilton, James D., and Òscar Jordà. 2002. "A Model of the Federal Funds Target." Journal of Political Economy 110(5) (October): 1135-1167.

[27] Ho, Thomas S. Y., and Anthony Saunders. 1985. "A Micro Model of the Federal Funds Market." Journal of Finance 40(3) (July): 977-988.

[28] Keister, Todd, Antoine Martin, and James McAndrews. 2008. "Divorcing Money from Monetary Policy." Federal Reserve Bank of New York Economic Policy Review (September): 41-56.

[29] Kiyotaki, Nobuhiro, and Ricardo Lagos. 2007. "A Model of Job and Worker Flows." Journal of Political Economy 115(5) (October): 770-819.

[30] Kuo, Dennis, David Skeie, and James Vickery. 2010. "How Well Did Libor Measure Bank Wholesale Funding Rates During the Crisis?" Manuscript.

[31] Lagos, Ricardo. 2010a. "Some Results on the Optimality and Implementation of the Friedman Rule in the Search Theory of Money." Journal of Economic Theory 145(4) (July): $1508-1524$.

[32] Lagos, Ricardo. 2010b. "Asset Prices and Liquidity in an Exchange Economy." Journal of Monetary Economics 57(8) (November): 913-930.

[33] Lagos, Ricardo. 2011. "Asset Prices, Liquidity, and Monetary Policy in an Exchange Economy." Journal of Money, Credit and Banking 43(s2) (October): 521-552.

[34] Lagos, Ricardo, and Guillaume Rocheteau. 2007. "Search in Asset Markets: Market Structure, Liquidity, and Welfare." American Economic Review 97(2) (May): 198-202. 
[35] Lagos, Ricardo, and Guillaume Rocheteau. 2009. "Liquidity in Asset Markets with Search Frictions." Econometrica 77(2) (March): 403-426.

[36] Lagos, Ricardo, Guillaume Rocheteau, and Pierre-Olivier Weill. 2011. "Crashes and Recoveries in Illiquid Markets." Journal of Economic Theory 146(6) (November): 2169-2205.

[37] Lagos, Ricardo, and Randall Wright. 2005. "A Unified Framework for Monetary Theory and Policy Analysis." Journal of Political Economy 113(3) (June): 463-484.

[38] Meulendyke, Anne-Marie. 1998. U.S. Monetary Policy and Financial Markets. New York: Federal Reserve Bank of New York.

[39] Miao, Jianjun. 2006. "A Search Model of Centralized and Decentralized Trade." Review of Economic Dynamics 9(1) (January): 68-92.

[40] Murota, Kazuo. 2003. Discrete Convex Analysis. Philadelphia: SIAM Monographs on Discrete Mathematics and Application.

[41] Ok, Efe A. 2007. Real Analysis with Economic Applications. Princeton, NJ: Princeton University Press.

[42] Poole, William. 1968. "Commercial Bank Reserve Management in a Stochastic Model: Implications for Monetary Policy." Journal of Finance 23(5) (December): 769-791.

[43] Rust, John, and George Hall. 2003. "Middlemen versus Market Makers: A Theory of Competitive Exchange." Journal of Political Economy 111(2) (April): 353-403.

[44] Spulber, Daniel F. 1996. "Market Making by Price-Setting Firms." Review of Economic Studies 63(4) (October): 559-580.

[45] Stokey, Nancy, and Robert E. Lucas. 1989. Recursive Methods in Economic Dynamics. Cambridge: Harvard University Press.

[46] Vayanos, Dimitri, and Tan Wang. 2007. "Search and Endogenous Concentration of Liquidity in Asset Markets." Journal of Economic Theory 136(1) (September): 66-104.

[47] Vayanos, Dimitri, and Pierre-Olivier Weill. 2008. "A Search-Based Theory of the On-theRun Phenomenon." Journal of Finance 63(3) (June): 1361-1398. 
[48] Weill, Pierre-Olivier. 2007. "Leaning against the Wind." Review of Economic Studies 74(4) (October): 1329-1354.

[49] Weill, Pierre-Olivier. 2008. "Liquidity Premia in Dynamic Bargaining Markets." Journal of Economic Theory 140(1) (May): 66-96. 


\begin{tabular}{|c|c|c|c|c|}
\hline \begin{tabular}{c}
8 \\
$\infty$ \\
11 \\
$1 \leqslant 2$ \\
\hdashline
\end{tabular} & $\begin{array}{l}\tilde{8} \\
8 \\
8 \\
\stackrel{8}{0}\end{array}$ & $\begin{array}{l}\stackrel{0}{ } \\
\stackrel{8}{8} \\
\stackrel{0}{0}\end{array}$ & $\begin{array}{l}\stackrel{0}{\circ} \\
\stackrel{8}{8} \\
\stackrel{0}{0}\end{array}$ & $\begin{array}{l}\stackrel{10}{\stackrel{8}{8}} \\
\stackrel{0}{0}\end{array}$ \\
\hline 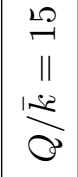 & $\begin{array}{l}\vec{F} \\
\stackrel{\sigma}{8} \\
\stackrel{0}{0}\end{array}$ & $\begin{array}{l}\text { ஸे } \\
\stackrel{8}{0} \\
\stackrel{0}{0}\end{array}$ & $\begin{array}{l}\overrightarrow{2} \\
\stackrel{8}{8} \\
0 \\
0\end{array}$ & 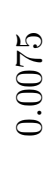 \\
\hline \begin{tabular}{c}
0 \\
\hdashline \\
11 \\
$1 \leq 2$ \\
\hdashline
\end{tabular} & $\begin{array}{l}\stackrel{\infty}{\stackrel{8}{8}} \\
\stackrel{0}{0}\end{array}$ & 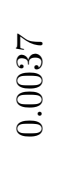 & $\begin{array}{l}\stackrel{0}{\circ} \\
\stackrel{8}{8} \\
\stackrel{0}{0}\end{array}$ & 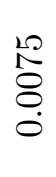 \\
\hline $\mid \begin{array}{c}10 \\
11 \\
1 \leq 2 \\
0\end{array}$ & $\begin{array}{l}\stackrel{\infty}{\stackrel{\leftrightarrow}{8}} \\
\stackrel{8}{0}\end{array}$ & $\begin{array}{l}\stackrel{+}{\&} \\
\stackrel{8}{8} \\
\stackrel{0}{0}\end{array}$ & $\begin{array}{l}\mathscr{8} \\
\stackrel{8}{8} \\
\stackrel{0}{0}\end{array}$ & $\begin{array}{l}0 \\
\stackrel{0}{8} \\
\stackrel{0}{0}\end{array}$ \\
\hline 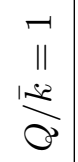 & $\begin{array}{l}\infty \\
\stackrel{\infty}{\mathscr{8}} \\
\stackrel{0}{0} \\
\stackrel{0}{0}\end{array}$ & $\begin{array}{l}\overrightarrow{1} .0 \\
\stackrel{8}{8} \\
\stackrel{0}{0}\end{array}$ & $\begin{array}{l}\Re_{0} \\
8 \\
0 \\
\dot{0}\end{array}$ & $\begin{array}{l}0 \\
\stackrel{0}{8} \\
8 \\
0\end{array}$ \\
\hline \begin{tabular}{c}
20 \\
0 \\
11 \\
$1 \leq 2$ \\
\hdashline 0
\end{tabular} & $\begin{array}{l}\stackrel{2}{\mathscr{8}} \\
\stackrel{8}{0}\end{array}$ & $\begin{array}{l}\sqrt{2} \\
8 \\
8 \\
0\end{array}$ & $\begin{array}{l}\stackrel{H}{8} \\
8 \\
\stackrel{8}{0}\end{array}$ & $\begin{array}{l}0 \\
\stackrel{2}{8} \\
\stackrel{8}{0}\end{array}$ \\
\hline 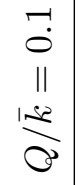 & $\begin{array}{l}\stackrel{\circ}{~} \\
\stackrel{8}{8} \\
\stackrel{0}{0}\end{array}$ & $\begin{array}{l}\text { Iै } \\
\stackrel{2}{8} \\
\stackrel{8}{0}\end{array}$ & $\begin{array}{l}\text { Hீ } \\
\stackrel{8}{8} \\
\dot{0}\end{array}$ & $\begin{array}{l}0 \\
\stackrel{0}{8} \\
\stackrel{8}{0} \\
\dot{0}\end{array}$ \\
\hline 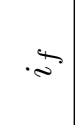 & 0 & $\begin{array}{l}\stackrel{2}{\mathscr{Q}} \\
\stackrel{8}{8} \\
\stackrel{0}{0}\end{array}$ & $\begin{array}{l}\stackrel{8}{8} \\
\stackrel{8}{8} \\
\dot{0}\end{array}$ & $\begin{array}{l}10 \\
\stackrel{10}{8} \\
\stackrel{8}{0} \\
0\end{array}$ \\
\hline
\end{tabular}

\begin{tabular}{|c|c|c|c|c|c|c|}
\hline 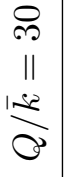 & 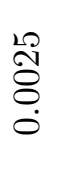 & $\begin{array}{l}\stackrel{20}{\stackrel{8}{8}} \\
\stackrel{8}{0}\end{array}$ & $\begin{array}{l}\stackrel{0}{\mathscr{Q}} \\
\stackrel{8}{8} \\
\stackrel{0}{0}\end{array}$ & $\begin{array}{l}\stackrel{0}{\mathscr{D}} \\
\stackrel{8}{0} \\
\stackrel{0}{0}\end{array}$ & $\begin{array}{l}\hat{N} \\
\stackrel{\delta}{\delta} \\
\stackrel{0}{0}\end{array}$ & $\begin{array}{l}\hat{N} \\
\stackrel{\delta}{\delta} \\
\stackrel{0}{0}\end{array}$ \\
\hline 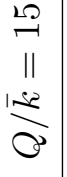 & $\begin{array}{l}\stackrel{20}{\mathscr{Q}} \\
\stackrel{8}{0} \\
\stackrel{0}{0}\end{array}$ & 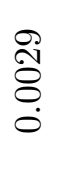 & $\begin{array}{l}\text { ஜे } \\
\stackrel{8}{8} \\
\stackrel{0}{0}\end{array}$ & $\begin{array}{l}\mathscr{0} \\
\mathscr{8} \\
\stackrel{8}{0} \\
\dot{0}\end{array}$ & $\begin{array}{l}\mathscr{O} \\
\stackrel{8}{8} \\
\dot{0}\end{array}$ & $\begin{array}{l}\stackrel{9}{8} \\
\stackrel{0}{0}\end{array}$ \\
\hline 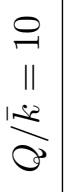 & $\begin{array}{l}\stackrel{20}{\mathscr{8}} \\
\stackrel{8}{\circ}\end{array}$ & $\begin{array}{l}\vec{\infty} \\
\stackrel{8}{8} \\
\stackrel{0}{\circ}\end{array}$ & \begin{tabular}{l}
1 \\
\multirow{8}{8}{} \\
$\stackrel{8}{0}$ \\
$\stackrel{0}{0}$
\end{tabular} & $\begin{array}{l}\stackrel{9}{8} \\
\stackrel{0}{0}\end{array}$ & $\begin{array}{l}\stackrel{g}{+} \\
\stackrel{8}{0} \\
\stackrel{0}{0}\end{array}$ & $\begin{array}{l}10 \\
20 \\
8 \\
0 \\
0\end{array}$ \\
\hline 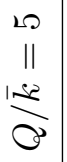 & $\begin{array}{l}\stackrel{\leftrightarrow}{2} \\
\stackrel{8}{0} \\
\stackrel{0}{0}\end{array}$ & $\begin{array}{l}\stackrel{20}{\mathscr{O}} \\
\stackrel{0}{0} \\
\dot{0}\end{array}$ & $\begin{array}{l}\vec{H} \\
\stackrel{8}{8} \\
\stackrel{0}{0}\end{array}$ & $\begin{array}{l}P_{0}^{0} \\
8 \\
0 \\
0\end{array}$ & 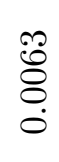 & $\begin{array}{l}\stackrel{N}{\hat{D}} \\
\stackrel{8}{0} \\
0\end{array}$ \\
\hline 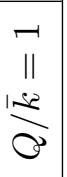 & 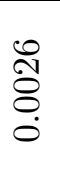 & $\begin{array}{l}\infty \\
\stackrel{\infty}{8} \\
\stackrel{8}{8} \\
\stackrel{0}{0}\end{array}$ & $\begin{array}{l}\overrightarrow{10} \\
\stackrel{8}{8} \\
\stackrel{0}{0}\end{array}$ & $\begin{array}{l}\stackrel{8}{8} \\
8 \\
0 \\
0\end{array}$ & 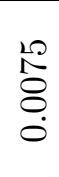 & $\begin{array}{l}1 \\
\stackrel{\infty}{8} \\
\stackrel{8}{0} \\
\dot{0}\end{array}$ \\
\hline 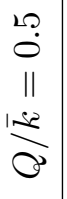 & $\begin{array}{l}\stackrel{0}{\circ} \\
\stackrel{8}{8} \\
\stackrel{0}{0}\end{array}$ & 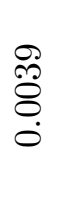 & $\begin{array}{l}\sqrt{2} \\
\stackrel{8}{8} \\
\stackrel{0}{0}\end{array}$ & $\begin{array}{l}\overrightarrow{8} \\
\dot{8} \\
\dot{0}\end{array}$ & $\begin{array}{l}\mathbf{N} \\
\text { م } \\
0 \\
0\end{array}$ & $\begin{array}{l}0 \\
\infty \\
8 \\
0 \\
0\end{array}$ \\
\hline 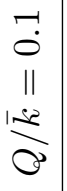 & 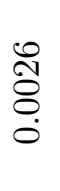 & $\begin{array}{l}\stackrel{\leftrightarrow}{\circ} \\
\stackrel{8}{8} \\
\stackrel{0}{0}\end{array}$ & $\begin{array}{l}\text { iै } \\
\text { I̊ } \\
\stackrel{8}{0} \\
\stackrel{0}{2}\end{array}$ & $\begin{array}{l}18 \\
\mathscr{8} \\
8 \\
0 \\
0\end{array}$ & $\begin{array}{l}\infty \\
\stackrel{0}{0} \\
8 \\
0\end{array}$ & $\begin{array}{l}\vec{\delta} \\
\dot{8} \\
\dot{0}\end{array}$ \\
\hline$\prod_{\infty}^{\infty}$ & 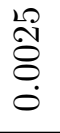 & $\begin{array}{l}0 \\
\stackrel{2}{8} \\
8 \\
0\end{array}$ & 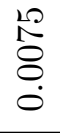 & $\begin{array}{l}8 \\
\stackrel{0}{0} \\
0 \\
0\end{array}$ & $\begin{array}{l}\stackrel{L}{N} \\
\stackrel{0}{0} \\
\stackrel{0}{0}\end{array}$ & $\begin{array}{l}0 \\
\stackrel{0}{10} \\
\stackrel{0}{0} \\
0\end{array}$ \\
\hline
\end{tabular}




\begin{tabular}{|c|c|c|c|c|c|}
\hline \begin{tabular}{c}
$\infty$ \\
$\infty$ \\
11 \\
$1 \leqslant 2$ \\
\hdashline
\end{tabular} & $\begin{array}{l}8 \\
\& \\
\stackrel{8}{\circ}\end{array}$ & $\stackrel{\stackrel{L}{Q}}{\stackrel{8}{O}} \stackrel{0}{\stackrel{0}{0}}$ & $\begin{array}{l}0 \\
\stackrel{8}{8} \\
8 \\
0 \\
0\end{array}$ & 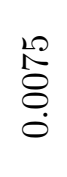 & $\begin{array}{l}8 \\
0 \\
0 \\
\dot{0}\end{array}$ \\
\hline 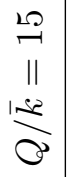 & $\begin{array}{l}\stackrel{3}{8} \\
\stackrel{8}{0} \\
\stackrel{0}{0}\end{array}$ & 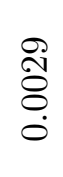 & $\begin{array}{l}\vec{B} \\
\stackrel{8}{8} \\
\stackrel{0}{0}\end{array}$ & $\begin{array}{l}\stackrel{9}{0} \\
\stackrel{8}{8} \\
0 \\
0\end{array}$ & $\begin{array}{l}\vec{J} \\
\stackrel{0}{0} \\
\dot{0}\end{array}$ \\
\hline $\begin{array}{c}\stackrel{0}{\rightarrow} \\
\| \\
1 \leqslant 2 \\
\stackrel{0}{\sigma}\end{array}$ & $\begin{array}{l}8 \\
8 \\
8 \\
\stackrel{8}{0}\end{array}$ & $\begin{array}{l}\overrightarrow{\mathscr{O}} \\
\dot{8} \\
\dot{0}\end{array}$ & $\begin{array}{l}0 \\
\stackrel{2}{8} \\
8 \\
0 \\
0\end{array}$ & $\begin{array}{l}-1 \\
\stackrel{\infty}{8} \\
0 \\
0\end{array}$ & $\begin{array}{l}0 \\
0 \\
0 \\
0 \\
0\end{array}$ \\
\hline$\underset{\substack{10 \\
11 \\
1 \leqslant 2}}{\stackrel{0}{\sigma}}$ & $\begin{array}{l}\stackrel{0}{\circ} \\
\stackrel{8}{\circ} \\
\stackrel{0}{\circ}\end{array}$ & $\begin{array}{l}\stackrel{20}{\mathscr{O}} \\
\stackrel{8}{8} \\
0\end{array}$ & $\begin{array}{l}8 \\
8 \\
8 \\
0 \\
\dot{0}\end{array}$ & $\begin{array}{l}20 \\
\infty \\
8 \\
0 \\
0\end{array}$ & $\begin{array}{l}0 \\
\vec{G} \\
0 \\
\dot{0}\end{array}$ \\
\hline$\underset{\substack{\| \\
1}}{\vec{\sigma}}$ & $\begin{array}{l}\stackrel{m}{\stackrel{8}{8}} \\
\stackrel{0}{0}\end{array}$ & $\begin{array}{l}\infty \\
\stackrel{0}{8} \\
\stackrel{0}{0}\end{array}$ & $\begin{array}{l}\stackrel{8}{8} \\
8 \\
0 \\
0\end{array}$ & $\begin{array}{l}\infty \\
\infty \\
8 \\
0 \\
0\end{array}$ & $\begin{array}{l}\stackrel{m}{\exists} \\
\vec{\sigma} \\
\dot{0}\end{array}$ \\
\hline $\begin{array}{c}10 \\
0 \\
\| \\
11 \\
1 \\
0\end{array}$ & $\begin{array}{l}\stackrel{H}{8} \\
\stackrel{8}{8}\end{array}$ & $\begin{array}{l}\mathscr{O} \\
\dot{8} \\
\dot{0} \\
\dot{0}\end{array}$ & $\begin{array}{l}\overrightarrow{8} \\
\stackrel{8}{0} \\
\stackrel{0}{0}\end{array}$ & $\begin{array}{l}\mathscr{D} \\
\stackrel{0}{0} \\
\stackrel{0}{0}\end{array}$ & $\begin{array}{l}\vec{J} \\
\vec{J} \\
0 \\
\dot{0}\end{array}$ \\
\hline 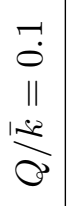 & $\begin{array}{l}\stackrel{H}{\circ} \\
\stackrel{8}{\circ} \\
\stackrel{0}{0}\end{array}$ & $\begin{array}{l}\stackrel{8}{8} \\
\dot{8} \\
\dot{0}\end{array}$ & $\begin{array}{l}\overrightarrow{8} \\
\stackrel{8}{0} \\
\dot{0}\end{array}$ & $\begin{array}{l}\mathscr{D} \\
\stackrel{\infty}{0} \\
\stackrel{0}{0}\end{array}$ & $\begin{array}{l}\vec{J} \\
\vec{J} \\
0 \\
\dot{0}\end{array}$ \\
\hline 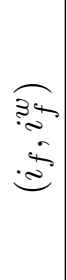 & 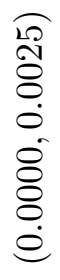 & $\begin{array}{l}\text { Oे } \\
20 \\
8 \\
0 \\
0 \\
10 \\
\stackrel{2}{0} \\
\stackrel{8}{0} \\
\dot{0}\end{array}$ & $\begin{array}{l}10 \\
\stackrel{1}{0} \\
8 \\
0 \\
0 \\
0 \\
0 \\
0 \\
0 \\
0 \\
0\end{array}$ & $\begin{array}{l}\widehat{8} \\
8 \\
0 \\
0 \\
0 \\
10 \\
0 \\
0 \\
0 \\
0 \\
0\end{array}$ & 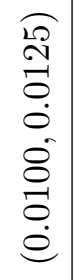 \\
\hline
\end{tabular}

\begin{tabular}{|c|c|c|c|c|c|c|c|}
\hline$\stackrel{\stackrel{20}{\rightleftharpoons}}{\stackrel{20}{11}}$ & $\begin{array}{l}\overrightarrow{8} \\
\stackrel{8}{\circ} \\
\stackrel{0}{0}\end{array}$ & $\begin{array}{l}\vec{\sigma} \\
\stackrel{0}{0} \\
\stackrel{0}{0}\end{array}$ & $\begin{array}{l}\stackrel{8}{\circ} \\
\text { } \\
\stackrel{0}{0}\end{array}$ & $\begin{array}{l}\stackrel{8}{8} \\
\stackrel{\leftrightarrow}{0} \\
\stackrel{0}{0}\end{array}$ & $\begin{array}{l}8 \\
\stackrel{0}{0} \\
\stackrel{0}{0}\end{array}$ & $\begin{array}{l}8 \\
8 \\
0 \\
0 \\
0\end{array}$ & $\begin{array}{l}8 \\
8 \\
0 \\
0 \\
\dot{0}\end{array}$ \\
\hline 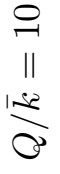 & $\begin{array}{l}\stackrel{\leftrightarrow}{8} \\
\stackrel{8}{0} \\
\stackrel{0}{0}\end{array}$ & $\begin{array}{l}\mathscr{\theta} \\
\stackrel{0}{0} \\
\stackrel{0}{0}\end{array}$ & $\begin{array}{l}\text { Oे } \\
\text { Oे } \\
\stackrel{0}{0}\end{array}$ & $\begin{array}{l}\text { Oे } \\
\text { ฯి } \\
\stackrel{0}{0}\end{array}$ & $\begin{array}{l}\text { Oे } \\
\stackrel{+}{0} \\
\stackrel{0}{0}\end{array}$ & $\begin{array}{l}\text { Oे } \\
\text { bD } \\
0 \\
0\end{array}$ & $\begin{array}{l}\overrightarrow{0} \\
\stackrel{8}{8} \\
\dot{0}\end{array}$ \\
\hline $\begin{array}{c}10 \\
\| \\
1 \\
1 \\
0\end{array}$ & $\begin{array}{l}\hat{\widehat{a}} \\
\stackrel{\delta}{o} \\
\stackrel{0}{0}\end{array}$ & $\begin{array}{l}\stackrel{20}{\stackrel{0}{0}} \\
\stackrel{0}{0}\end{array}$ & $\begin{array}{l}\text { ते } \\
\text { Oे } \\
\stackrel{0}{0}\end{array}$ & 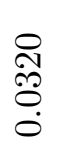 & $\begin{array}{l}\text { 긍 } \\
\stackrel{+}{0} \\
\stackrel{0}{0}\end{array}$ & $\begin{array}{l}\frac{10}{20} \\
20 \\
0 \\
0\end{array}$ & $\begin{array}{l}\stackrel{m}{0} \\
\stackrel{6}{8} \\
\stackrel{0}{0}\end{array}$ \\
\hline 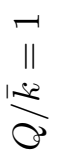 & 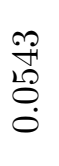 & 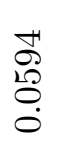 & $\begin{array}{l}\vec{H} \\
\stackrel{H}{0} \\
\stackrel{0}{0}\end{array}$ & $\begin{array}{l}\mathscr{L D} \\
\mathscr{0} \\
\stackrel{0}{0} \\
\dot{0}\end{array}$ & $\begin{array}{l}\stackrel{0}{1} \\
\stackrel{1}{0} \\
\stackrel{0}{0}\end{array}$ & 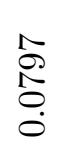 & $\begin{array}{l}\stackrel{N}{+} \\
\infty \\
0 \\
0\end{array}$ \\
\hline 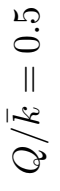 & $\begin{array}{l}\stackrel{20}{N} \\
\stackrel{I}{0} \\
\stackrel{0}{0}\end{array}$ & $\begin{array}{l}\stackrel{9}{\rho} \\
\stackrel{1}{\circ} \\
\stackrel{0}{0}\end{array}$ & $\begin{array}{l}\mathscr{2} \\
\stackrel{D}{0} \\
0 \\
0\end{array}$ & $\begin{array}{l}\text { N } \\
\text { o } \\
\text { Oे } \\
\stackrel{0}{0}\end{array}$ & $\begin{array}{l}\bar{b} \\
\infty \\
0 \\
0 \\
0\end{array}$ & $\begin{array}{l}0 \\
\mathscr{D} \\
0 \\
0 \\
0\end{array}$ & $\begin{array}{l}\stackrel{8}{\mathscr{O}} \\
\stackrel{0}{0} \\
\stackrel{0}{0}\end{array}$ \\
\hline 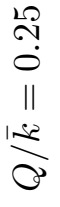 & $\begin{array}{l}\stackrel{2}{\circ} \\
\stackrel{0}{0} \\
\stackrel{0}{0}\end{array}$ & $\begin{array}{l}0 \\
\text { N } \\
\text { o } \\
\stackrel{0}{0}\end{array}$ & $\begin{array}{l}\overrightarrow{1} \\
2 \\
0 \\
0 \\
0\end{array}$ & $\begin{array}{l}\vec{\infty} \\
\infty \\
\infty \\
0 \\
0\end{array}$ & $\begin{array}{l}\stackrel{g}{\circ} \\
\stackrel{8}{\circ} \\
\dot{0}\end{array}$ & $\begin{array}{l}0 \\
\text { Oூ. } \\
\stackrel{0}{0} \\
\dot{0}\end{array}$ & 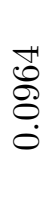 \\
\hline 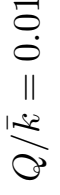 & $\begin{array}{l}0 \\
\stackrel{0}{0} \\
0 \\
0 \\
0 \\
0\end{array}$ & $\begin{array}{l}\stackrel{R}{\infty} \\
\infty \\
\stackrel{0}{0} \\
\dot{0}\end{array}$ & $\begin{array}{l}\overrightarrow{8} \\
\stackrel{8}{8} \\
\dot{0}\end{array}$ & $\begin{array}{l}\stackrel{\mathscr{N}}{\mathscr{S}} \\
\stackrel{0}{0} \\
\stackrel{0}{0}\end{array}$ & $\begin{array}{l}\stackrel{19}{9} \\
\stackrel{8}{0} \\
\dot{0}\end{array}$ & $\begin{array}{l}\infty \\
\mathscr{8} \\
\stackrel{8}{0} \\
\dot{0}\end{array}$ & $\begin{array}{l}\stackrel{8}{\circ} \\
\stackrel{8}{0} \\
\dot{0}\end{array}$ \\
\hline$\stackrel{\infty}{\infty}$ & 0 & $\stackrel{\overrightarrow{0}}{0}$ & 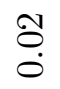 & $\stackrel{\Re}{0}$ & $\stackrel{\overrightarrow{0}}{0}$ & $\stackrel{10}{0}$ & $\begin{array}{l}\mathscr{Q} \\
\stackrel{0}{0}\end{array}$ \\
\hline
\end{tabular}




\begin{tabular}{|c|c|c|c|c|c|c|}
\hline 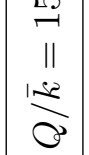 & 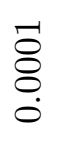 & $\begin{array}{l}\overrightarrow{8} \\
8 \\
8 \\
0\end{array}$ & $\begin{array}{l}\sigma \\
8 \\
8 \\
0\end{array}$ & $\begin{array}{l}\tilde{\delta} \\
\delta \\
0 \\
0\end{array}$ & $\begin{array}{l}\sigma \\
\delta \\
0 \\
0\end{array}$ & $\begin{array}{l}\vec{\delta} \\
\delta \\
0 \\
0\end{array}$ \\
\hline 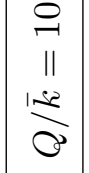 & $\begin{array}{l}\stackrel{\leftrightarrow}{8} \\
\stackrel{8}{8} \\
\dot{0}\end{array}$ & $\begin{array}{l}m \\
\stackrel{8}{8} \\
\stackrel{0}{0}\end{array}$ & $\begin{array}{l}\Re \\
\stackrel{8}{8} \\
0 \\
0\end{array}$ & $\begin{array}{l}\ddot{8} \\
\dot{8} \\
\dot{0} \\
\dot{0}\end{array}$ & $\begin{array}{l}\mathscr{8} \\
8 \\
0 \\
\dot{0}\end{array}$ & $\begin{array}{l}\ddot{8} \\
\stackrel{8}{8} \\
\dot{0}\end{array}$ \\
\hline $\begin{array}{c}10 \\
\| \\
1 \leqslant \\
\stackrel{0}{\circlearrowleft}\end{array}$ & $\begin{array}{l}\stackrel{\leftrightarrow}{0} \\
\stackrel{8}{0} \\
\stackrel{0}{0}\end{array}$ & $\begin{array}{l}\hat{\widehat{O}} \\
\stackrel{\mathrm{Q}}{0} \\
\stackrel{0}{0}\end{array}$ & $\begin{array}{l}\hat{\widehat{O}} \\
\stackrel{\delta}{0} \\
\dot{0}\end{array}$ & $\begin{array}{l}\infty \\
\stackrel{0}{0} \\
\stackrel{\delta}{0} \\
0\end{array}$ & $\begin{array}{l}\stackrel{\infty}{1} \\
\stackrel{8}{0} \\
\stackrel{0}{0}\end{array}$ & $\begin{array}{l}\stackrel{\leftrightarrow}{8} \\
\stackrel{8}{0} \\
\stackrel{0}{0}\end{array}$ \\
\hline 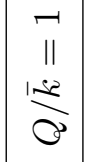 & $\begin{array}{l}\stackrel{\infty}{\overrightarrow{1}} \\
\stackrel{2}{0} \\
\stackrel{0}{0}\end{array}$ & 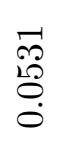 & $\begin{array}{l}\stackrel{9}{P} \\
\stackrel{2}{2} \\
\stackrel{0}{0}\end{array}$ & $\begin{array}{l}10 \\
20 \\
20 \\
0 \\
0\end{array}$ & $\begin{array}{l}\infty \\
0 \\
10 \\
0 \\
0 \\
0\end{array}$ & $\begin{array}{l}8 \\
0 \\
2 \\
0 \\
0\end{array}$ \\
\hline \begin{tabular}{c}
20 \\
0 \\
11 \\
$1 \leq 2$ \\
\hdashline 0
\end{tabular} & $\begin{array}{l}\stackrel{0}{\mathscr{O}} \\
\stackrel{0}{0} \\
\stackrel{0}{0}\end{array}$ & $\begin{array}{l}\stackrel{\infty}{?} \\
\stackrel{2}{0} \\
\stackrel{0}{0}\end{array}$ & $\begin{array}{l}\stackrel{L D}{N} \\
\stackrel{D}{0} \\
\stackrel{0}{0}\end{array}$ & $\begin{array}{l}\text { F } \\
\text { ○ } \\
0 \\
0\end{array}$ & $\begin{array}{l}10 \\
\stackrel{1}{2} \\
0 \\
0 \\
0\end{array}$ & $\begin{array}{l}\stackrel{+}{N} \\
\stackrel{0}{0} \\
\stackrel{0}{0}\end{array}$ \\
\hline 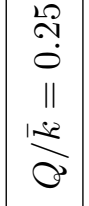 & $\begin{array}{l}\stackrel{0}{0} \\
\stackrel{0}{0} \\
\stackrel{0}{0}\end{array}$ & $\begin{array}{l}0 \\
\infty \\
\stackrel{0}{0} \\
0 \\
0\end{array}$ & $\begin{array}{l}\mathscr{R} \\
\stackrel{0}{0} \\
0 \\
0\end{array}$ & $\begin{array}{l}r \\
-\infty \\
0 \\
0 \\
0\end{array}$ & $\begin{array}{l}\mathscr{L} \\
\mathscr{0} \\
0 \\
0 \\
0\end{array}$ & $\begin{array}{l}20 \\
10 \\
0 \\
0 \\
0 \\
0\end{array}$ \\
\hline $\begin{array}{c}\overrightarrow{0} \\
\dot{0} \\
11 \\
1 \leq 2 \\
0\end{array}$ & $\begin{array}{l}\stackrel{1}{-} \\
\stackrel{\infty}{0} \\
\stackrel{0}{0}\end{array}$ & $\begin{array}{l}1 \\
\infty \\
\infty \\
\infty \\
0 \\
\dot{0}\end{array}$ & $\begin{array}{l}0 \\
2 \\
0 \\
0 \\
0 \\
0\end{array}$ & $\begin{array}{l}0 \\
0 \\
0 \\
0 \\
0\end{array}$ & $\begin{array}{l}\mathscr{L} \\
\mathscr{D} \\
0 \\
0 \\
0\end{array}$ & $\begin{array}{l}\stackrel{10}{\circ} \\
\stackrel{2}{0} \\
\dot{0}\end{array}$ \\
\hline ?ై & $\begin{array}{l}\frac{10}{2} \\
20 \\
0 \\
0\end{array}$ & $\begin{array}{l}8 \\
8 \\
0 \\
0\end{array}$ & $\begin{array}{l}\stackrel{L}{0} \\
\stackrel{\tilde{O}}{8} \\
0 \\
0\end{array}$ & $\begin{array}{l}0 \\
\stackrel{1}{0} \\
8 \\
0 \\
0\end{array}$ & $\begin{array}{l}12 \\
10 \\
0 \\
0 \\
0\end{array}$ & $\begin{array}{l}8 \\
\mathbb{8} \\
0 \\
0 \\
0\end{array}$ \\
\hline
\end{tabular}



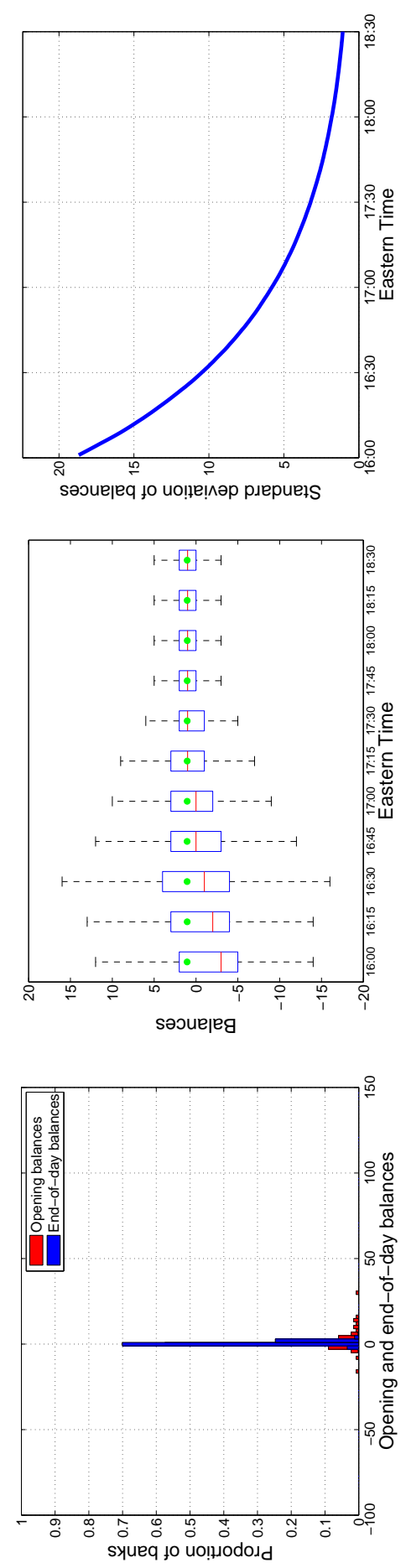

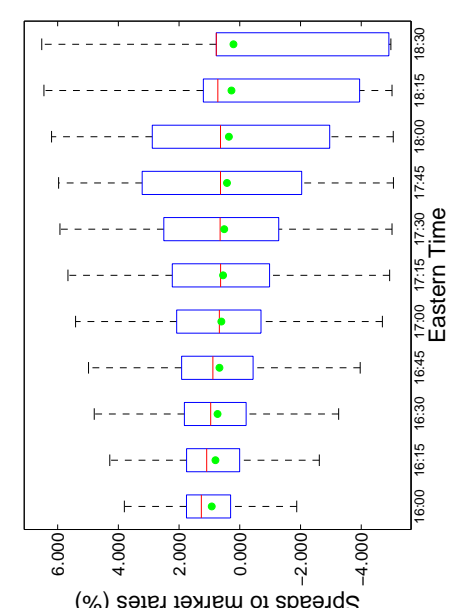

(\%) sәтел ғәулеш о speәdds
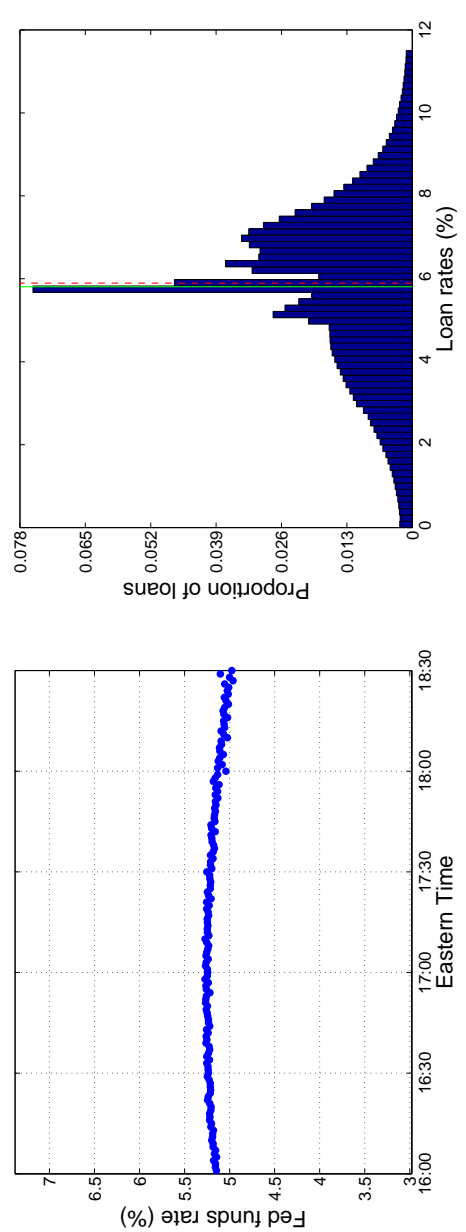

(\%) әəеג spunı pəə

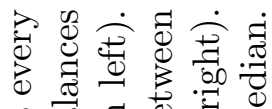

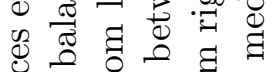

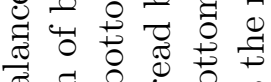

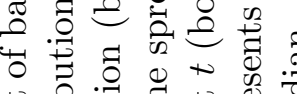

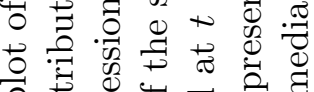

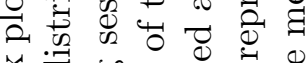

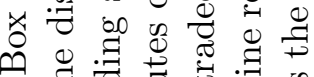

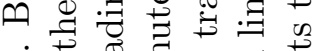

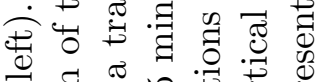

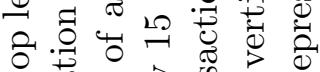

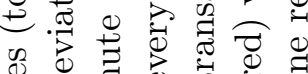

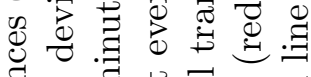

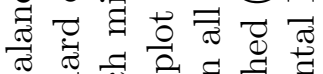

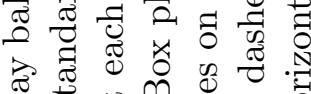

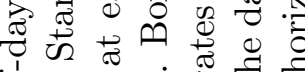

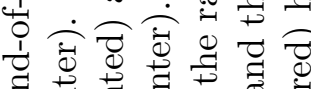

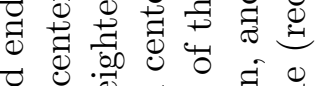

चี

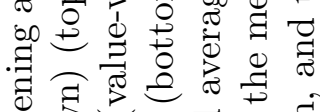

范

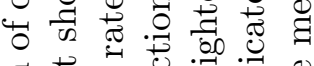

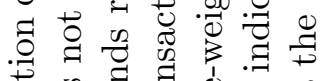

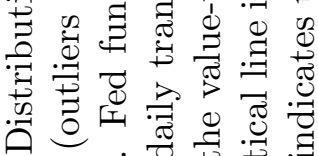

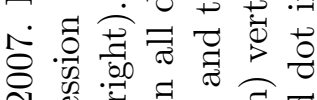
సิ

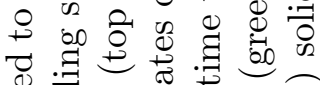

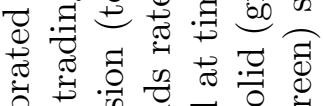

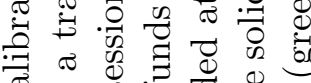
శై ठ

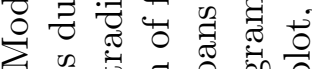
पै ن

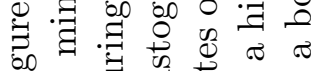

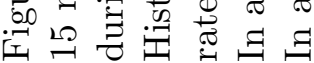



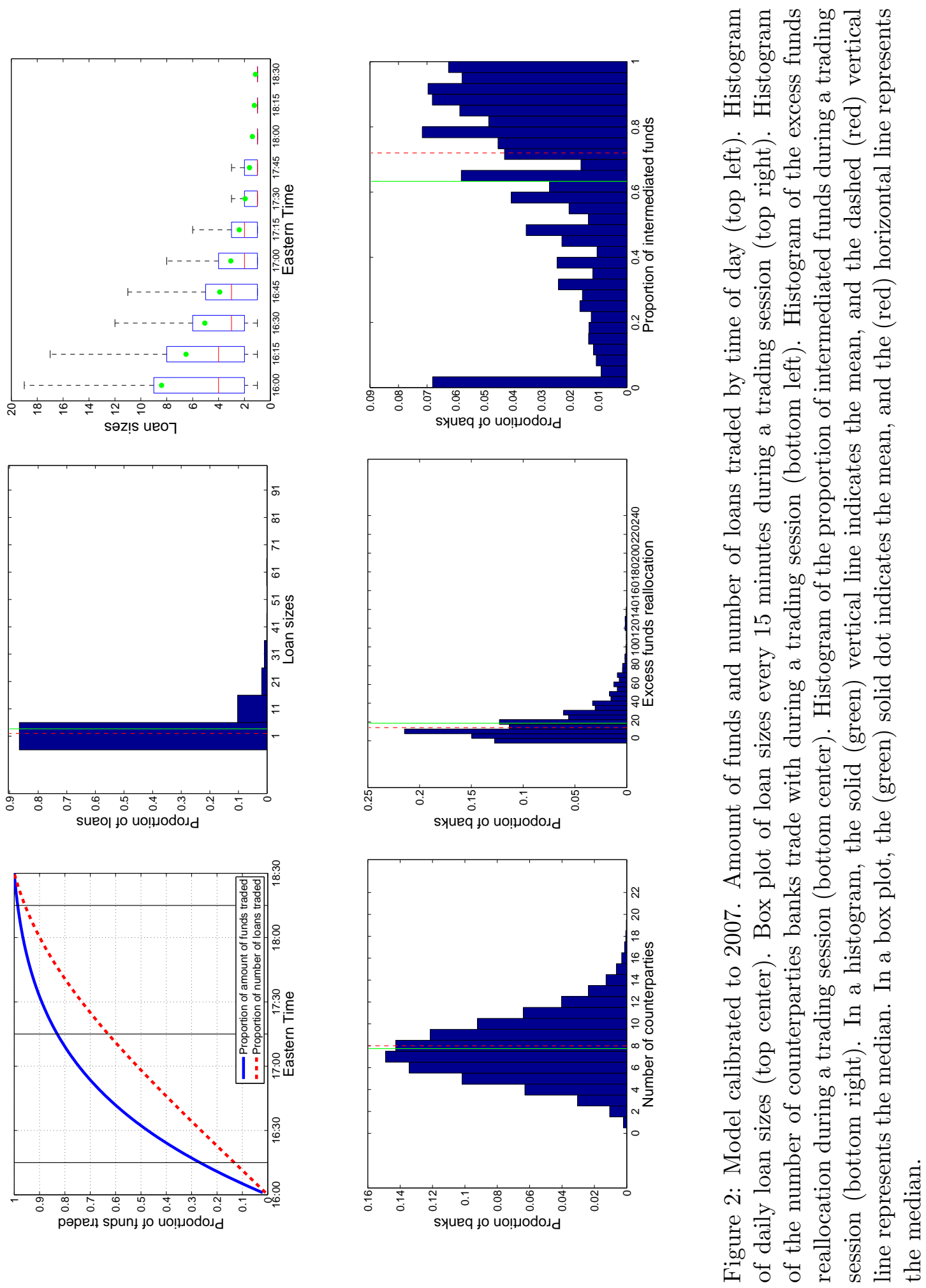


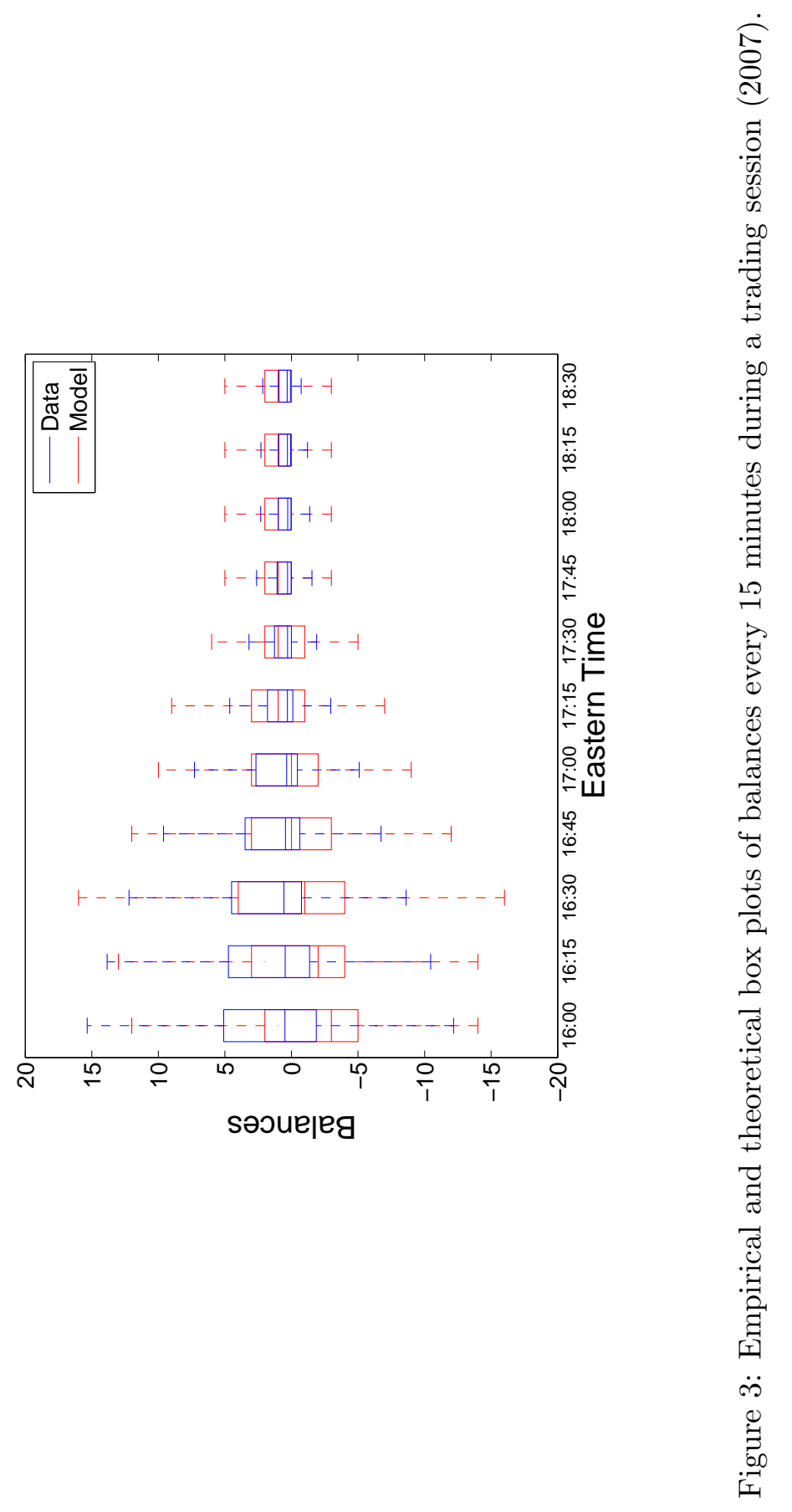



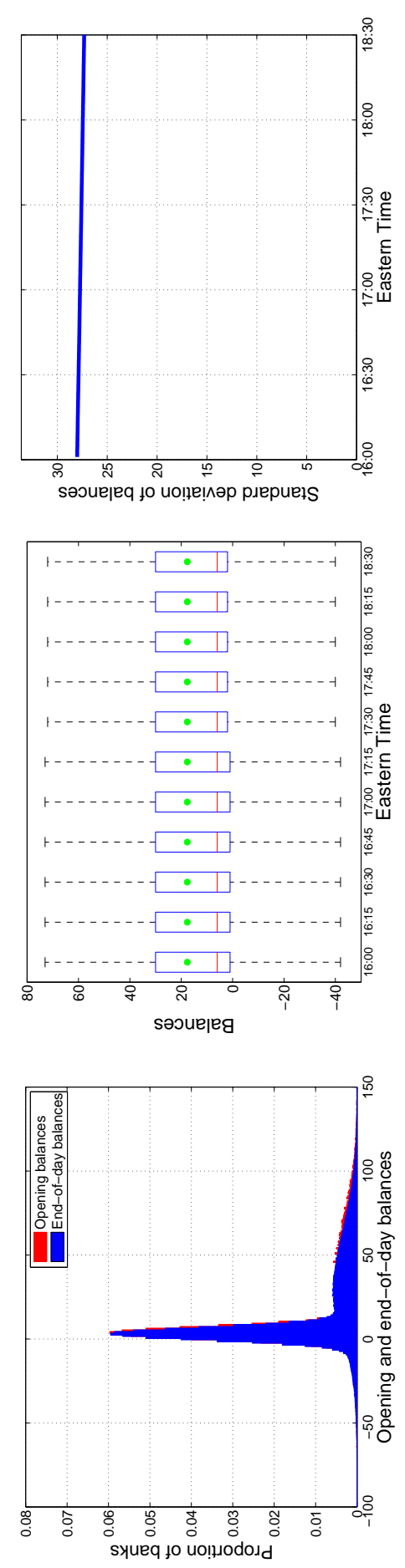

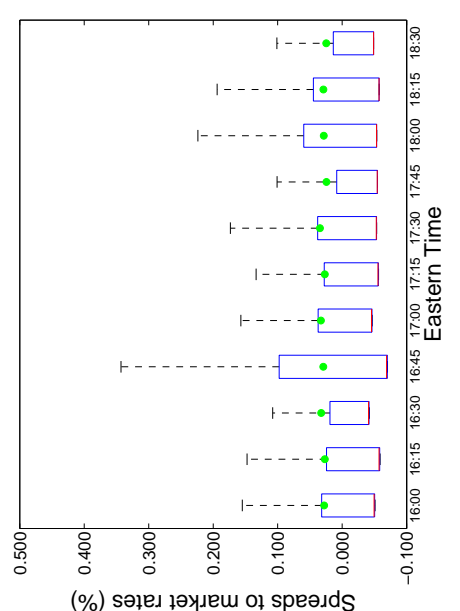

(\%) sәteג ғәулеш 아 speəגds
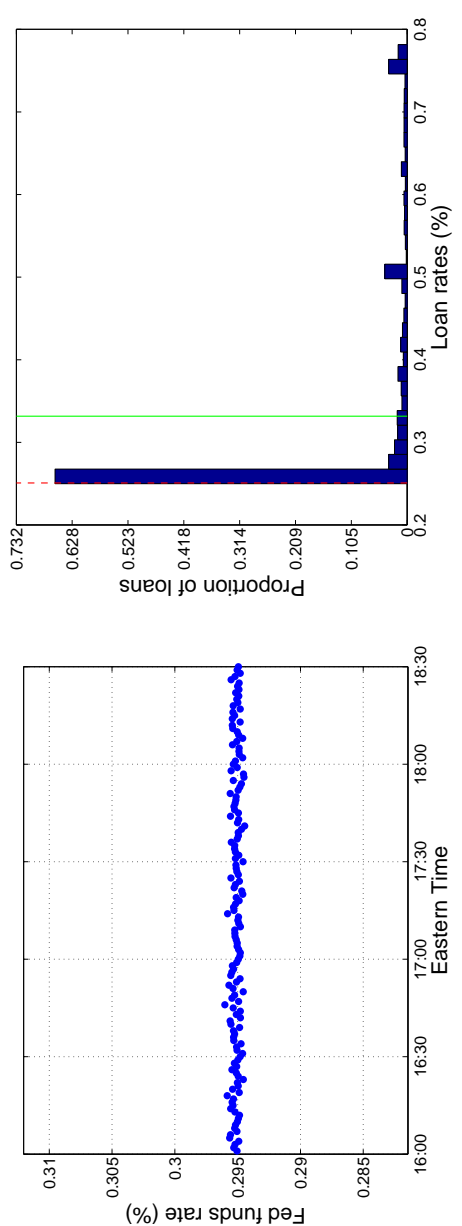

(\%) әəех spunł pә

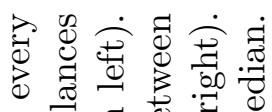

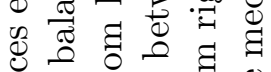

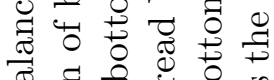

总.

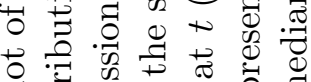

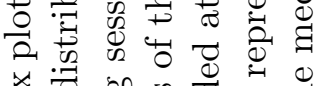

它

ค

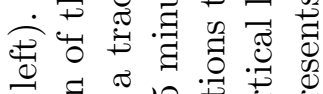

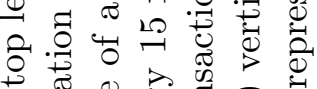

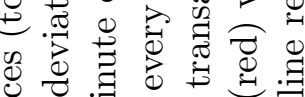

$0 \cdot \exists+\exists$

䨌

‡.

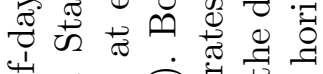

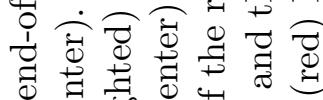

0

สี

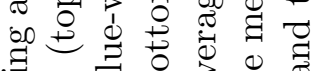

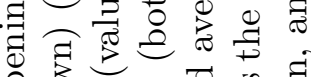

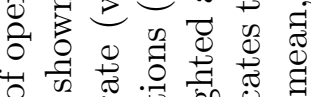

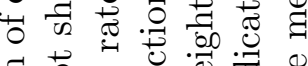

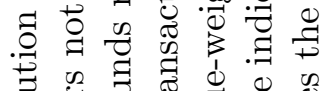

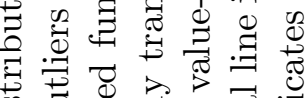

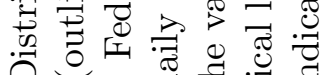

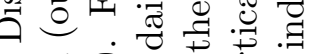

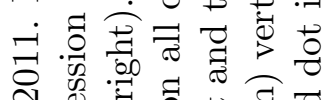
సิ 萧 苛

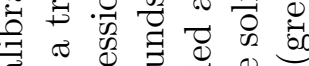
đ广

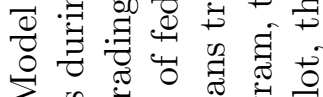
$\Sigma$ y

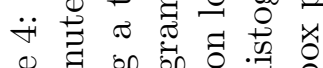
․․․

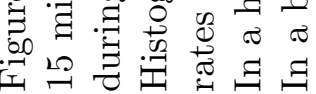



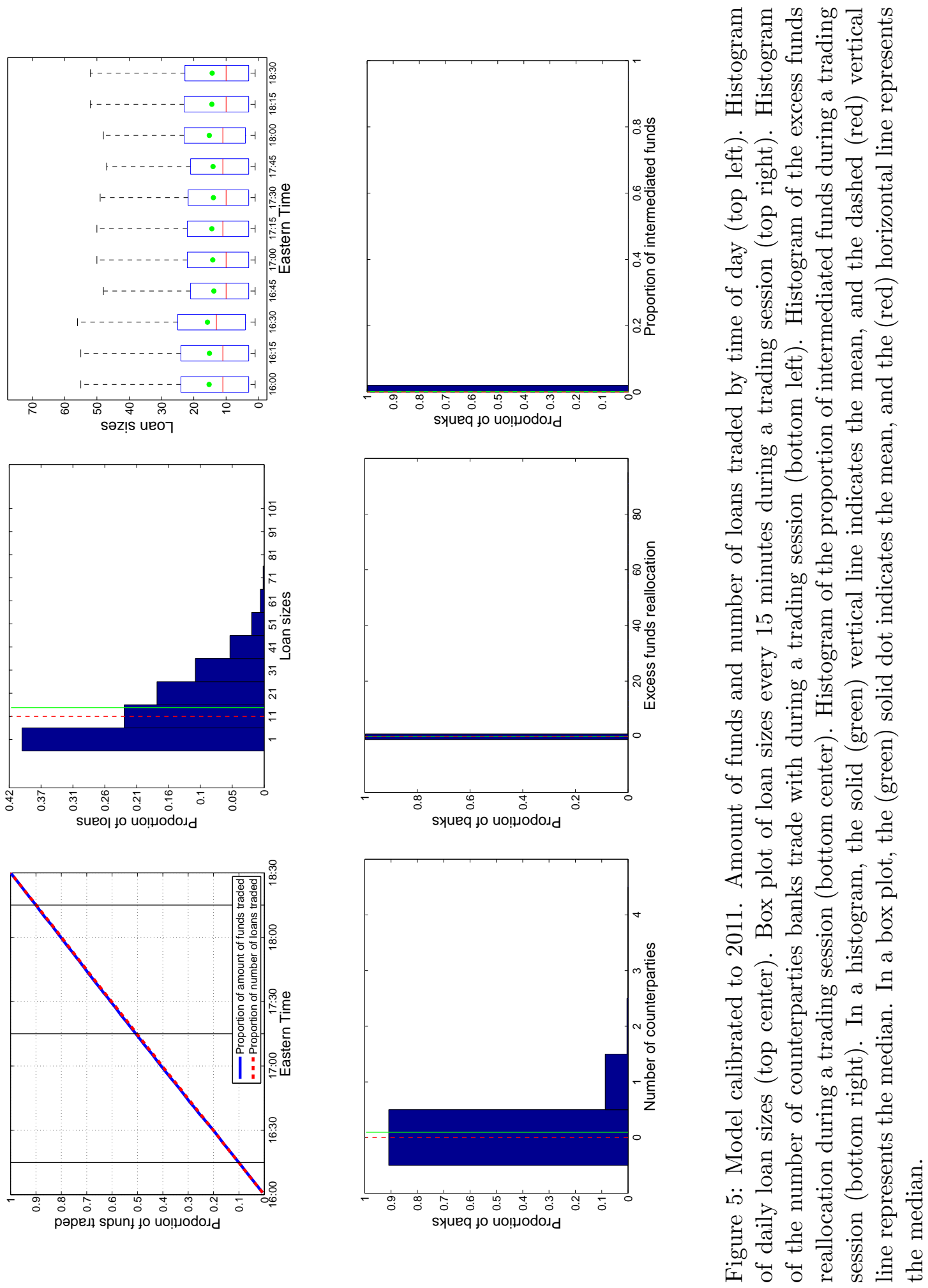


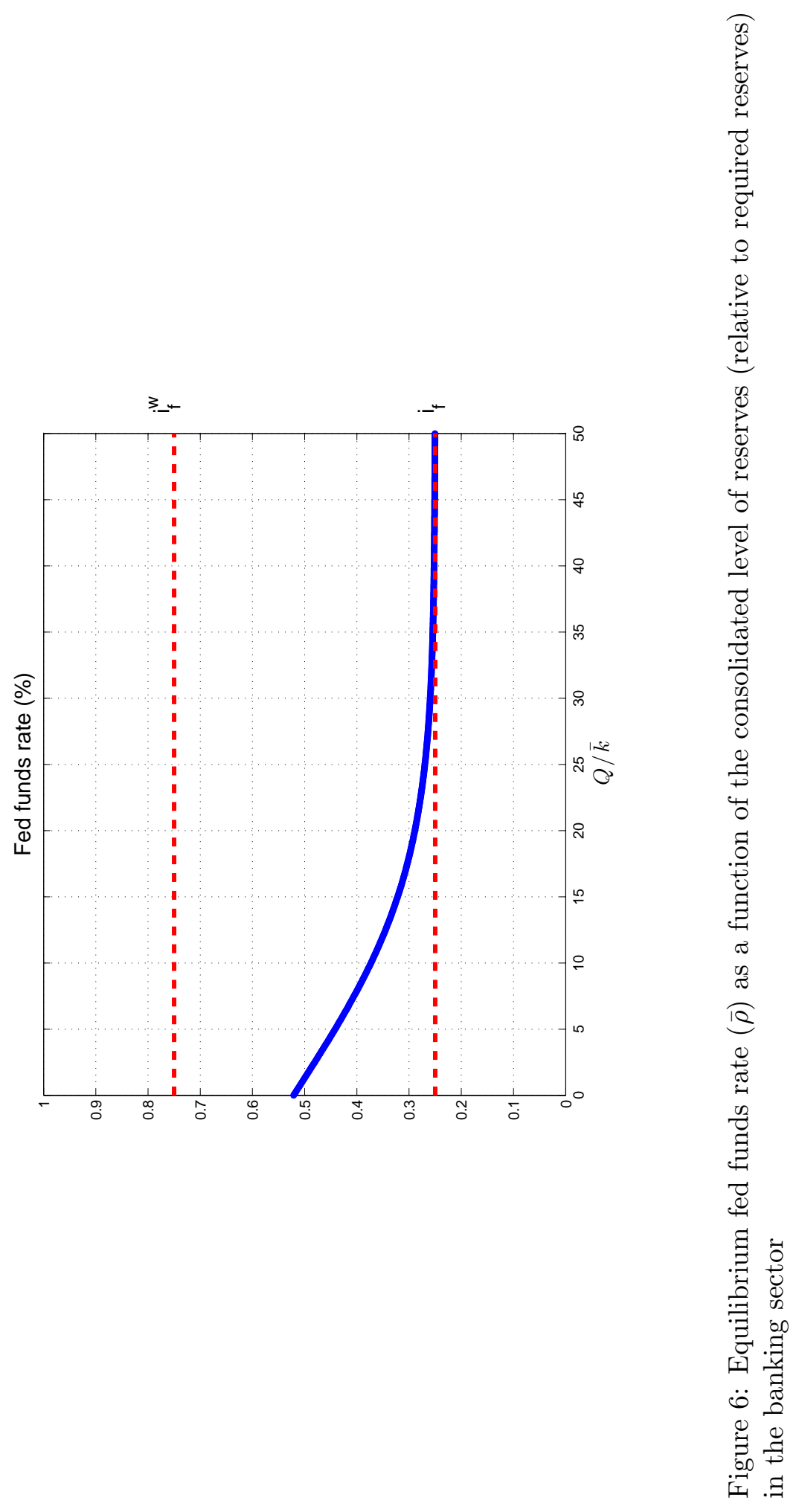



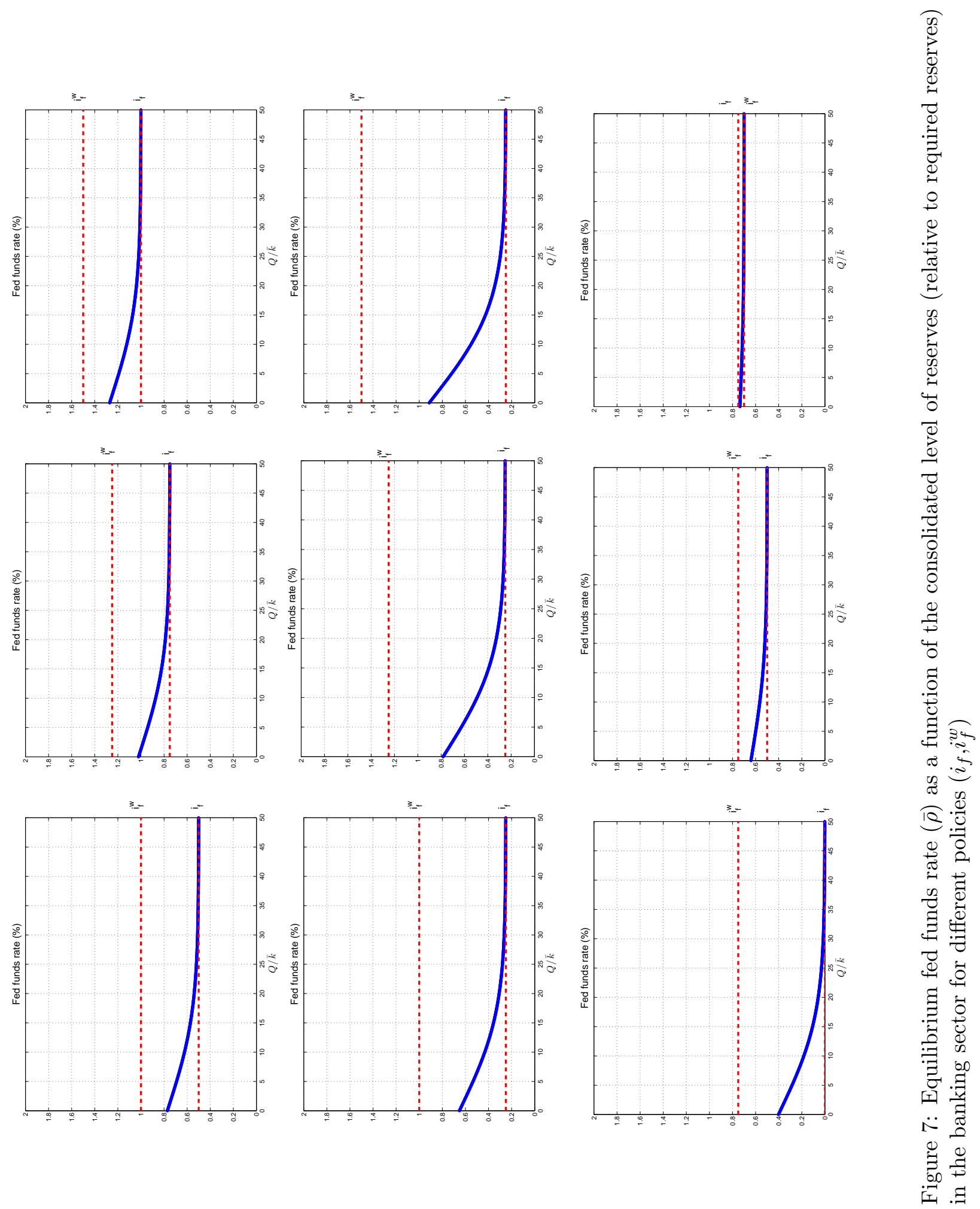

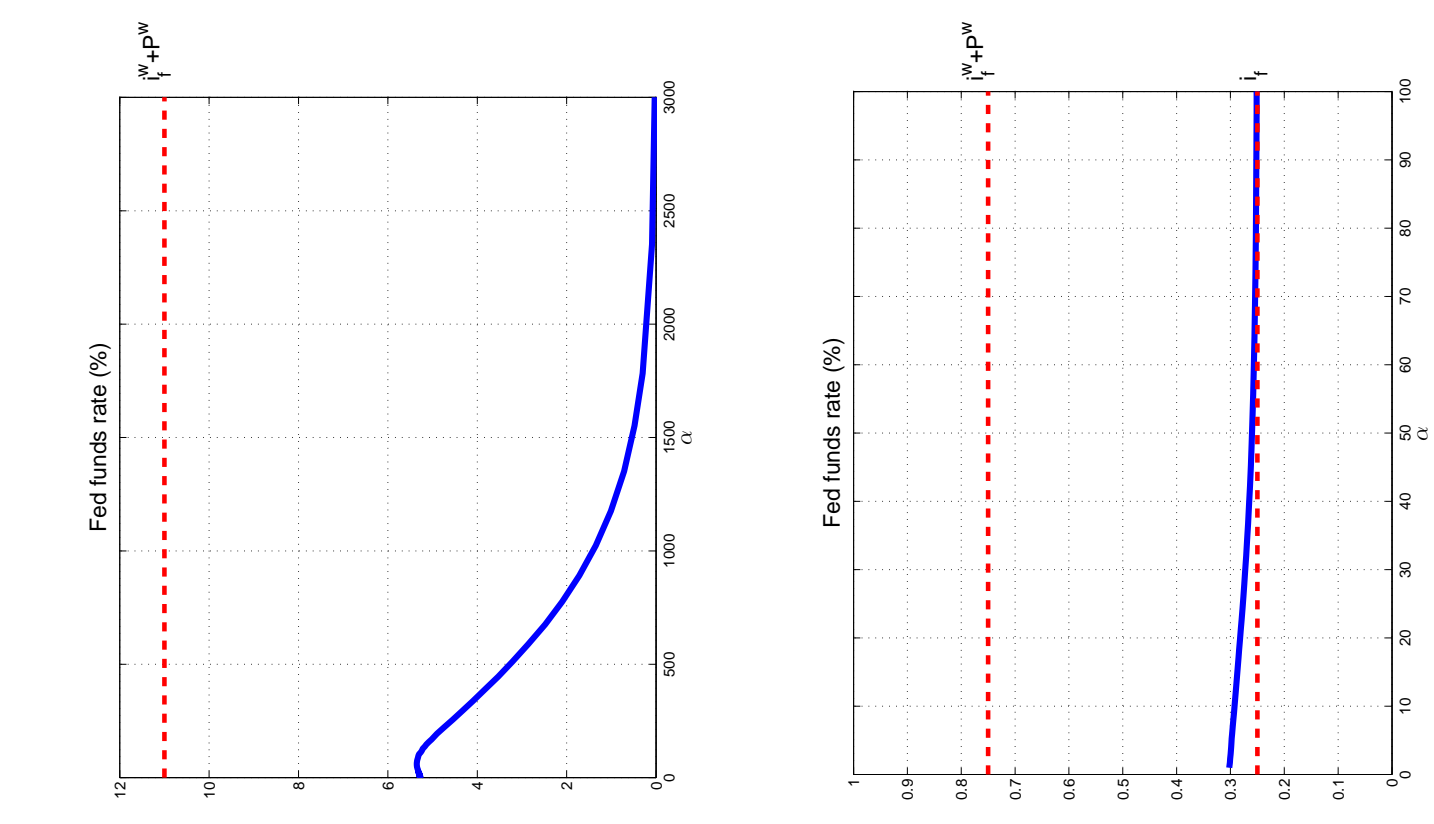

$\underset{\Xi}{0}$

ำ

궁
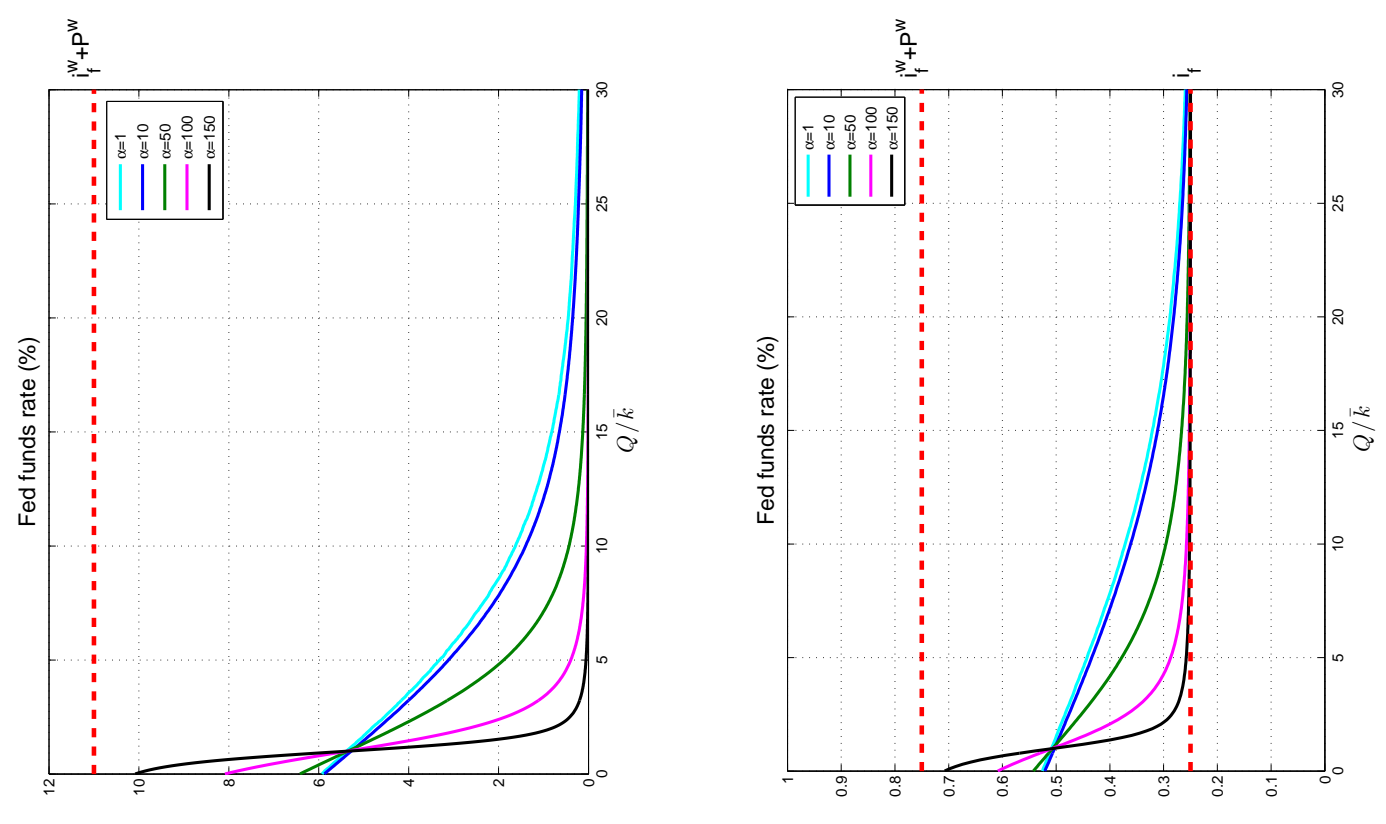

岁苛

䒿

๘

बि.

芯

㐘

Ð્ન

छ્气

苛

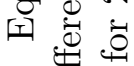

ช ت

迥.

$\div \overparen{Ð}$

苞焉

잃 유

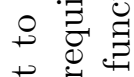

尫

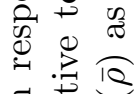

壳恋

$\frac{n}{5}$ के

㤀昰志

눈

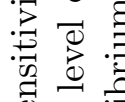

ळ

$\ddot{\infty}$ 嵒

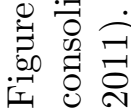



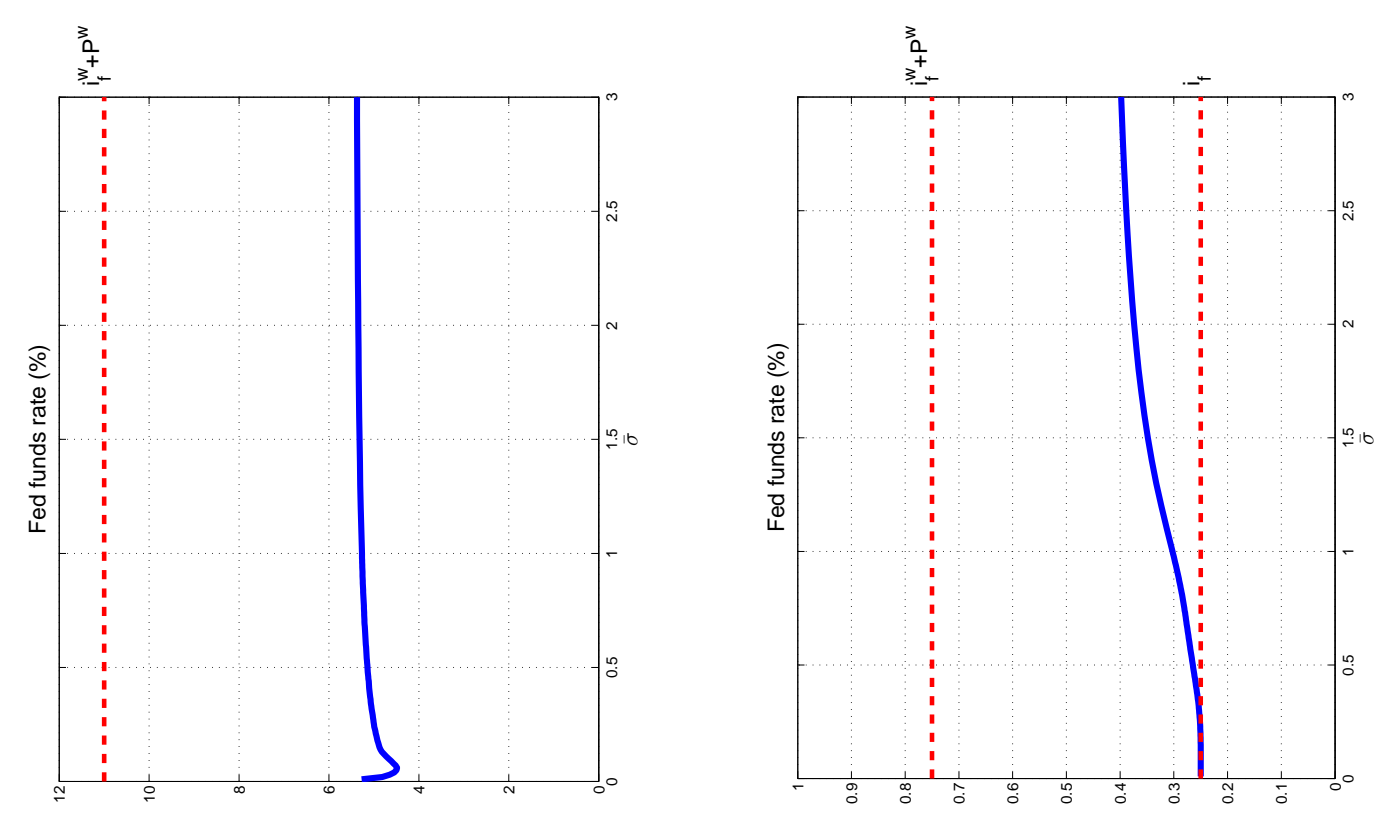

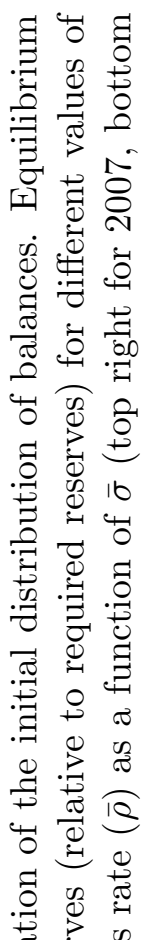

ำ

공
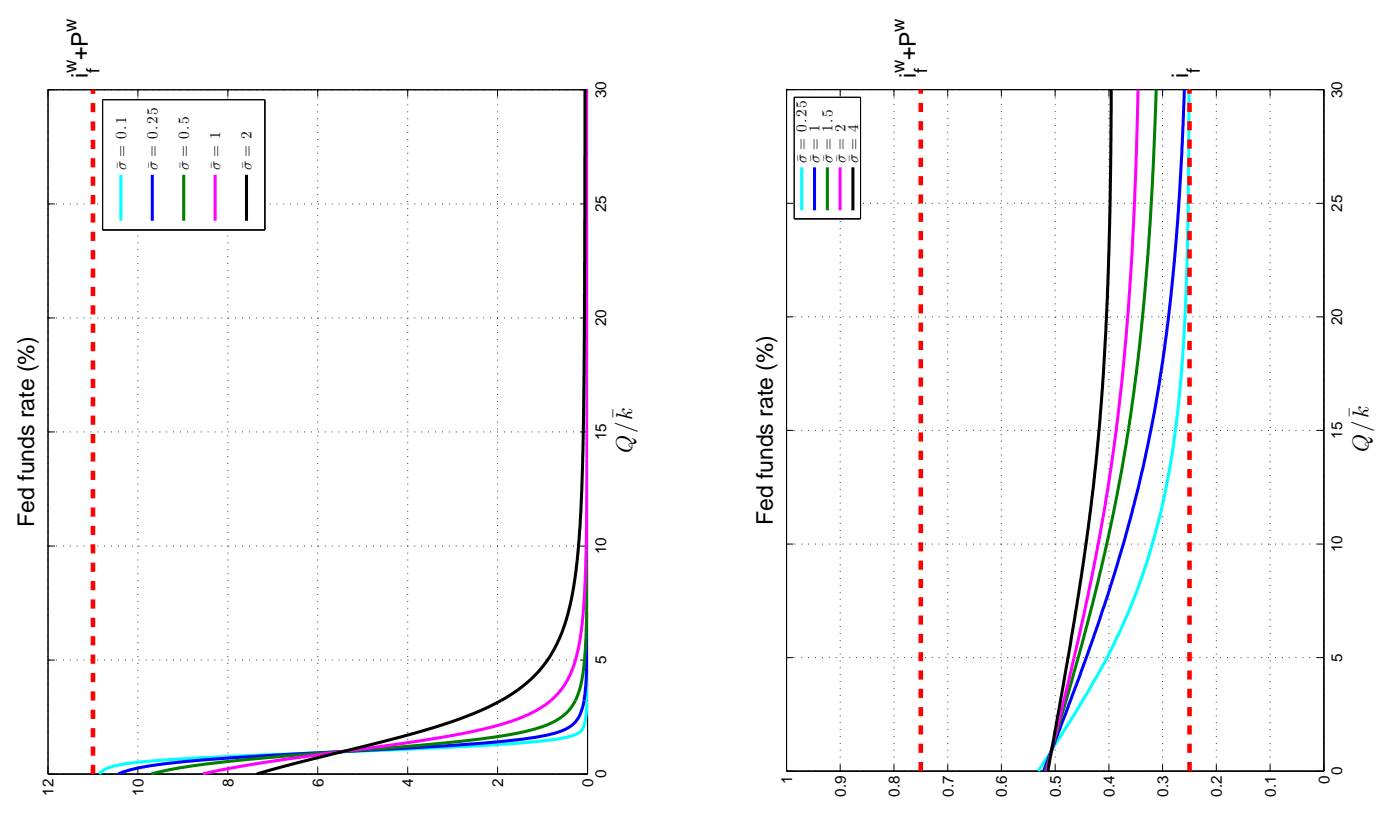

蛋焉

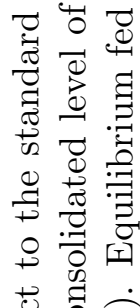

苍

Ð

声芯

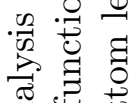

ส

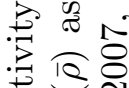

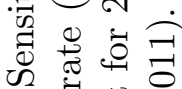

$\ddot{\theta} \stackrel{0}{0}$

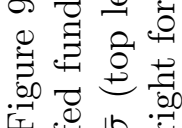

